JOANA MONA E PINTO

eCG e densidade vascular em úteros bovinos

São Paulo

2009 


\section{eCG e densidade vascular em úteros bovinos}

Dissertação apresentada ao Programa de Pós-Graduação em Anatomia dos Animais Domésticos e Silvestres da Faculdade de Medicina Veterinária e Zootecnia da Universidade de São Paulo para obtenção do título de Mestre em Ciências

\section{Departamento:}

Cirurgia

\section{Área de Concentração:}

Anatomia dos Animais Domésticos e Silvestres

\section{Orientadora:}

Profa. Dra. Paula de Carvalho Papa

São Paulo 
Autorizo a reprodução parcial ou total desta obra, para fins acadêmicos, desde que citada a fonte.

DADOS INTERNACIONAIS DE CATALOGAÇÃO-NA-PUBLICAÇÃO

(Biblioteca Virginie Buff D’Ápice da Faculdade de Medicina Veterinária e Zootecnia da Universidade de São Paulo)

T.2212

FMVZ

Pinto, Joana Mona e

eCG e densidade vascular em úteros bovinos / Joana Mona e Pinto. -2009.

$97 \mathrm{f}$ : : il.

Dissertação (Mestrado) - Universidade de São Paulo. Faculdade de Medicina Veterinária e Zootecnia. Departamento de Cirurgia, São Paulo, 2009.

Programa de Pós-Graduação: Anatomia dos Animais Domésticos e Silvestres.

Área de concentração: Anatomia dos Animais Domésticos e Silvestres.

Orientador: Profa. Dra. Paula de Carvalho Papa.

1. Densidade vascular. 2. Útero. 3. eCG. 4. Estimulação. 5. Superovulação I. Título. 


\section{FACUIDADE DE MFDICINA VETERINÁRIA E ZOOTECNIA}

\section{CERTIFICADO}

Certificamos que o Projeto intitulado "Análise diferencial da expressão gênica e protéica no corpo lúteo de bovinos submetidos a tratamentos com eCG", utilizando 21 (vinte e um) bovinos, protocolado sob o $\mathrm{n}^{0} 1638 / 2009$, sob a responsabilidade da Profa Dra Paula de Carvalho Papa, está de acordo com os princípios éticos de experimentação animal da Comissão de Bioética da Faculdade de Medicina Veterinária e Zootecnia da Universidade de São Paulo e foi aprovado em reunião de 22/04/09.

We certify that the Research "Differential analysis of gene and protein expression in bovine corpus luteum submitted to treatment with eCG", utilizing 21 (twenty one) bovine, protocol number 1638/2009, under the responsibility Profa Dra Paula de Carvalho Papa, agree with Ethical Principles in Animal Research adopted by Bioethic Commission of the School of Veterinary Medicine and Animal Science of University of São Paulo and was approved in the meeting of day $04 / 22 / 09$.

São Paulo, 23 de abril de 2009

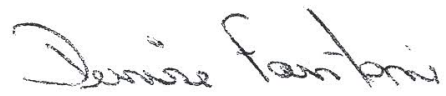

Profa Dra Denise Tabacchi Fantoni

Vice-Presidente da Comissão de Bioética

FMVZ/USP 


\section{FOLHA DE AVALIAÇÃO}

Nome: Pinto, Joana Mona

Título: eCG e densidade vascular em úteros bovinos

Dissertação apresentada ao Programa de PósGraduação em Anatomia dos Animais Domésticos e Silvestres da Faculdade de Medicina Veterinária e Zootecnia da Universidade de São Paulo para obtenção do título de Mestre em Ciências

Data:

1

\section{Banca Examinadora}

Prof. Dr. Instituição:

Assinatura: Julgamento:

Prof. Dr. Instituição:

Assinatura: Julgamento:

Prof. Dr. Instituição:

Assinatura: Julgamento: 
"Uma vida sem desafios não vale a pena ser vivida".

Sócrates 
Aos meus pais José Francisco e Ellen Mona, pelo amor incondicional e apoio de todas as horas

Aos meus segundos pais Rogério e Sandra, pelo carinho, auxilio e por fazer-me filha

Aos meus irmãos Luiza, Gabriel e Breno, por alegrarem meus dias...

Ao meu namorado Diogo, que acreditou em mim e esteve sempre presente

Muito Obrigada por tudo...Amo todos vocês 
AGRADECIMETO ESPECIAL

À minha orientadora, Profa. Dra. Paula de Carvalho Papa, por me receber em seu laboratório com atenção e carinho, dividindo comigo seus ensinamentos, e conhecimentos, proporcionando-me grande enriquecimento profissional e pessoal. 


\section{AGRADECIMENTOS}

À Professora Maria Angélica Miglino, pela proveitosa oportunidade, ao tornar possivel o ingresso na Pos-graduação.

Aos Professores do setor de Anatomia, Francisco Javier $\mathbf{H}$. Blasquez, José Roberto Kfoury Júnior, Pedro Primo Bombonato, pelo aprendizado durante as aulas de Pós-Graduação, e por terem disponibilizado seus labaratórios para execução dos experimentos.

As colegas de laboratório Luciana Alvez de Fátima e Liza Margareth, que auxiliaram fundamentalmente na realização e produção do trabalho. E também pela amizade e companhia de todos os dias.

Agradeço também ao Diogo Nader Palermo, técnico do laboratório de Anatomia Microscópica e Imnunohistoquímica, e meu companheiro, pela preparação e confecção do material utilizado no trabalho.

Ao Professor Francisco Palma Rennó, por disponibilizar o espaço e colaborar no tratamento dos animais.

Ao Professor Pietro Baruselli, e seus orientados Henderson e Lindsey, pela disponibilidade, e por auxiliarem no tratamento e exames dos animais.

Aos amigos e colegas de laboratório, Mariana, Alex, Valdir e Nathia por ajudarem durante a realização deste trabalho, e pela companhia e amizade.

Aos técnicos Edinaldo (Índio) e Ronaldo, pela disponibilidade durante a realização dos experimentos.

Aos secretários do setor de Antomia Maicon e Jackeline, pela consideração, simpatia e auxilio durante a minha estada neste programa. 
À minhas queridas tias Marta e Virgínia, pelos conselhos e por estarem sempre dispostas a colaborar.

À colega Janaína Marim Martins, pela colaboração nas correções do trabalho.

Aos amigos e colegas de pós-graduação com os quais compartilhei novas experiências e conhecimentos. Especialmente a minha querida amiga Renatinha, pelas grandes aventuras.

À Faculdade de Medicina Veterinária e Zootecnia da Universidade de São Paulo, por proporcionar um desenvolvimento científico, profissional e pessoal.

À CAPES pelo indispensável apoio financeiro, colaborando com o desenvolvimento científico. 


\section{RESUMO}

PINTO, J. M. eCG e densidade vascular em úteros bovinos [eCG and vascular density of bovine uterus] 2009. (97)f. Dissertação (Mestrado em Ciências) Faculdade de Medicina Veterinária e Zootecnia, Universidade de São Paulo, São Paulo, 2009.

A dinâmica folicular, bem como a preparação do endométrio para a gestação, é dependente do estabelecimento de vascularização adequada. Alguns estudos apontam para a importância do tratamento com eCG após o emprego de protocolos de IATF, de forma a aumentar as taxas de ovulação e prenhez, e para a uma possível propriedade angiogênica, influenciando o fluxo sanguíneo e a vascularização. $O$ objetivo do presente trabalho foi avaliar a influência do eCG na espessura e área do endométrio e miométrio, calibre e área da artéria uterina do corno ipsilateral e também na densidade vascular do endométrio e miométrio de vacas submetidas a tratamentos de sincronização (grupo controle), estimulação do folículo dominante e superovulação. Para tal, foram utilizadas 16 vacas mestiças de Nelore ciclando com escore corporal entre 2 e 3 que foram divididas em 3 grupos de acordo com tratamento hormonal: o grupo controle foi submetido apenas ao protocolo de sincronização da ovulação $(n=5)$, o grupo estimulado recebeu 400 UI de eCG no dia 4 após início do protocolo $(\mathrm{n}=6)$ e o grupo superovulado recebeu 2000UI de eCG no dia 8 após início do tratamento $(\mathrm{n}=5)$. No dia 5 após a ovulação (p.o) foram realizados exames ultrasonográficos para mensuração do miométrio e endométrio dos cornos uterinos, bem como para análise do calibre da artéria uterina. Os animais foram abatidos, os úteros coletados no dia 6 p.o. e imediatamente fixados em paraformaldeido a 4\%. Para análise da densidade vascular, foi realizada imunohistoquímica para o KDR com o intuito de marcação das células endoteliais e contagem dos vasos por estereologia. As espessuras e áreas, tanto do miométrio quanto do endométrio, não foram influenciadas pelos tratamentos. A artéria uterina nos animais superovulados apresentou maior calibre do que nos animais do grupo controle $(\mathrm{p}<0,05)$. A densidade vascular do endométrio nos animais estimulados foi menor quando comparada à dos animais do grupo controle $(\mathrm{p}<0,05)$, e no grupo superovulado, a densidade vascular apresentou-se diminuída $(\mathrm{p}<0,05)$ no miométrio. Os resultados obtidos sugerem que o aumento de vascularização do endométrio após tratamentos com ECG, relatado em outros trabalhos, seja provavelmente influenciado pelo concepto e não exclusivamente pelo tratamento. Além disso, a 
influência do eCG no útero pode ser dependente tanto da dose quanto do estágio do ciclo estral.

Palavras-chave: Densidade vascular. Útero. eCG. Estimulação. Superovulação. 


\begin{abstract}
PINTO, J. M. eCG and vascular density of bovine uterus [eCG e densidade vascular em úteros bovinos]. 2009. (97)f. Dissertação (Mestrado em Ciências) Faculdade de Medicina Veterinária e Zootecnia, Universidade de São Paulo, São Paulo, 2009.
\end{abstract}

Follicle dynamic, as well as the uterus preparation for gestation, is dependent of an adequate vascularization establishment. Currently, many studies point towards the importance of eCG treatment following fixed-time artificial insemination (FTAI), in a manner to improve ovulation and gestational rates. Moreover, eCG have been implicated in angiogenesis, leading to important changes in uterine blood flow and vascularization. Thus, the present study was designed to investigate the influence of eCG on the endometrial and myometrial thickness and area; on the caliber and area of the uterine artery of the ipsilateral horn; and, on endometrial and myometrial uterine vascular density of cows submitted to sincronization (control group), stimulation (stimulated group), and superovulatory (superovulated group) treatments. For that, we used 16 cows with body score between 2 and 3, randomly distributed into the 3 above described groups: the cows of the control group $(n=5)$ did not receive eCG, while the cows of the stimulated group $(n=6)$ and superovulated group $3(\mathrm{n}=5)$ received, respectively, $400 \mathrm{UI}$ and $2000 \mathrm{UI}$ of eCG at days 4 and 8 after the protocol beginning. For endometrial and myometrial measurements, as well as for uterine artery caliber and area analysis, ultrasonographic evaluations were done at day 5 after ovulation. At day 6, the animals were slaughtered, the uterus were harvested and fixed in $4 \%$ paraformaldehyde. In order to analyze the vascular density, immunohistochemistry for KDR detection and blood vessels counting by stereology were performed. In all studied groups, treatments did not influence either uterine wall thickness or area. In the superovulated animals, the uterine artery presented higher caliber than in the control ones $(\mathrm{P}<0.05)$. Endometrial vascular density of stimulated animals in the ipsilateral uterine horn was lower when compared to that of the control $(\mathrm{P}<0.05)$, and in the superovulated, vascular density was lower in the myometrium $(\mathrm{P}<0.05)$. These results suggest that the endometrial vascularization increase following eCG treatment, described by other groups, is probably influenced by the concept, not only 
by the treatment. Moreover, the influence of eCG in the uterus could be dependent of both the hormonal dosis and the estrous cycle phase.

Key words: Vascular density. Uterus. eCG. Estimulation. Superovulation. 


\section{LISTA DE FIGURAS}

Figura 1 - Representação esquemática dos tratamentos para sincronização, estimulação e superestimulação da ovulação com dispositivo intravaginal de progesterona associado ou não ao eCG em vacas. 1 - Estrogin $^{\circledR}$ - Syntex; 2 - BID ${ }^{\circledR}$ - Syntex; D = dia; $M=$ manhã; $\mathrm{T}=$ tarde

Figura 2 - Ultrasonografia dos cornos uterinos. (A) Ultra-sonografia com Doppler dos cornos uterinos. Visualização da artéria uterina pixels em azul. D1 e D2 - diâmetros da artéria uterina do corno ipsilateral; (B) ipsilateral a direita e contralateral a esquerda, D1 e D2 diâmetro do endométrio do corno uterino ipsilateral; D3 e D4 diâmetro do endométrio do corno uterino contralateral; D5 diâmetro do miométrio do corno ipsilateral

Figura 3 - Fotomicrografia do endométrio do corno uterino contralateral ao CL de bovino estimulado com um frame sobreposto. Para estimar o número de vasos $(*)$, consideram-se as estruturas contidas no interior do frame e que não estejam interceptadas pelas linhas de exclusão (linhas cheias). Barra $=50 \mu \mathrm{m}$

Figura 4 - Imagem ultrasonográfica dos cornos uterinos, evidenciando as mensurações realizadas no dia 5 p.o.; D1-D4 medidas do diâmetro do endométrio, D5 medidas do miométrio. (A) animal do grupo controle; (B) animal do grupo estimulado; (C) animal do grupo superovulado

Figura 5 - Imagem ultrasonográfica dos cornos uterinos, evidenciando as mensurações realizadas no dia 5 p.o.; Em colorido a artéria uterina, identificada por seu fluxo sanguíneo. D1 e D2 medidas do diâmetro da artéria. (A) animal do grupo controle; (B) animal do grupo estimulado; (C) animal do grupo superovulado.

Figura 6 - $\quad$ Fotomicrografias do endométrio do corno ipsilateral evidenciando a imunomarcação para anticorpo KDR. (A) Controle Negativo; (B) Animal do grupo controle; (C) Animal do grupo superovulado; (D) Animal do grupo estimulado. Barras equivalem a $50 \mu \mathrm{m}$.

Figura 7 - $\quad$ Análise comparativa da densidade vascular dos cornos ipsilateral dos grupos controle, estimulado e da média de ambos os cornos do grupo superovulado; (A) Gráfico representa a densidade vascular total; (B) Gráfico representa a densidade vascular do endométrio. Barras representam a média \pm EPM dos grupos, valores expressam a quantidade de vasos/corno uterino. 
grupos

Figura 8 - Análise comparativa da densidade vascular dos cornos contralateral dos grupos controle, estimulado e da média de ambos os cornos do grupo superovulado: (A) Gráfico representa a densidade vascular do endométrio somado ao miométrio; (B) Gráfico representa a densidade vascular do endométrio; (C) Gráfico representa a densidade vascular do miométrio. Barras representam a média \pm EPM dos grupos, valores expressam a quantidade de vasos/corno uterino; Não foi observada diferença entre os grupos $(\mathrm{p}>0,05)$......

Figura 9 - Análise comparativa da densidade vascular dos cornos contralateral e ipsilateral do grupo controle. (A) Gráfico representa a densidade vascular do endométrio somada a densidade vascular do miométrio $(\mathrm{p}=0,0089)$; (B) Gráfico representa a densidade vascular do endométrio $(\mathrm{p}=0,0045)$; Gráfico representa a densidade vascular do miométrio Barras representam a média \pm EPM dos cornos uterinos, valores expressam a quantidade de vasos/corno uterino; * corresponde a diferença significativa $(p<0,05)$ entre os cornos uterinos

Figura 10 - Análise comparativa da densidade vascular dos cornos contralateral e ipsilateral do grupo estimulado. gráfico representa a densidade vascular do endométrio somada ao miométrio. Barras representam a média \pm EPM dos cornos uterinos, valores expressam a quantidade de vasos/segmento uterino coletado; não houve diferença $(p>0,05)$ entre os cornos uterinos. (A) Gráfico representa a densidade vascular do endométrio; (B) Gráfico representa a densidade vascular do miométrio.

Figura 11 - Análise comparativa da densidade vascular dos cornos direito e esquerdo do grupo controle. (A) Gráfico representa a densidade vascular do endométrio somada a densidade vascular do miométrio ( $\mathrm{p}=0,0089)$; (B) Gráfico representa a densidade vascular do endométrio $(\mathrm{p}=0,0045)$.(C) Gráfico representa a densidade vascular miométrio Barras representam a média \pm EPM dos cornos uterinos, valores expressam a quantidade de vasos/corno uterino; * corresponde a diferença significativa $(p<$ $0,05)$ entre os cornos uterinos 


\section{LISTA DE TABELAS}

Tabela 1 - Área $\left(\mathrm{mm}^{2}\right)$ do miométrio e endométrio dos cornos uterinos dos bovinos submetidos aos tratamentos de estimulação $(n=6)$, superovulação $(n=5)$ e controle $(n=5)$. Os valores estão expressos em média (a) e erro padrão da média (b).

Tabela 2 - $\quad$ Espessura $(\mathrm{mm})$ do miométrio e endométrio dos cornos uterinos dos bovinos submetidos aos tratamentos de estimulação $(n=6)$, superovulação $(n=5)$ e controle $(n=5)$. Os valores estão expressos em média (a) e erro padrão da média (b)

Tabela 3 - Área das artérias uterinas dos animais controle (mm), estimulados e superovulados. a média dos valores de áreas das artéria uterinas de todos animais; b erro padrão da media. ${ }^{*} \mathrm{p}<0.05$ em relação ao grupo controle.

Tabela 4 - Diâmetro ( $\mathrm{mm})$ das artérias uterinas dos animais controle, estimulados e superovulados. a média dos valores de diâmetro das artérias uterinas de todos animais; $\mathbf{b}$ erro padrão da media. ${ }^{*} \mathrm{p}<$ 0.05 em relação ao grupo controle.

Tabela 5 - Intervalo de variação da densidade vascular do endométrio e miométrio encontrada nos animais dos grupos controle, estimulado e superovulado. Valores mínimos e máximos expressam o número de vasos/segmento uterino coletado.

Tabela 6 - Correlação da densidade vascular do endométrio em relação ao miométrio no corno ipsilateral, dos grupos controle, estimulado e superovulado. Não houve correlação entre as camadas 
ANG angiopoetinas

ANOVA análise de variância

CL corpo lúteo

d. p.o. dias após a ovulação

$\mathrm{E}_{2} \quad$ estradiol-17 $\beta$

eCG gonadotrofina coriônica eqüina

EL epitélio luminal

EPM erro padrão médio

FGF fator de crescimento fibroblástico

FIV fertilização in vitro

Flt-1 fms-like tyrosine kinase

FSH hormônio folículo estimulante

GnRH hormônio liberador de gonadotropinas

hCG gonadotrofina coriônica humana

HIF-1 $\alpha$ fator indudor de hipóxia $1 \alpha$

IA inseminação artificial

INF- $\tau$ interferon-tau

KDR kinase insert domain containing receptor

LH hormônio luteinizante

mm milímetros

OMTE ovulação multipla e transferencia de embrião

$\mathrm{P}_{4} \quad$ progesterona

p.o. após ovulação

PGF $2_{\alpha} \quad$ prostaglandina $2_{\alpha}$ 
PR receptores de progesterona

TE transferência de embrião

$\operatorname{Tr} \quad$ trofoderma do concepto

VEGF fator de crescimento vascular endotelial

VEGFR receptor para fator de crescimento vascular endotelial 
1 INTRODUÇÃO.................................................................................... 22

2 OBJETIVOS ..................................................................................................... 26

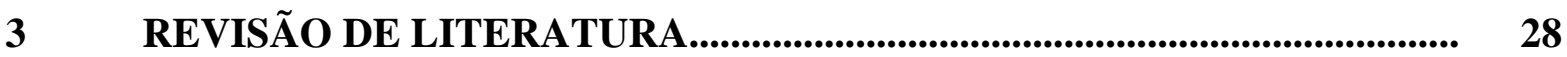

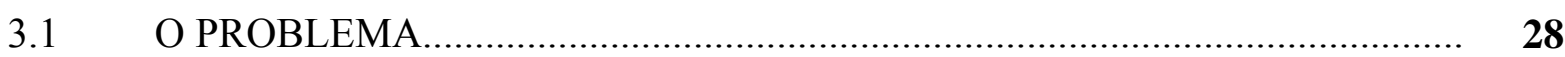

3.2 CONTROLE HORMONAL E VASCULARIZAÇÃO UTERINA......................... 31

3.3 INFLUÊNCIA DOS PROTOCOLOS UTILIZADOS COMUMENTE NAS BIOTÉCNICAS SOBRE AS FUNÇÕES LUTEÍNICA E UTERINA................... 35

4 MATERIAIS E MÉTODOS..................................................................... 40

$4.1 \quad$ GRUPOS DE TRATAMENTO ……………….................................... 40

4.2 EXAMES ULTRASONOGRÁFICOS E MENSURAÇÕES DOS CORNOS E 42 ARTÉRIAS UTERINAS.

4.3 COLETA DAS AMOSTRAS E IMUNOHISTOQUÍMICA PARA KDR ............ $4 \mathbf{4 4}$

4.4 ESTIMATIVA DA DENSIDADE VASCULAR NO CORNO UTERINO DE VACAS..... $\mathbf{4 5}$

4.5 ANÁLISE ESTATÍSTICA........................................................................ 46

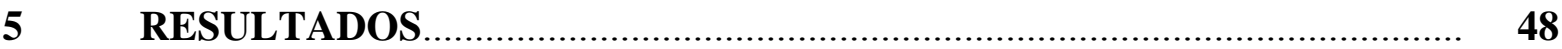

5.1 EFEITO DOS TRATAMENTOS ESTIMULATÓRIO E SUPEROVULATÓRIO NA ÁREA DE MIOMÉTRIO E ENDOMÉTRIO DOS CORNOS UTERINOS.

5.2 EFEITO DOS TRATAMENTOS ESTIMULATÓRIO E SUPEROVULATÓRIO NA ESPESSURA DE MIOMÉTRIO E ENDOMÉTRIO DOS CORNOS UTERINOS.

5.3 EFEITO DOS TRATAMENTOS NA ÁREA DE FLUXO E DIÂMETRO DA ARTÉRIA UTERINA.

5.4 EFEITO DOS TRATAMENTOS NA DENSIDADE VASCULAR UTERINA... 
.5.4.2 DENSIDADE VACULAR O CORNO CONTRALATERAL............................... 59

5.4.3 DENSIDADE VASCULAR DO CORNO IPSILATERAL $\quad \mathrm{X}$ CORNO $\mathbf{6 1}$

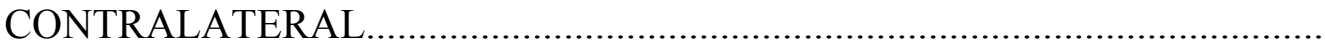

6 DISCUSSÃO.

7 CONCLUSÕES 76 REFERÊNCIAS 
1 INTRODUÇÃO 


\section{INTRODUÇÃO}

A pecuária tem uma grande importância econômica para o Brasil, principalmente a pecuária de corte visto que o país é o segundo maior produtor e maior exportador de carne bovina do mundo (FAO, 2007). No intuito de elevar a eficiência econômica da pecuária nacional, tem-se procurado utilizar novas tecnologias para aumentar os ganhos genéticos do rebanho. Neste contexto, biotecnologias reprodutivas como a transferência de embriões destacam-se pela diminuição do intervalo de gerações e pelo rápido progresso genético. Entretanto, em programas de transferência de embriões, é dada atenção especial às doadoras, ao contrário das receptoras, que são relegadas ao segundo plano (FERNANDES, 1999), prática que tem reflexos nos baixos índices de gestação alcançados com esta tecnologia, principalmente pela elevada incidência de morte embrionária, nas três primeiras semanas de gestação (SREENAN; DISKIN, 1987).

As técnicas mais utilizadas no manejo reprodutivo são sincronização de cio, a superovulação, a inseminação artificial (IA) e transferência de embriões (TE), além da produção de embriões in vitro (REICHENBACH et al., 2002; BARUSELLI et al., 2008). As taxas de gestação com o uso de embriões oriundos de procedimentos de transferência de embriões são menores que as obtidas por IA ou monta natural (PETERSON; LEE, 2003). Considerando que o estabelecimento e a manutenção da gestação envolvem complexa interação entre o embrião, o ambiente uterino e o corpo lúteo (MANN et al., 1995), a menor taxa de gestação utilizando-se a transferência de embriões pode estar associada ao subdesenvolvimento dos embriões, à má qualidade do corpo lúteo $(\mathrm{CL})$ das receptoras, ou ainda à assincronia útero-embrião (SREENAN; DISKIN, 1987), ou seja, o ambiente uterino adequado para a gestação deve coincidir com o momento da receptividade sexual e da ovulação da receptora (HAFEZ, 2004). Todos estes fatores representam grande limitação biológica para que índices reprodutivos satisfatórios sejam atingidos.

Nos tratamentos superovulatórios, fêmeas de comprovada qualidade genética são tratadas com hormônios gonadotróficos e seus oócitos são fecundados in vivo ou in vitro; os embriões resultantes são transferidos para receptoras, mães substitutas com 
potencial genético inferior (DINIZ et al., 1999). Notáveis progressos já foram alcançados no refinamento dos procedimentos de manejo reprodutivo (HAFEZ, 2004). Abordagens incluindo a determinação do status folicular antes da estimulação hormonal (PURWANTARA et al., 1993; KAWAMATA, 1994; SINGH et al., 2004) e eliminação dos efeitos de supressão do folículo dominante (BUNGARTZ; NIEMANN, 1994; LINDSEY et al., 1994; KIM et al., 2001) têm sido utilizadas para reduzir a imprevisibilidade da resposta superovulatória em bovinos e aumentar o número de embriões transferíveis. No entanto, estes métodos não eliminam a variabilidade na resposta superovulatória e uma melhor previsão ainda é crítica para a aplicação dos programas de ovulação múltipla e transferência de embriões (OMTE) (ARMSTRONG, 1993; KAFI; MCGOWAN, 1997; ALVAREZ et al., 1998; MAPLETOFT; STEWARD; ADAMS, 2002; BO; GUERRERO; ADAMS, 2008).

A taxa de prenhez após a transferência de embrião é grandemente influenciada pelas condições e pela preparação das receptoras, o procedimento de TE em animais domésticos depende inteiramente da disponibilidade de uma fonte de embriões de boa qualidade e de um ambiente uterino apropriado na receptora no momento da transferência (HAFEZ, 2004). O impacto de um ambiente uterino inadequado da receptora impede o desenvolvimento embrionário normal, criando um fator limitante nos programas de TE (LOZANO et al., 2003; ISHIGAME et al., 2004; ALVAREZ et al., 2005).

A ação dos esteróides ovarianos causa mudanças cíclicas em inúmeras respostas uterinas como no fluxo sanguíneo (FORD et al., 1979), na histologia e citologia endometrial (MARINOV; LOVELL, 1968; PRIEDKALNS, 1976) e no perfil protéico do fluido uterino (ROBERTS; PARKER, 1976). Essas alterações ocorrem devido ao requerimento biológico para estabelecer um ambiente intra-uterino capaz de sustentar o concepto bovino (SREENAN, 1978). Alguns trabalhos associam o aumento da concentração plasmática de progesterona $\left(\mathrm{P}_{4}\right)$ com o desenvolvimento embrionário e o estabelecimento da gestação (HASLER et al., 1980; SREENAN, DISKIN 1983; MANN, LAMMING 1999; BINELLI et al., 2001; MANN, LAMMING 2001; MANN et al., 2006; LONERGAN et al., 2007; BAZER et al., 2009) o que denota a importância da perfeita interação entre o CL, a produção hormonal e o ambiente uterino para o sucesso reprodutivo. 
A vascularização tem uma função importante nos processos reprodutivos como no desenvolvimento do folículo dominante, formação do $\mathrm{CL}$, crescimento do endométrio e implantação (ABULAFIA; SHERER, 2000; SMITH, 2001). Diversos trabalhos foram realizados analisando o fluxo sanguíneo uterino como um método de estudo para prever o sucesso da concepção e da receptividade uterina em mulheres (BLOECHLE et al., 1997; ENGMANN et al., 1999; CHIANG et al., 2000; KUPESIC et al., 2001; SCHILD et al., 2001; CHIEN et al., 2002; WU et al., 2003; HICKEY et al., 2003; CHIEN et al., 2004; YU et al., 2006; MERC et al., 2008; WEN et al., 2009). Em bovinos alguns trabalhos mostraram a influência da administração de gonadotrofina (eCG ou FSH) na formação e vascularização do CL, produção de progesterona e fluxo sanguíneo uterino tanto em receptoras como em doadoras bovinas (FUCK et al., 2002; BARUSELLI et al., 2004; PAPA et al., 2007; HONNENS et al., 2008). No entanto, análises referentes à influência deste tratamento na densidade vascular uterina ainda não foram realizadas.Diante do exposto, o objetivo deste trabalho foi avaliar a influência dos tratamentos estimulatório e superestimulatório com eCG no tecido uterino bovino, principalmente através da quantificação da densidade vascular. É necessário conhecer melhor o efeito destes tratamentos no ambiente uterino para embasar futuros estudos e abordagens das técnicas de superovulação e estimulação visando otimizar o processo reprodutivo principalmente em receptoras. 
2 OBJETIVOS 


\section{OBJETIVOS}

Hipotetizou-se que o tratamento estimulatório ou superovulatório com eCG pode influenciar na microvascularização do endométrio e miométrio de vacas tratadas, e consequentemente a receptividade do ambiente uterino.

Para testar esta hipótese os seguintes objetivos específicos foram determinados:

1. Mensurar a espessura e a área do endométrio e miométrio juntos e separadamente, através de exame ultrasonográfico em vacas apenas sincronizadas, estimuladas ou superovuladas.

2. Mensurar o diâmetro e a área da artéria uterina através do exame ultrasonográfico com Doppler colorido em vacas apenas sincronizadas, estimuladas ou superovuladas.

3. Quantificar a densidade vascular do endométrio e miométrio de ambos os cornos uterinos de vacas superovuladas e dos cornos ipsilateral e contralateral de vacas apenas sincronizadas e estimuladas.

4. Comparar os dados obtidos em animais apenas sincronizados com animais estimulados e superovulados.

5. Comparar a densidade vascular entre o corno ipsolateral e contralateral dos animais apenas sincronizados e estimulados. 
3 REVISÃO DE LITERATURA 


\section{REVISÃO DE LITERATURA}

Nesta revisão de literatura são abordados temas referentes aos problemas encontrados nos índices reprodutivos do rebanho bovino, bem como os fatores limitantes dos programas de reprodução assistida. Em seguida, o controle hormonal e vascularização uterina em ciclos normais de reprodução. Finalmente, os protocolos utilizados comumente nas biotécnicas da reprodução e sua influência sobre as funções luteínica e uterina, bem como a sobre a vascularização. O receptor 2 (KDR) do fator de crescimento vascular endotelial (VEGF) também será abordado pois foi utilizado como marcados para células endoteliais.

\subsection{O PROBLEMA}

O rebanho bovino brasileiro é composto por mais de 200 milhões de animais (MAPA, 2007), e na sua grande maioria observa-se comprometimento nos índices reprodutivos, principalmente devido ao prolongamento do período de anestro pós-parto. O intervalo de partos recomendado zootecnicamente é de aproximadamente 12 meses. Para alcançar esse índice, as vacas devem tornar-se gestantes rapidamente após o parto (entre 70 e 90 dias). Assim, para atingir a meta de 12 meses, as vacas necessitam ser sincronizadas e inseminadas precocemente (BARUSELLI et al., 2004).

Sabe-se que naturalmente após o parto as matrizes passam por um estado fisiológico conhecido como anestro pós-parto com duração de aproximadamente 45 dias. Esse período pode se estender de acordo com o escore corpóreo do animal, sistema de produção e nível nutricional. Esse período permite a reestruturação dos órgãos genitais assim como o restabelecimento dos mecanismos endócrinos responsáveis pela ciclicidade nos animais, e o seu final é determinado pela primeira ovulação fértil (YAVAS; WALTON, 2000).

Os principais fatores que comprometem a ovulação são a condição nutricional e a amamentação (MONTIEL; AHUJA, 2005). Quanto à nutrição, sabe-se que animais 
criados em regiões tropicais apresentam comprometimento na atividade ovariana pósparto devido principalmente ao inadequado conteúdo energético fornecido pelas pastagens. Dessa maneira, a energia ingerida pelo animal é priorizada para funções vitais de manutenção e de produção de leite, em detrimento das funções reprodutivas (revisado em MONTIEL; AHUJA, 2005). Outro fator que pode inibir a ovulação no período pós-parto é a amamentação, por reduzir a liberação de $\mathrm{GnRH}$ e a secreção de LH (WILLIAMS, 1990).

Bos taurus apresentam duas ou três ondas de crescimento folicular por ciclo estral. A primeira onda consistentemente emerge no dia da ovulação, e a segunda onda surge entre os dias 8 e 10 após a ovulação. Dentro de cada onda, um folículo se torna dominante e é responsável por suprimir o crescimento de folículos subordinados, levando-os à atresia (ADAMS et al., 1992; ADAMS, 1994).

A superovulação é uma técnica utilizada para estimular o crescimento e a múltipla ovulação dos folículos antrais através da administração de gonadotrofinas exógenas em vacas de alto valor comercial (denominadas de doadoras). O objetivo é que um número maior de folículos do que o geneticamente estabelecido durante um ciclo sexual natural seja selecionado e recrutado (ADAMS, 1994). A variabilidade na resposta das doadoras ao tratamento superestimulatório com gonadotrofinas continua sendo um dos maiores problemas nos programas comerciais de TE (MAPLETOFT et al., 2002, BARROS; NOGUEIRA, 2004; BARUSELLI et al., 2006). Esta variação individual ao tratamento superovulatório foi relatada tanto em vacas Nelore (Bos indicus; BARUSELLI et al., 2003), quanto em vacas Holandesas de alta produção (Bos taurus; MARTINS, 2005).

Algumas estratégias vêm sendo estudadas para estabelecer o período ideal para iniciar a hiperestimulação com uma maior eficiência do tratamento. Vários estudos têm demonstrado a importância do tratamento com gonadotrofinas ser iniciado no momento da emergência da segunda onda de crescimento folicular, pois a ausência do folículo dominante no início do tratamento aumenta a eficácia da superovulação (ADAMS et al., 1994; MAPLETOFT et al., 2002). A sincronização das ondas foliculares antes do tratamento superovulatório é um passo importante. Um estudo feito por Bo et al. (1996) mostrou que a sincronização das ondas de crescimento folicular, com estradiol-17 $\beta\left(\mathrm{E}_{2}\right)$ 
e $\mathrm{P}_{4}$, seguidos por administração do hormônio folículo estimulante (FSH) aumenta a eficiência da resposta superovulatória ( $\mathrm{BO}$ et al., 2002). Além do $\mathrm{E}_{2}$ e da $\mathrm{P}_{4}$ outros estudos mostram que o hormônio liberador de gonadotrofinas (GnRH) (KOHRAM et al., 1998), LH, hCG (BÓ et al., 1993, 1995) também são usados para controlar a emergência de ondas foliculares.

Embora as técnicas de transferência de embriões sejam amplamente utilizadas em todo o mundo, com mais de 500.000 embriões transferidos a cada ano (THIBIER, 2003), a alta variabilidade e imprevisibilidade no rendimento do embrião após o tratamento superovulatório em vacas ainda criam problemas que afetam a eficiência e a rentabilidade dos programas de transferência de embrião convencional (TE) em bovinos (ARMSTRONG, 1993; KAFI M et al., 1997; MAPLETOFT et al., 2002; BO et al., 2008). Inúmeros fatores interferem na eficiência de programas de TE na resposta superovulatória em doadoras: o meio ambiente e a fisiologia inerente da doadora, que varia com a idade (LERNER et al.,1986), temporada (LERNER et al.,1986), o estado nutricional (HENDRICKS et al.,1986), história reprodutiva (HASLER et al.,1983), repetição do tratamento superovulatório (DONALDSON et al.,1983) estado ovariano no momento do tratamento (LINDSELL et al., 1986) e tempo de tratamento com relação ao ciclo estral (LINDSELL et al., 1986).

Destaque especial é dado às receptoras (HASLER, 2001; SPELL et al., 2001) que, em geral, apresentam baixas taxas de aproveitamento nos programas de TE comerciais (\% de receptoras aptas à inovulação por total de receptoras tratadas). Normalmente, em um lote de receptoras tratadas com protocolos tradicionais (uso de prostaglandina associado à detecção de estro), somente 40 a $50 \%$ dos animais são aproveitados para a inovulação. Considerando-se uma taxa de concepção de $50 \%$ do total de animais aproveitados, obtém-se apenas 20 a 25\% de gestações ao final do tratamento (BARUSELLI et al., 2000a, 2000b; BÓ et al., 2002).Desta forma, o incremento das taxas de aproveitamento e de concepção das receptoras é fundamental para maximizar a taxa de prenhez e, com isso, elevar o retorno zootécnico e econômico da TE. Em receptoras foram apontados efeitos positivos do eCG em protocolos de transferência de embriões em tempo fixo aumentando a taxa de aproveitamento das receptoras e induzindo a formação de um corpo lúteo que produz mais progesterona no dia da inovulação dos embriões (Baruselli et al., 2000c; Bó et al., 2002). 
$\mathrm{Na}$ medicina humana, problemas similares são encontrados em mulheres inférteis submetidas ao tratamento com gonadotrofinas para a fertilização in vitro (FIV) e programas de TE, mostrando a baixa previsibilidade das taxas de concepção, principalmente devido a variações na receptividade uterina (COULAM et al., 1994; STEER et al., 1995; CACCIATORE et al., 1996; GROUTZ et al., 1997; TOHMA et al., 1997; CHIEN et al., 2002; ADAKAN et al., 2005; LILIC et al., 2007). Diversos parâmetros têm sido propostos para a avaliação da receptividade endometrial em mulheres, incluindo a espessura endometrial, o padrão endometrial e o fluxo sangüíneo endometrial e subendometrial (COULAM et al., 1994; APPLEBAUM, 1995; ZAIDI et al., 1995; REMOHI et al., 1997; SUNDSTROM, 1998; BOURGAIN et al., 2003). Vários estudos têm associado uma prejudicada perfusão das artérias uterinas a falhas de implantação durante a fertilização in vitro (FIV) (STEER et al., 1992; ZAIDI et al., $1996^{b}$ ). Raine-Fenning et al. (2004) observaram em mulheres com inexplicável subfertilidade, que a vascularização endometrial e subendometrial encontra-se significativamente reduzida.

\subsection{CONTROLE HORMONAL E VASCULARIZAÇÃO UTERINA}

Os hormônios ovarianos apresentam substancial envolvimento na regulação do metabolismo uterino. $\mathrm{O}$ crescimento do útero, tanto na síntese protéica quanto nas divisões celulares, é induzido por estrógenos. $\mathrm{O} \mathrm{E}_{2}$ aumenta a freqüência das contrações uterinas em ovelhas ovariectomizadas, nas quais a $\mathrm{P}_{4}$ reduz essa freqüência. Altos níveis de $\mathrm{P}_{4}$ são observados quando a atividade contrátil é relativamente quiescente. A implantação envolve a fixação do trofoderma do concepto em desenvolvimento (embrião e membranas extra-embrionárias) ao epitélio luminal uterino, em uma série de eventos altamente sincronizados que exige recíprocas interações, secretoras e físicas, durante um período restrito, conhecido como a "janela de receptividade" (CARSON et al., 2000; DEY et al., 2004). A "janela de receptividade para implantação" é estabelecida através das ações da $\mathrm{P}_{4}$ e, em algumas espécies, do $\mathrm{E}_{2}$ que regulam citocinas produzidas localmente, fatores de crescimento, fatores de transcrição homeobox e prostaglandinas ciclooxigenase-derivadas através de vias autócrina e parácrina (PARIA et al., 2002). 
Quando ocorre a implantação embrionária e reconhecimento da prenhez, as células trofoblásticas produzem gonadotrofinas, que estimulam o $\mathrm{CL}$ a continuar secretando $\mathrm{P}_{4}$. A progesterona faz as glândulas uterinas ficarem mais dilatadas, mais tortuosas e produzirem mais secreção que durante a fase proliferativa (JUNQUEIRA; CARNEIRO, 2004).

Durante o início da prenhez, o útero dos mamíferos é exposto sequencialmente ao $\mathrm{E}_{2}, \mathrm{P}_{4}$, interferon-tau (INF- $\tau$ ) e ao lactogênio placentário (SPENCER; BAZER, 2004). No útero dos mamíferos, os receptores de progesterona (PR) estão expressos no epitélio e estroma endometrial durante o início da fase luteínica, permitindo uma regulação direta na transcrição de uma série de genes. Entretanto, a exposição continua do endométrio a $\mathrm{P}_{4}$ diminui a expressão dos PR no epitélio endometrial (SPENCER; BAZER, 2004). A expressão dos PR é detectável no estroma e no miométrio de ovinos durante a maior parte da gestação. O paradigma da diminuição na quantidade dos PR no epitélio após a implantação ocorre na ovelha (SPERCER et al., 1995), nas vacas (KIMMINS; MACLAREN, 2001) e nas porcas (GEISERT et al., 1994). A $\mathrm{P}_{4}$ age no útero para estimular e manter as funções uterinas que permitem o desenvolvimento embrionário inicial, a implantação, a placentação e o desenvolvimento fetal a termo. Os dias 15 a 19 após o estro constituem um período crítico para a manutenção da gestação. Nesse período, o útero de animais não gestantes produz e libera pulsos de prostaglandina $\mathrm{F}_{2 \alpha}\left(\mathrm{PGF}_{2 \alpha}\right)$, molécula responsável pela luteólise, que se caracteriza pela regressão funcional e estrutural do corpo lúteo. Após a diminuição na concentração plasmática de progesterona ocorrem as etapas finais do crescimento do folículo dominante pré-ovulatório, culminando na sua ovulação e início de um novo ciclo estral. Entretanto, na ocorrência da concepção, o mecanismo luteolítico deve ser bloqueado para possibilitar o estabelecimento da gestação.

Para o estabelecimento da gestação é necessário que o concepto sinalize sua presença no útero. Esse processo é denominado reconhecimento materno da gestação, e se caracteriza por um diálogo molecular entre o concepto e a fêmea que resulta em mecanismos para a manutenção do CL e, consequentemente, da gestação (HAFEZ, 2004; SPENCER et al, 2007). 
O útero é um órgão pertencente ao aparelho reprodutor feminino, cuja principal função é o favorecimento do desenvolvimento inicial do embrião, sua implantação e crescimento do feto durante a gestação. O útero é composto de dois cornos uterinos, um corpo e uma cérvix (colo), sua forma e disposição varia entre as espécies. Nos bovinos, assim como em ovinos, um útero bipartido é típico e apresenta um septo que separa os dois cornos e permite que apenas uma região pequena represente o corpo uterino; ambas as margens uterinas são unidas à parede pélvica e abdominal pelo ligamento largo (HAFEZ, 2004). A parede uterina é relativamente espessa e formada de três camadas. Externamente há uma serosa, em seguida o miométrio, constituído de musculatura lisa, e a camada mais interna chamada de endométrio, ou mucosa uterina. $\mathrm{O}$ endométrio e seus fluidos têm grande relevância no processo reprodutivo: transporte dos espermatozóides, regulação da função do CL, início da implantação, gestação e parto (HAFEZ, 2004).

O endométrio consiste em um epitélio e uma lâmina própria que contém glândulas tubulares simples que, às vezes, se ramificam nas porções mais profundas (próximo ao miométrio). O epitélio uterino é do tipo colunar simples e constituído por células ciliadas e células secretoras. $\mathrm{O}$ endométrio pode ser subdividido em duas camadas, a camada basal, adjacente ao miométrio e a camada funcional, que sofre mudanças intensas durante os ciclos estrais. Ambas as camadas do endométrio são irrigadas por vasos provenientes do miométrio, as artérias retas irrigam a camada basal e as artérias espirais irrigam a camada funcional (JUNQUEIRA; CARNEIRO, 2004). O endométrio metaboliza carboidratos, lipídios e proteínas para suprir os requerimentos necessários para a nutrição celular, para a rápida proliferação do tecido uterino e para o desenvolvimento do concepto. Essas reações dependem dos seguintes fenômenos: as reações enzimáticas envolvidas no metabolismo da glicose, aumento da circulação através de arteríolas espiraladas, alterações morfológicas que ocorrem no endométrio e no miométrio, ação estimulante dos hormônios ovarianos e outros hormônios (HAFEZ, 2004).

O sucesso da prenhez exige a remodelação do complexoendométrio para orquestrar a implantação e a angiogênese, que fornece o apoio hematotrófico para o desenvolvimento do concepto (CHARNOCK-JONES et al., 2004; KAUFMANN et al., 2004; RED-HORSE et al., 2004). Em ruminantes, o contato entre o corioalantóide e a 
carúncula, leva ao desenvolvimento dos cotilédones, estruturas altamente vascularizadas que formam em conjunto os placentomas. Os placentomas são críticos para a troca de nutrientes e gases em toda a placenta (REYNOLDS et al., 2005). Falhas no desenvolvimento dos placentomas resultam na perda fetal, porque eles permitem a proximidade de vasos sangüíneos maternos e fetais para a troca de oxigênio e nutrientes (WU et al., 2004; REYNOLDS et al., 2005).

O micro-ambiente uterino é composto por macromoléculas, secretadas pelo concepto e endométrio e oriundas da circulação periférica que fornecem os nutrientes e o meio físico-químico adequado para o desenvolvimento do embrião desde sua chegada no útero até a sua implantação (SPENCER et al., 2006). Diversos autores sugerem que a produção de substâncias vasoativas pelo embrião e / ou endométrio seja responsável pela estimulação local da perfusão uterina observada em bovinos (FORD et al., 1979; FORD, 1982), ovinos (GREISS et al., 1970; FORD, 1982; REYNOLDS, 1984), suínos (FORD, CHRISTENSON, 1979; FORD, 1982; ANDERSON et al., 1994), e equinos (BOLLWEIN et al., 2003; SILVA et al., 2005; SILVA; GINTHER, 2006).

Em resposta a secreção seqüencial de $\mathrm{E}_{2}$ e $\mathrm{P}_{4}$ do ovário, o endométrio prolifera e se diferencia tornando-se receptivo ao embrião. São induzidos significativo crescimento, ramificações e dilatações dos vasos endometriais pela ação coordenada do $\mathrm{E}_{2}$ e $\mathrm{P}_{4}$, assim assegurando o suprimento de sangue adequado para o endométrio receptivo. No período peri-implantação, as artérias espiraladas endometriais submetemse a mudanças características, como a ampliação das paredes dos vasos sanguíneos e da camada muscular das artérias (FAZLEABAS; STRAKOVA, 2002). Seguinte à implantação, ocorrem três fases consecutivas, a justaposição do concepto ao epitélio materno, a adesão de ambos e a invasão do tecido materno, momento em que o concepto se aproxima da microvascularização da mãe (NORWITZ; SCHUST; FISHER, 2001).

Wen et al. (2009) demonstraram que a progesterona poderia estimular a secreção do fator de crescimento vascular endotelial (VEGF) das células epiteliais do endométrio e, subsequentemente, aumentar a vascularização subendometrial e o fluxo sanguíneo. Portanto, o grupo concluiu que a progesterona aumenta a receptividade do útero para o embrião através da indução da angiogênese endometrial. 


\subsection{INFLUENNCIA DOS PROTOCOLOS UTILIZADOS COMUMENTE NAS BIOTÉCNICAS SOBRE AS FUNÇÕES LUTEÍNICA E UTERINA.}

Folículos em vários estágios de desenvolvimento estão normalmente presentes nos ovários. No entanto, para que ocorra a ovulação do folículo dominante, a freqüência dos pulsos de LH deve ser de aproximadamente um pulso por hora (revisado em BÓ et al., 2003). A ausência ou a inadequada pulsatilidade de LH faz com que o folículo dominante não se desenvolva muito além do diâmetro da divergência folicular.

O objetivo do tratamento superovulatório é fornecer, àqueles folículos que normalmente se tornariam atrésicos, um meio hormonal adequado para que continuem seus processos de maturação, culminando com a ovulação (DINIZ et al., 1999). As gonadotrofinas estimulam o crescimento dos folículos pequenos, revertendo a atresia dos folículos acima de 1,7mm (MOOR; KRUIP; GREEN, 1984). Os principais hormônios aplicados diretamente na superestimulação ovariana são: o FSH (hormônio folículo-estimulante), LH (hormônio luteinizante), e a gonadotrofina coriônica humana (hCG) (HERR et al., 2004).

$\mathrm{O}$ eCG (gonadotrofina coriônica equina) é um fármaco de meia vida longa (até 3 dias), produzido nos cálices endometriais da égua prenhe (40 a 130 dias; MURPHY; MARTINUK, 1991), que se liga aos receptores de FSH e LH dos folículos e aos receptores de LH do corpo lúteo (STEWART; ALLEN, 1981). Em eqüinos, o eCG causa ovulação ou luteinização de folículos durante a gestação, com conseqüente aumento da progesterona circulante (revisado por MURPHY; MARTINUK, 1991). A eCG quando administrada a vacas em anestro cria condições para estimular o crescimento folicular e a ovulação, mesmo em vacas que tenham comprometimento na liberação de gonadotrofinas. Ainda, devido sua ação de LH e FSH e meia vida longa, a eCG pode ser utilizada em dose única em protocolos para superovulação em bovinos (BARUSELLI et al., 2008).

Baruselli et al. (2004) em um estudo realizado com o objetivo de avaliar os efeitos do uso do eCG na dinâmica folicular de vacas Nelore (Bos indicus) comprovadamente em anestro e sincronizadas para IATF, observou que o tratamento 
com eCG na retirada do implante auricular de progestágeno aumentou o diâmetro do folículo dominante, além de aumentar as taxas de ovulação e de concepção. Esse efeito também foi verificado em novilhas Nelore ciclando tratadas com dispositivo intravaginal de progesterona (CIDR; BARUSELLI et al., 2004a). Apesar do aumento significativo do tratamento com eCG na taxa de prenhez os resultados apresentaram-se aquém do esperado, indicando que outros efeitos estão influenciando a eficiência da IATF em novilhas Nelore (BARUSELLI et al., 2008). Em outros estudos foi visto que os animais que receberam eCG apresentaram maiores concentrações plasmáticas de progesterona no diestro subseqüente ao protocolo de sincronização da ovulação. Resultados semelhantes foram observados em vacas de leite de alta produção. Esses dados sugerem que o aumento na taxa de concepção após o tratamento com eCG pode também ser devido à elevação nas concentrações plasmáticas de progesterona. Mann et al. (1999) demonstraram que vacas que apresentam maiores concentrações de progesterona no diestro apresentam melhores condições de crescimento embrionário e de reconhecimento materno da gestação, culminando em maiores taxas de concepção.

O emprego da eCG também tem sido relatado em receptoras de embrião. Receptoras que recebem eCG durante o tratamento de sincronização apresentam aumento da taxa de ovulação e de aproveitamento, além de possuírem maiores níveis de progesterona circulante no diestro (BARUSELLI et al., 2000c), minimizando falhas no reconhecimento da gestação (BINELLI et al., 2001) e aumentando a eficiência da transferência de embriões. Alguns trabalhos associam o aumento da concentração plasmática de progesterona com o desenvolvimento embrionário e o estabelecimento da gestação (HASLER et al., 1980; SREENAN; DISKIN, 1983; MANN, LAMMING 1999; MANN, LAMMING 2001; BINELLI et al., 2001; MANN et al., 2006; LONERGAN et al., 2007; BAZER et al., 2009).

No Brasil, já existem trabalhos que também relataram correlação positiva entre a concentração plasmática de progesterona e a taxa de concepção em receptoras de embrião bovino (REIS et al., 2004). Assim, pode-se supor que o aumento da taxa de concepção em animais tratados com eCG pode estar relacionada a: 1) incremento na taxa de ovulação, principalmente em animais em anestro, e; 2) aumento das concentrações plasmáticas de progesterona no diestro do ciclo subseqüente à IATF, que pode melhorar o desenvolvimento embrionário e a manutenção da gestação. 
A hiperestimulação ovariana provoca alterações morfológicas e funcionais importantes no CL e consequentemente no ambiente uterino. O estabelecimento e a manutenção da gestação, bem como o crescimento embrionário em bovinos, estão correlacionados à habilidade do CL em secretar P4, hormônio intimamente relacionado com o ambiente uterotubário (FIELDS; FIELDS, 1996) e ao desenvolvimento adequado deste ambiente.

O útero produz fatores angiogênicos que afetam o desenvolvimento do trato reprodutivo, que incluem o fator de crescimento endotelial vascular (VEGF), fator de crescimento fibroblastico 2 (FGF2), angiopoetinas (ANG), e seus receptores vasculares (BOROWICZ et al. 2007). Ambos os fatores, o VEGF e FGF2 são os principais fatores de crescimento angiogênicos do útero e também da placenta. O VEGF estimula a permeabilidade vascular, migração de células do endotélio vascular e produção de protease para melhorar a angiogênese. Uma gestação bem sucedida exige o desenvolvimento de uma rede vascular que facilita a comunicação materno-fetal (GORDON et al., 1995). A angiogênese é um componente fundamental na implantação do blastocisto e o desenvolvimento do endométrio no início da prenhez (REYNOLDS et al., 1992; ATHANASSIADES et al., 1998).

Diversos parâmetros têm sido utilizados para avaliar a receptividade uterina, incluindo a espessura e padrão endometrial e o fluxo sanguíneo do endométrio e subendometrial (FRIEDLER et al., 1996). Um aumento do fluxo sanguíneo do útero após a estimulação hormonal para crescimento folicular tem sido demonstrado em pacientes de FIV na Medicina humana (WEINEER et al., 1993; BASSIL et al., 1995).

Elucidar o padrão de mudanças de fluxo sanguineo que ocorrem no estroma ovariano e artérias uterinas durante um tratamento de ciclo estimulado podem constituir uma base importante para a compreensão da relação entre o fluxo de sangue anormais do útero e ovário e a falha na implantação (ENGMANN et al., 1999).

A família dos VEGFs contém diversas proteínas, incluindo o VEGF-A (VEGF), sendo o primeiro e melhor descrito membro, inicialmente isolado e purificado a partir de meio de cultura de células foliculares da pituitária de bovinos (FERRARA; HENZEL, 1989), o VEGF-B (OLOFSSON et al., 1996; PAAVONEN et al., 1996), 
VEGF-C (JOUKOV et al., 1996; PAAVONEN et al., 1996), VEGF-D (ACHEN et al., 1998), VEFG-F (YAMAZAKI et al.,2005; SUTO et al., 2005), VEGF-related protein (LEE et al., 1996), fator de crescimento placentário (PIGF) (PARK et al., 1994) e o homólogo viral VEGF-E (MEYER et al., 1999; OGAWA et al., 1998). O VEGF é considerado um dos marcadores da receptividade do útero para implantação, por estar associado com a angiogênese e vascularização dos tecidos (HAOUZI et al., 2009). Os VEGFs exercem seu papel biológico através de interações com seus receptores. Esses receptores do tipo tirosina quinase apresentam localização transmembrana: VEGFR1/Flt-1 (Fms-like tyrosine kinase 1) (DE VRIES et al., 1992), VEGFR-2/Flk-1/KDR (Kinase insert domain containing receptor) (TERMAN at al., 1992). O Flt-1 e o KDR são predominantemente expressos em células endoteliais (FERRARA, 1999). A maior parte das respostas das células endoteliais ao VEGF, incluindo mitogênese, migração (BERNATCHEZ; SOKER; SIROIS, 1999; GILLE et al., 2001; WALTENBERGER et al., 1994), alterações na forma, reorganização do citoesqueleto (WALTENBERGER et al., 1994) e indução da permeabilidade vascular (GILLE et al., 2001; GÓMEZ et al., 2002) são medidas pela ativação do KDR. O KDR tem um papel chave na proliferação e diferenciação de células endoteliais (FERRARA, 2001; PEICHEV et al., 2000). Diversos trabalhos utilizaram o KDR como importante marcador endotelial, (YASUHARA et al, 2004; KHARFAN-DABAJA et al., 2006; KUNG et al., 2006; WAGATSUM et al., 2006; HERVÉ et al., 2006) 
4 MATERIAS E MÉTODOS 


\section{MATERIAIS E MÉTODOS}

Os experimentos de sincronização de ciclo estral e tratamentos hormonais foram conduzidos na Faculdade de Medicina Veterinária Zootecnia, campus de Pirassununga SP, durante o período de maio a agosto de 2009. Foram utilizadas 16 vacas mestiças da raça Nelore com idade entre 2 e 5 anos, mantidas a pasto e recebendo complementação alimentar por concentrado. Anteriormente ao período experimental, os animais foram avaliados quanto à condição de escore corporal em escala de 1 a 5 (WILDMAN et al., 1982) da condição ovariana, por palpação retal conforme Madureira et al., (2004), e ultra-sonografia, sendo selecionadas aquelas que apresentaram escore de condição entre 2,0 e 3,0 e condição ovariana adequada (presença de folículos e CL).

\subsection{GRUPOS DE TRATAMENTO}

Nesse experimento, as fêmeas foram distribuídas aleatoriamente em três grupos $($ controle $=5$, estimulado $=6$ e superovulado $=5$ ). Os protocolos de sincronização, estimulação e superovulação utilizados nesse trabalho constam na figura 1. Em breves palavras, todos os animais receberam um implante vaginal contendo $1 \mathrm{~g}$ de progesterona (Dispositivo Intravaginal Bovino - DIB; Progesterona 1g; Primer ${ }^{\circledR}$; Bueno Aires, Argentina) e uma injeção intramuscular de $2 \mathrm{mg}$ de benzoato de estradiol (Estrogin ${ }^{\circledR}$; Syntex $^{\circledR}$; Buenos Aires, Argentina) no dia 0. No dia 8, foram retirados os implantes intravaginais e administrados $0,150 \mathrm{mg}$ de prostaglandina $\mathrm{F}_{2 \alpha}\left(\mathrm{PGF}_{2 \alpha}\right.$, Prolise ${ }^{\circledR}$; Arsa, Buenos Aires, Argentina) nas fêmeas dos do grupo controle e estimulado. As vacas do grupo controle não receberam eCG (Gonadotrofina Coriônica Eqüina, Novormon ${ }^{\circledR}$ Syntex; Buenos Aires Argentina), enquanto as do grupo estimulado receberam 400 UI. Quarenta e oito (48) horas após a retirada do dispositivo de $\mathrm{P}_{4}$, os animais desses dois grupos receberam $0.025 \mathrm{mg}$ de hormônio liberador de gonadotropina (GnRH; Gestran Plus $^{\circledR}$, Arsa, Buenos Aires, Argentina). Às fêmeas do grupo superovulado foram administrados 2000 UI de eCG no dia 4 e $0,150 \mathrm{mg}$ de $\mathrm{PGF}_{2 \alpha}$ no dia 6 . No dia 7, foram retirados os implantes intravaginais e administrado $\mathrm{PGF}_{2 \alpha}$ e, 12 horas após a retirada do dispositivo, foram administrados $0.025 \mathrm{mg}$ de $\mathrm{GnRH}$. 
Gr upo $1-$ Contr ole $(1)=5$,

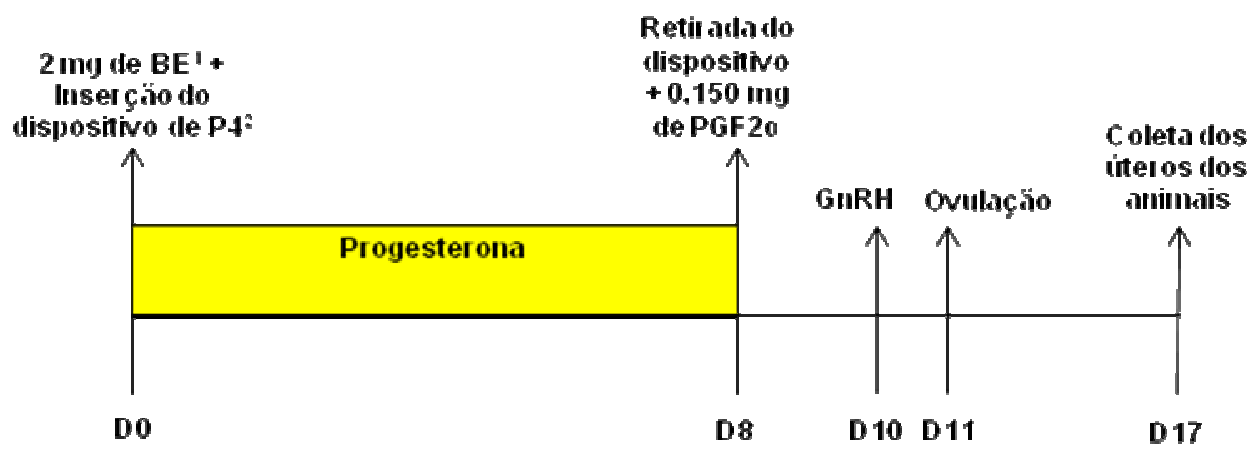

G! upo 2 - Estimulaulo (uI $=6$ )

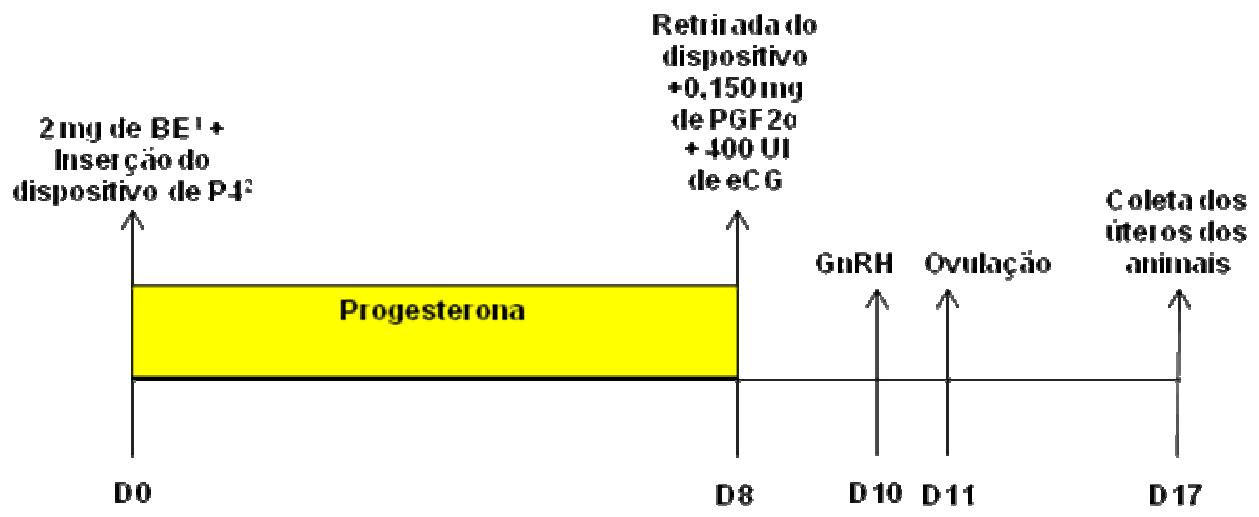

Gr tupo $3-$ Silpel ovilado $(i)=6$ t

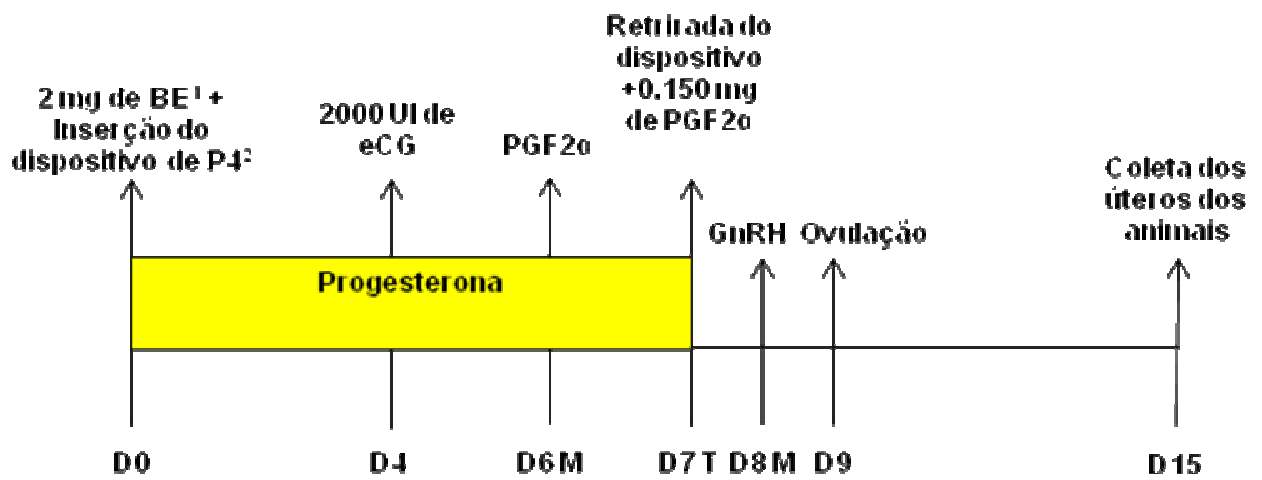

Figura 1 - Representação esquemática dos tratamentos para sincronização, estimulação e superestimulação da ovulação com dispositivo intravaginal de progesterona associado ou não ao eCG em vacas. 1 - Estrogin ${ }^{\circledR}$ - Syntex; 2 - BID $^{\circledR}$ - Syntex; D = dia; M = manhã; $\mathrm{T}=$ tarde 


\subsection{EXAMES ULTRASONOGRÁFICOS E MENSURAÇÕES DOS CORNOS E ARTÉRIAS UTERINAS}

Todos os animais foram submetidos a exames ultrasonográficos, com o auxílio de um ultra-som Doppler (MyLab 30, Pie Medical, Itália) equipado com uma sonda linear de 7.5 Mhz multifrequencial. Os exames foram realizados no quinto dia após a ovulação, para detectar a presença dos corpos lúteos, determinar a espessura dos cornos uterinos e o calibre das artérias uterinas.

O calibre da artéria uterina do corno ipsilateral dos animais controle e estimulados e a artéria uterina de um dos cornos uterinos dos animais superovulados foram mensurados. No modo color-Doppler, os sinais coloridos foram utilizados para se determinar os sinais de fluxo sanguíneo da artéria uterina, com o objetivo de localização e mensuração de seu diâmetro interno (Figura 2A). O diâmetro do miométrio e do endométrio foram mensurados separadamente. Tanto para mensuração do calibre da artéria uterina quanto da espessura dos cornos uterinos (miométrio e endométrio) foram feitas duas medidas de diâmetro (D1 e D2) e utilizou-se a média destes dois diâmetros para cálculo da área na formula de área de um círculo (Figura 2B):

$$
\begin{gathered}
\text { Área do circulo }=\pi \times \boldsymbol{r}^{2}(\mathrm{r}=\text { raio do círculo }) . \\
\mathrm{r}=\operatorname{diâmetro} / 2 \\
\text { Área }=\pi[(\mathrm{D} 1+\mathrm{D} 2) / 2]^{2}
\end{gathered}
$$



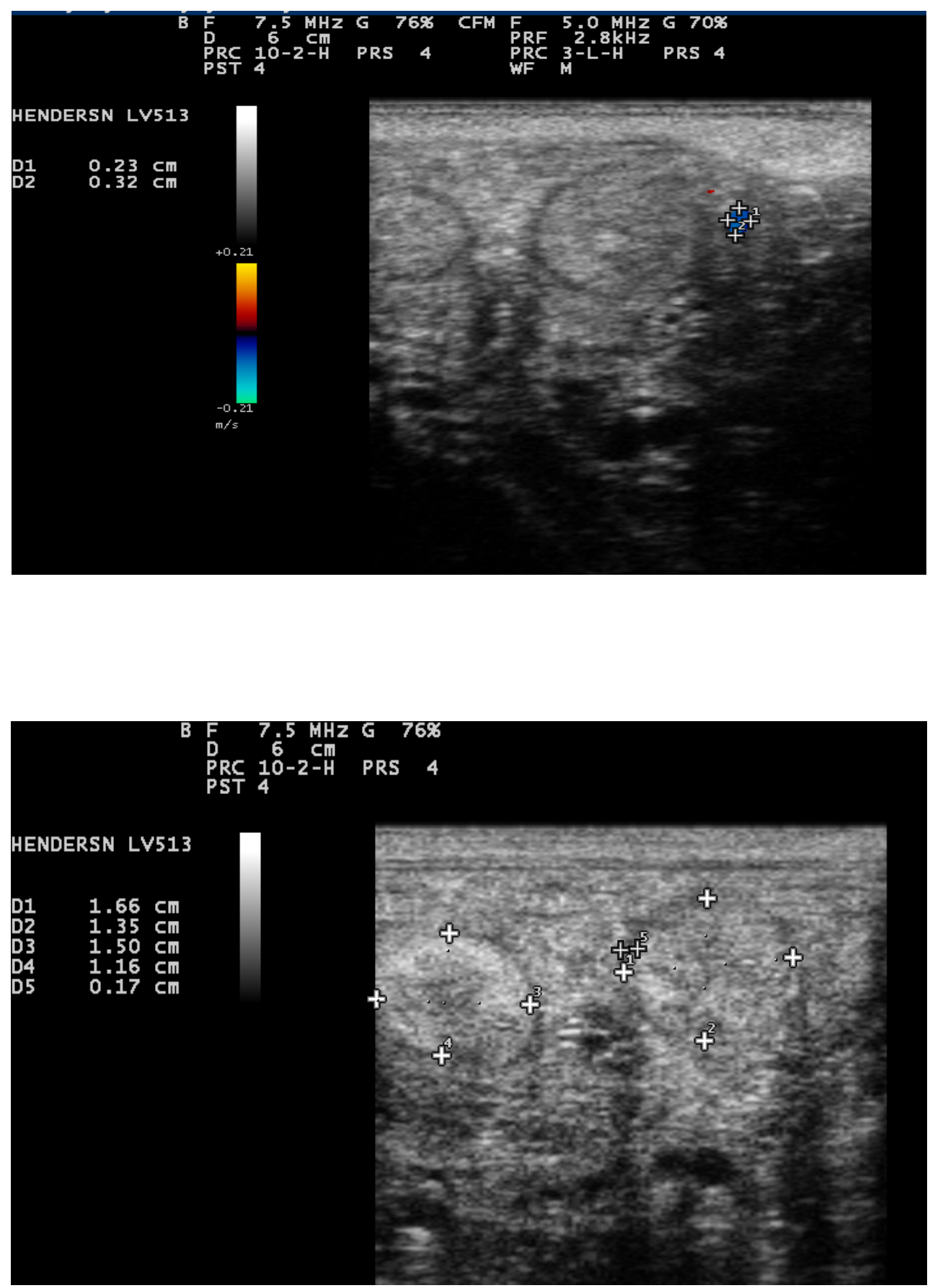

Figura 2 - Ultra-sonografia dos cornos uterinos. (A) Ultra-sonografia com Doppler dos cornos uterinos. Visualização da artéria uterina - pixels em azul. D1 e D2 - diâmetros da artéria uterina do corno ipsilateral; (B) ipsilateral a direita e contralateral a esquerda, D1 e D2 diâmetro do endométrio do corno uterino ipsilateral; D3 e D4 diâmetro do endométrio do corno uterino contralateral; D5 diâmetro do miométrio do corno ipsilateral 


\subsection{COLETA DAS AMOSTRAS E IMUNOHISTOQUÍMICA PARA KDR}

No dia 6 após a ovulação, todos os animais foram abatidos no abatedouro-escola da Faculdade de Medicina Veterinária e Zootecnia da USP. Após o abate, os úteros foram retirados e fragmentos transversais do terço caudal de ambos os cornos foram coletados. Tais fragmentos foram pesados, mensurados e fixados em solução de paraformaldeído tamponado a $4 \%$ por 24 horas. Após a fixação, o material foi processado na rotina histológica para inclusão em parafina, seccionado em cortes de 5 $\mu \mathrm{m}$ de espessura. Para aderência dos cortes às lâminas, as mesmas foram tratadas com silano 2\% (3-aminopropyltriethoxysilane; Sigma- Aldrich, Germany), e posteriormente destinadas a imunohistoquímica utilizando-se o anticorpo anti-KDR (C-20, Santa Cruz Biotechnology Inc., Heidelberg, Germany) diluído 1:400. Para determinação da imunomarcação desse anticorpo no tecido, foi empregado o método da peroxidase indireta por meio de kit comercial (Kit LSAB+System-HRP; K0679; Dako Laboratories, USA), conforme se segue: os cortes foram desparafinizados em xilol e rehidratados em uma série de etanol em concentrações decrescentes. A recuperação antigênica foi realizada através de incubação em tampão citrato, em microondas potência alta ( 3 x 5 minutos). A atividade da peroxidase endógena foi bloqueada com $o$ reagente de bloqueio de peroxidase proveniente do kit (Peroxidase blocking reagent) por 20 minutos, em câmara úmida. Para reduzir ligações inespecíficas do segundo anticorpo, as lâminas foram incubadas por 20 minutos em solução protein block (Protein block serum-free; X0909; DakoCytomation; USA). Os cortes foram circulados com caneta histológica (Dako Pen; S2002; Dako, Denmark,) e incubados com o anticorpo primário por 20 horas a $4{ }^{\circ} \mathrm{C}$. Esses passos foram intercalados por três lavagens das lâminas em tampão ICC (solução tampão fosfato com Triton X-100) por 5 minutos, que logo foram incubadas com o anticorpo secundário do mesmo kit (Bioetinylated Link) por 15 minutos e novamente lavados com ICC ( 3 x 5 minutos). Em seguida, as lâminas foram incubadas em câmara úmida por 15 minutos com a estreptavidina do kit (Atreptavidina-HRP), a temperatura ambiente. O cromógeno tetrahidrocloreto de diaminobenzedina (DAB) foi pingado nos cortes para evidenciar a reação por aproximadamente 2 minutos, e após, a reação foi bloqueada com duas lavagens em água destilada de 5 minutos. Em seguida, as lâminas foram contra-coradas com hematoxilina de Harris por 30 segundos, lavadas em água corrente por 10 minutos 
e montadas com resina hitológica.Os controles negativos foram obtidos substituindo-se o anticorpo primário por tampão ICC.

\subsection{ESTIMATIVA DA DENSIDADE VASCULAR NO CORNO UTERINO DE VACAS}

As mensurações estereológicas para estimativa da densidade vascular nos cornos uterinos foram realizadas utilizando-se o princípio do método de contagem de pontos (Point counting test) de acordo com as recomendações descritas em Gundersen et al. (1988).

Primeiramente, três (03) lâminas por corno uterino, contendo um corte cada, foram selecionadas aleatoriamente. Após a imunohistoquímica para KDR, visualizou-se através de microscópio óptico e objetiva de 40x, a margem superior esquerda do corte e a partir dessa margem, foram tiradas fotografias dos campos de visão, com uma distância de $1 \mathrm{~mm}$ entre eles, de forma que todo o corte fosse fotografado. Tal distância foi determinada através dos eixos x e y do microscópio. As imagens foram captadas por câmera digital, acoplada ao microscópio Olympus, BX-60 (Center Valley, USA) e à câmera Axiocam HRc (Zeiss, Alemanha) por meio do programa Axio vison4.8 Lymous (Zeiss, Alemanha) e enviadas a um computador em arquivos formato “jpeg” e resolução de 3900 x 3090 pixels para análise.

Primeiramente, calculou-se a magnificação linear (M) das imagens utilizadas, através da seguinte equação: $\mathrm{M}=\mathrm{h} / \mathrm{h}$, onde $\mathrm{h}$ é o tamanho da imagem projetada no monitor e h' é o tamanho do campo varrido na amostra (HOWARD; REED, 2005). Posteriormente, frames de contagem de área conhecida $\left(\mathrm{A}_{[\mathrm{fra}]}\right.$; largura * altura) foram sobrepostos às imagens e os vasos do endométrio e do miométrio, contidos no interior do frame e que não estivessem interceptados pelas linhas de exclusão, foram tabulados (Figura 3). A área do corte $\left(\mathrm{A}_{\mathrm{A}}\right)$, na qual os vasos uterinos foram quantificados, foi estimada multiplicando-se a área do frame $\left(\mathrm{A}_{[\mathrm{fra}]}\right)$ pelo número de frames utilizados $\left(\mathrm{N}_{\text {[fra] }}\right)$, divididos pela magnificação linear da imagem ao quadrado $\left(\mathrm{M}^{2}\right)$, enquanto a densidade de vasos existentes por corte $\left(\mathrm{N}_{\mathrm{A}}\right)$ foi calculada dividindo-se o somatório dos vasos quantificados $\left(\sum \mathrm{Q}\right)$ pela respectiva área do corte $\left(\mathrm{A}_{\mathrm{A}}\right)$. Já o número total de vasos 
(N) existentes no endométrio ou no miométrio foi estimado multiplicando-se a densidade numérica $\left(\mathrm{N}_{\mathrm{A}}\right)$ pela área $\left(\mathrm{A}_{\mathrm{ref}}\right)$ da respectiva região, a qual foi previamente mensurada através de ultra-som.

Como os tecidos sofrem retração durante o processo de parafinização, foram calculados o coeficiente de erro $\left(\mathrm{CE}(\mathrm{N})=1 / \sqrt{ } \sum \mathrm{Q}\right)$ e o coeficiente de variação $(\mathrm{CE}=$ DP/média) para otimização do método (MILLER et al., 1997)

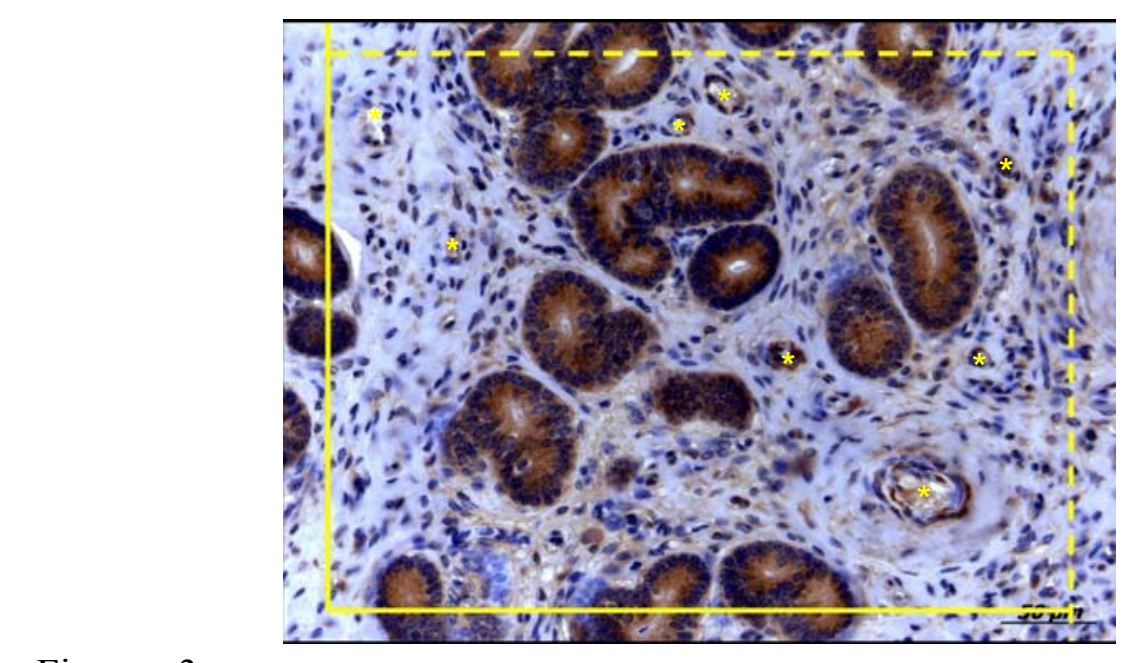

Figura 3

Fotomicrografia do endométrio do corno uterino contralateral ao CL de bovino estimulado com um frame sobreposto. Para estimar o número de vasos $\left(^{*}\right)$, consideram-se as estruturas contidas no interior do frame e que não estejam interceptadas pelas linhas de exclusão (linhas cheias). Barra $=50 \mu \mathrm{m}$

\subsection{ANÁLISE ESTATÍSTICA}

Ao compararmos a densidade vascular entre os grupos, foi sempre utilizado o valor da média da densidade vascular entre os dois cornos uterinos do grupo superovulado, devido à presença de CL em ambos os ovários dos animais, e conseguentemente a não distinção entre corno ipsilateral e contralateral.

Primeiramente, os dados obtidos foram submetidos a um teste de normalidade; dependendo da distribuição das amostras, os mesmos foram submetidos à análise paramétrica com o teste ANOVA ou não paramétrica com o teste de Mann-Whitney. O nível de significância adotado foi de $p<0,05$. 
5 RESULTADOS 


\section{RESULTADOS}

Inicialmente estão demonstrados os resultados relativos à influência dos tratamentos estimulatório e superovulatório sobre a área e espessura do endométrio e miométrio, separadamente e em conjunto e também sobre a área e diâmetro da artéria uterina, a partir de dados obtidos por meio de mensurações ultrasonográficas; em seguida, são descritos os resultados referentes à contagem da densidade vascular no endométrio e miométrio, separadamente e em conjunto, nos dois cornos uterinos dos três diferentes grupos.

\subsection{EFEITO DOS TRATAMENTOS ESTIMULATÓRIO E SUPEROVULATÓRIO NA ÁREA DE MIOMÉTRIO E ENDOMÉTRIO DOS CORNOS UTERINOS}

Os valores das áreas do endométrio e miométrio, correspondentes aos cornos uterinos ipsilateral e contralateral ao ovário contendo o corpo lúteo, dos animais dos grupos controle e estimulado, e dos cornos direto e esquerdo dos animais superovulados estão expressos na tabela 1 . Na figura 4 ultrasonografia dos cornos uterinos evidenciando as mensurações realizadas do endométrio e miométrio dos 3 grupos.

Observou-se que os tratamentos com eCG não influenciaram o tamanho da área tanto do miométrio quanto do endométrio dos cornos uterinos.

No entanto, quando comparamos a área dos cornos ipsilateral e contralateral dos animais dentro do mesmo grupo, observamos que no grupo controle, o miométrio e o endométrio do corno ipsilateral apresentam área maior $(\mathrm{p}=0.02$ e 0.037 , respectivamente) do que no corno contralateral, e as duas camadas em conjunto tendem a ser maior no corno ipsilateral $(p=0.062)$. Nos animais estimulados, observamos o mesmo comportamento para o endométrio do corno ipsilateral, que apresenta área maior $(\mathrm{p}=0.042)$ do que o endométrio do corno contralateral. A área do miométrio não apresentou diferença entre os dois cornos $(p=0.14)$, mas as duas camadas em conjunto apresentaram área maior $(\mathrm{p}=0.02)$ no corno ipsilateral. 
Tabela 1 - Área $\left(\mathrm{mm}^{2}\right)$ do miométrio e endométrio dos cornos uterinos dos bovinos submetidos aos tratamentos de estimulação $(n=6)$, superovulação $(n=5)$ e controle $(n=5)$. Os valores estão expressos em média (a) e erro padrão da média (b)

\begin{tabular}{|c|c|c|c|c|c|c|}
\hline \multicolumn{7}{|c|}{ Área dos cornos uterinos $\left(\mathrm{mm}^{2}\right)$} \\
\hline & \multicolumn{2}{|c|}{ Miométrio } & \multicolumn{2}{|c|}{ Endométrio } & \multicolumn{2}{|c|}{ Total } \\
\hline & Ipsilateral & Contralateral & Ipsilateral & Contralateral & Ipsilateral & Contralateral \\
\hline Controle & $2.8^{\mathbf{a}}(0,02)^{\mathbf{b}}$ & $2.6(0.2)$ & $14.6(0.9)$ & $13.0(0.8)$ & $1.74(0.11)$ & $15.7(0.9)$ \\
\hline Estimulado & $2.5(0.4)$ & $2.3(0.4)$ & $14.8(1.0)$ & $13.0(1.4)$ & $1.70(0.10)$ & $15.3(1.1)$ \\
\hline \multirow[t]{2}{*}{ Superovulado } & Direito & Esquerdo & Direito & Esquerdo & Direito & Esquerdo \\
\hline & $2.3(0.4)$ & $2.3(0.4)$ & $14.1(0.9)$ & $13.8(1.4)$ & $16.4(1.0)$ & $16.0(1.4)$ \\
\hline
\end{tabular}



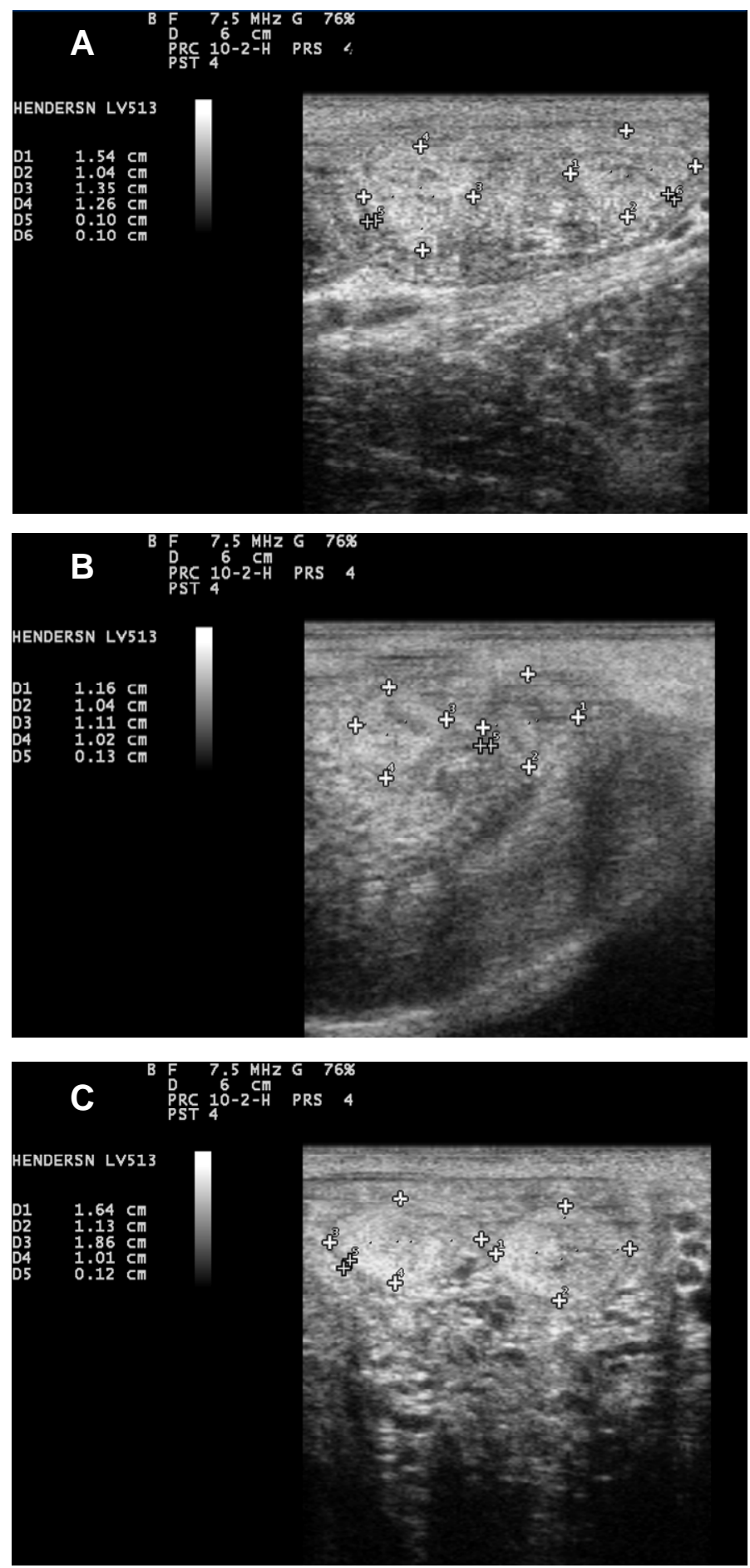

Figura 4 - Imagem ultrasonográfica dos cornos uterinos, evidenciando as mensurações realizadas no dia 5 p.o.; D1-D4 medidas do diâmetro do endométrio, D5 medidas do miométrio. (A) animal do grupo controle; (B) animal do grupo estimulado; (C) animal do grupo superovulado 


\subsection{EFEITO DOS TRATAMENTOS ESTIMULATÓRIO E SUPEROVULATÓRIO NA ESPESSURA DE MIOMÉTRIO E ENDOMÉTRIO DOS CORNOS UTERINOS}

A espessura das camadas do endométrio e miométrio correspondentes aos cornos uterinos ipsilateral e contralateral dos animais controles e estimulados, e dos cornos direto e esquerdo dos animais superovulados estão expressos na tabela 2 .

Observou-se que os tratamentos com eCG não influenciaram a espessura tanto do miométrio quanto do endométrio dos cornos uterinos.

Quando comparamos a espessura dos cornos ipsilateral e contralateral dos animais do grupo controle, observamos que o endométrio do corno ipsilateral apresenta área maior $(\mathrm{p}=0.04)$ e as duas camadas em conjunto tendem a ser maior no corno ipsilateral $(\mathrm{p}=0.06)$. Nos animais estimulados, observamos o mesmo comportamento, onde o corno ipsilateral apresenta maior espessura tanto do miométrio quanto das duas camadas em conjunto $(p=0.042$ e $p=0.046$, respectivamente) quando comparado com o corno contralateral. 
Tabela 2 - Espessura $(\mathrm{mm})$ do miométrio e endométrio dos cornos uterinos dos bovinos submetidos aos tratamentos de estimulação $(n=6)$, superovulação $(n=5)$ e controle $(n=5)$. Os valores estão expressos em média (a) e erro padrão da média (b)

Espessura das camadas dos cornos uterinos (mm)

\begin{tabular}{|c|c|c|c|c|c|c|}
\hline & \multicolumn{2}{|c|}{ Miométrio } & \multicolumn{2}{|c|}{ Endométrio } & \multicolumn{2}{|c|}{ Total } \\
\hline & Ipsilateral & Contralateral & Ipsilateral & Contralateral & Ipsilateral & Contralateral \\
\hline Controle & $\begin{array}{c}0.62^{\mathbf{a}} \\
(0.02)^{\mathbf{b}}\end{array}$ & $\begin{array}{c}0.62 \\
(0.02)\end{array}$ & $6.85(0.15)$ & $\begin{array}{c}6.42 \\
(0.14)\end{array}$ & $7.44(0.16)$ & $\begin{array}{c}7.05 \\
(0.15)\end{array}$ \\
\hline Estimulado & $\begin{array}{c}0.57 \\
(0.06)\end{array}$ & $\begin{array}{c}0.57 \\
(0.06)\end{array}$ & $6.85(0.16)$ & $\begin{array}{c}6.37 \\
(0.22)\end{array}$ & $7.43(0.15)$ & $\begin{array}{c}6.86 \\
(0.28)\end{array}$ \\
\hline \multirow[t]{2}{*}{ Superovulado } & Direito & Esquerdo & Direito & Esquerdo & Direito & Esquerdo \\
\hline & $\begin{array}{c}0.52 \\
(0.14)\end{array}$ & $\begin{array}{c}0.52 \\
(0.04)\end{array}$ & $6.56(0.22)$ & $\begin{array}{c}6.31 \\
(0.22)\end{array}$ & $7.14(0.18)$ & $\begin{array}{c}7.09 \\
(0.28)\end{array}$ \\
\hline
\end{tabular}

\subsection{EFEITO DOS TRATAMENTOS NA ÁREA DE FLUXO E DIÂMETRO DA} ARTÉRIA UTERINA

Observou-se que a área da artéria uterina é maior em animais superovulados quando comparados aos animais do grupo controle $(p=0.020)$. Nos animais estimulados, a área não diferiu em relação ao grupo controle ou superovulado $(p=0.29$ e $p=0.06$, respectivamente). $\mathrm{O}$ diâmetro médio da artéria uterina diferiu entre o grupo superovulado e controle $(\mathrm{p}=0.020)$, mas não diferiu entre o grupo controle e $\mathrm{o}$ estimulado $(p=0.29)$, mas apresentou tendência a aumento no grupo superovulado em relação ao grupo controle $(\mathrm{p}=0.057)$. Figura 5 evidencia as mensurações feitas no exame ultrasonográfico com Doppler colorido. 

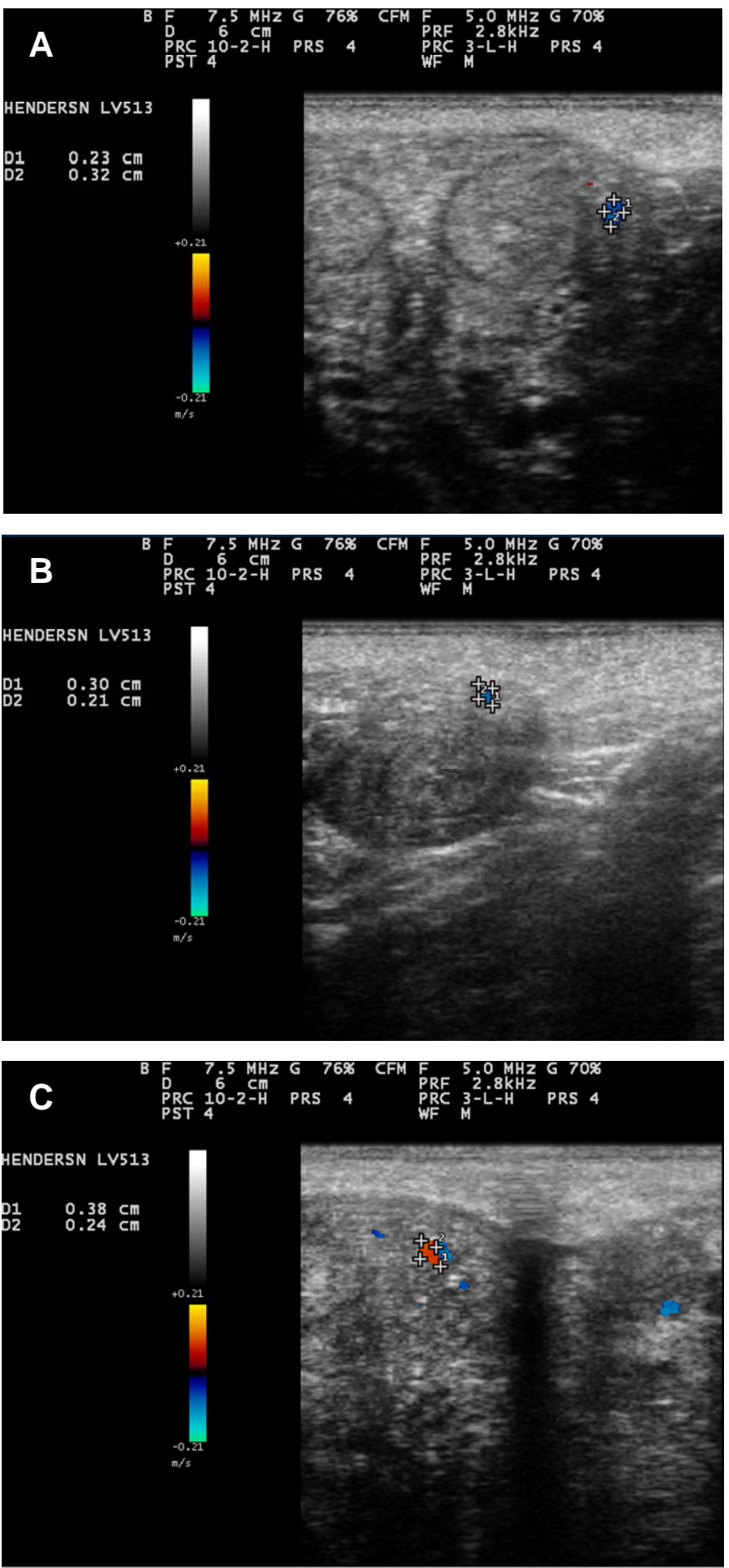

Figura 5 - Imagem ultrasonográfica dos cornos uterinos, evidenciando as mensurações realizadas no dia 5 p.o.; Em colorido a artéria uterina, identificada por seu fluxo sanguíneo. D1 e D2 medidas do diâmetro da artéria. (A) animal do grupo controle; (B) animal do grupo estimulado; (C) animal do grupo superovulado. 
Tabela 3 - Área das artérias uterinas dos animais controle (mm), estimulados e superovulados. a média dos valores de áreas das artéria uterinas de todos animais; $\mathbf{b}$ erro padrão da media. * $\mathrm{p}<0.05$ em relação ao grupo controle.

\begin{tabular}{ll}
\hline \multicolumn{2}{c}{ Área da artéria uterina $\left(\mathrm{mm}^{2}\right)$} \\
\hline \multicolumn{1}{l}{ Controle } & $0.492^{\mathrm{a}}(0.04)^{\mathrm{b}}$ \\
\hline Superovulado & $0.581(0.032)^{*}$ \\
\hline Estimulado & $0.527(0.036)$ \\
\hline
\end{tabular}

Tabela 4 - Diâmetro (mm) das artérias uterinas dos animais controle, estimulados e superovulados. a média dos valores de diâmetro das artérias uterinas de todos animais; $\mathbf{b}$ erro padrão da media. ${ }^{*} \mathrm{p}<0.05$ em relação ao grupo controle.

Diâmetro da artéria uterina (mm)

\begin{tabular}{cc}
\hline Controle & $0.255^{\mathbf{a}}(0.012)^{\mathbf{b}}$ \\
Superovulado & $0.271(0.008)^{*}$ \\
\hline Estimulado & $0.259(0.008)$ \\
\hline
\end{tabular}




\subsection{EFEITO DOS TRATAMENTOS NA DENSIDADE VASCULAR UTERINA}

A imuno marcação positiva das células endoteliais para o KDR foi utilizada para contagem do número de vasos em determinada área e consequentemente determinar a densidade vascular do endométrio e miométrio de ambos os cornos uterinos dos animais controle, estimulados e superovulados (Figura 6).
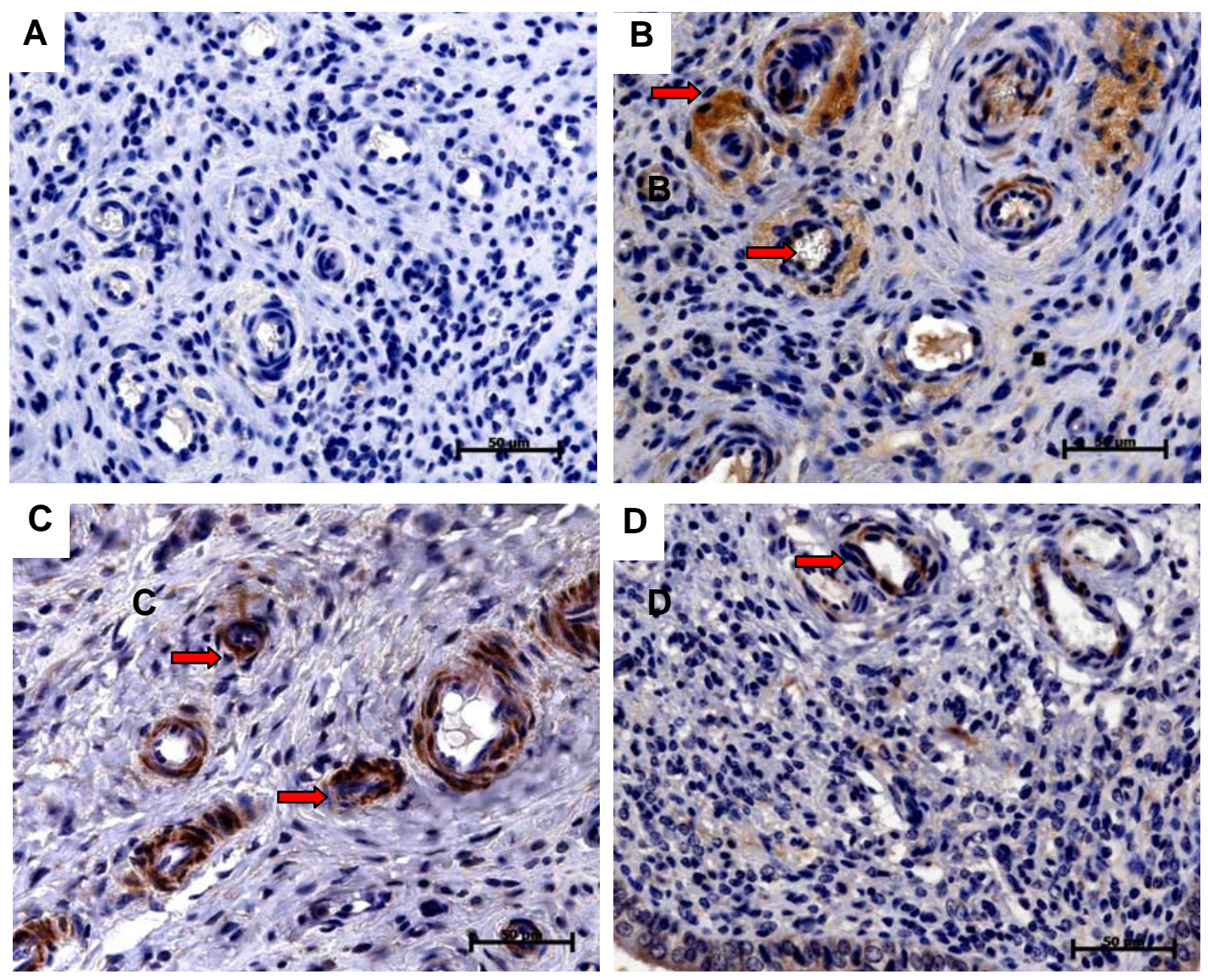

Figura 6 - Fotomicrografias do endométrio do corno ipsilateral evidenciando a imunomarcação para anticorpo KDR (setas). (A) Controle Negativo; (B) Animal do grupo controle; (C) Animal do grupo superovulado; (D) Animal do grupo estimulado. Barras equivalem a $50 \mu \mathrm{m}$. 


\subsubsection{DENSIDADE VASCULAR DO CORNO IPSILATERAL}

Quando comparada a densidade vascular do endométrio e miométrio em conjunto no corno ipsilateral entre os três grupos, foi observada uma menor densidade vascular ( $\mathrm{p}=0.0074)$ no grupo estimulado em relação ao controle (Figura 7A). O mesmo foi observado quando comparamos a densidade vascular apenas do endométrio entre os três grupos $(\mathrm{p}<0.01$; Figura $7 \mathrm{~B})$. No entanto, ao compararmos a densidade vascular do miométrio entre os grupos, foi observada uma menor densidade $(p<0.05)$ no grupo superovulado em relação ao grupo controle (Figura 7C).

$\mathrm{Na}$ Tabela 5 observamos a variação da densidade vascular do endométrio e miométrio encontrada nos animais dos grupos controle, estimulado e superovulado. Não foi encontrada qualquer correlação entre a densidade vascular do endométrio com o miométrio, nos animais controle $(\mathrm{p}=0.20 ; \mathrm{r}=0.45)$; estimulados $(\mathrm{p}=0.19 ; \mathrm{r}=0.49)$ ou superovulados $(\mathrm{p}=0.98 ; \mathrm{r}=0.0003)$ (Tabela 6$)$. 


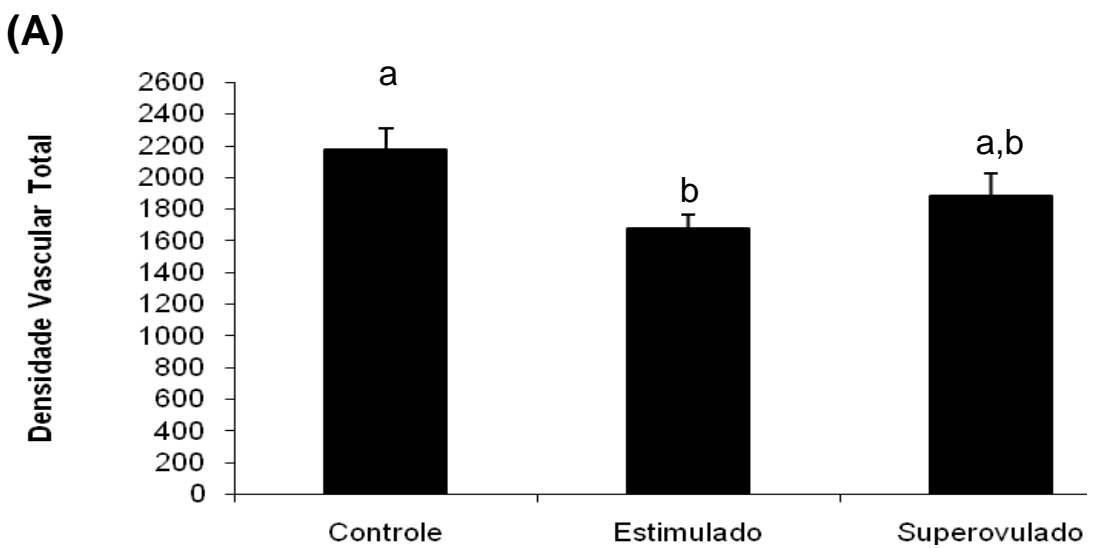

(B)

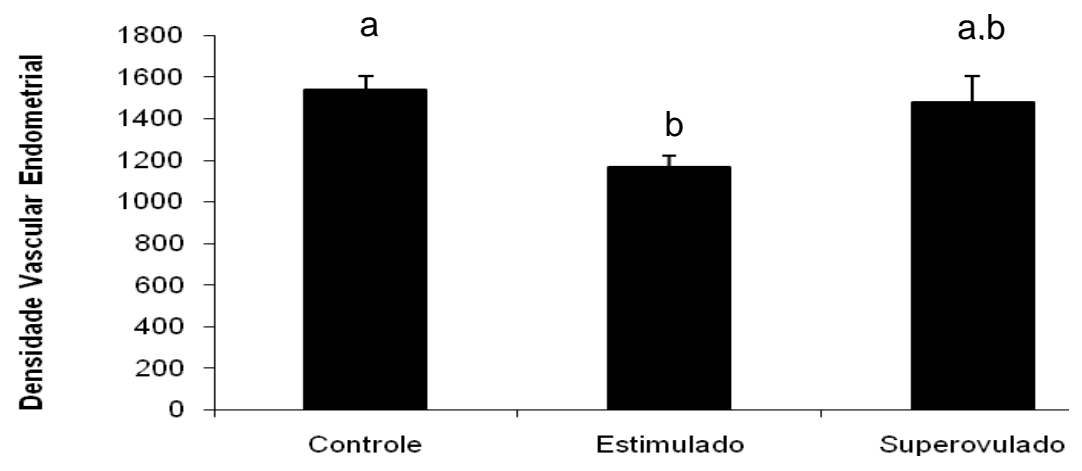

(C)

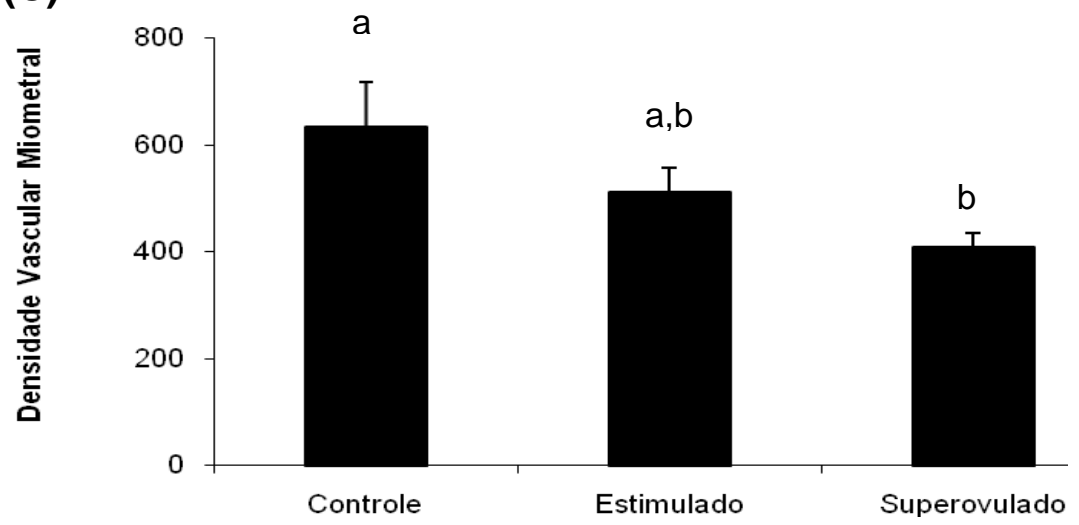

Figura 7 - Análise comparativa da densidade vascular do corno ipsilateral dos grupos controle, estimulado e da média de ambos os cornos do grupo superovulado; (A) Gráfico representa a densidade vascular total; (B) gráfico representa a densidade vascular do endométrio; (C) gráfico representa a densidade vascular do miométrio. Barras representam a média \pm EPM dos grupos, valores expressam a quantidade de vasos/corno uterino. Letras diferentes indicam diferenças significativas $(p<0,05)$ entre os grupos. 
Tabela 5 - Intervalo de variação da densidade vascular do endométrio e miométrio encontrada nos animais dos grupos controle, estimulado e superovulado. Valores mínimos e máximos expressam o número de vasos/segmento uterino coletado.

\begin{tabular}{lcccc}
\hline \multicolumn{4}{c}{ DENSIDADE VASCULAR } \\
\hline \multicolumn{4}{c}{ Endométrio } & \multicolumn{2}{c}{ Miométrio } \\
\hline & Mínimo & Máximo & Mínimo & Máximo \\
Controle & 1291,4 & 1799,2 & 449,1 & 1112,4 \\
Estimulado & 918,9 & 1488,9 & 330,1 & 819,8 \\
& & & & \\
Superovulado & 263,4 & 1986,8 & 195,5 & 593,7 \\
\hline
\end{tabular}

Tabela 6 - Correlação da densidade vascular do endométrio em relação ao miométrio no corno ipsilateral, dos grupos controle, estimulado e superovulado. Não houve correlação entre as camadas.

\begin{tabular}{ccc}
\hline Correlação & & \\
Endométrio X Miométrio & $\mathbf{r}$ & $\mathbf{p}$ \\
\cline { 2 - 3 } & 0,45 & 0,21 \\
Controle & 0,49 & 0,19 \\
Estimulado & 0,0003 & 0,98 \\
Superovulado & & \\
\hline
\end{tabular}




\subsubsection{DENSIDADE VASCULAR DO CORNO CONTRALATERAL}

No corno contralateral quando comparados a densidade vascular do endométrio juntamente ao miométrio ou de ambos separadamente, entre os três grupos, em controvérsia ao padrão observado no corno ipsilateral, não foi observada diferença significativa entre os grupos (Figura 8). 


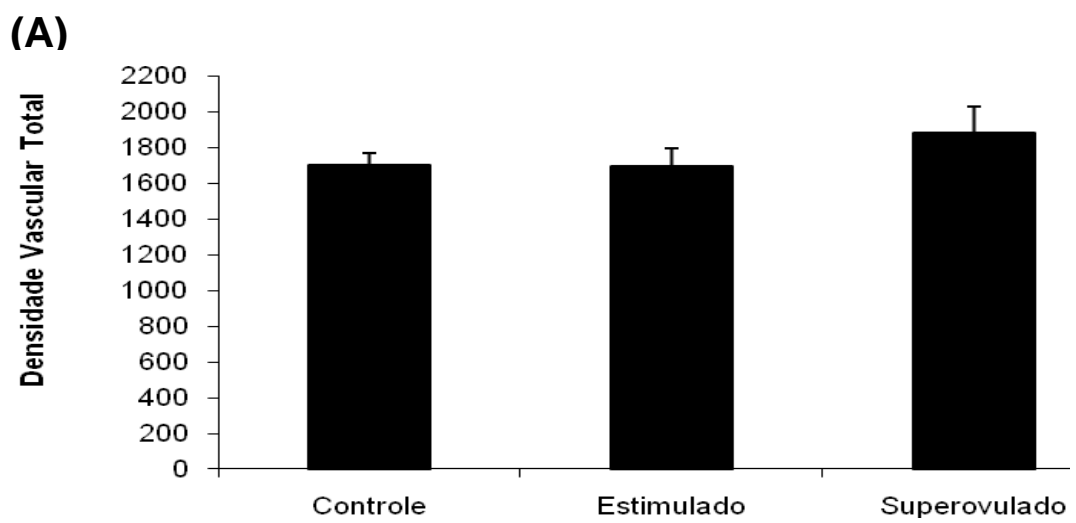

(B)

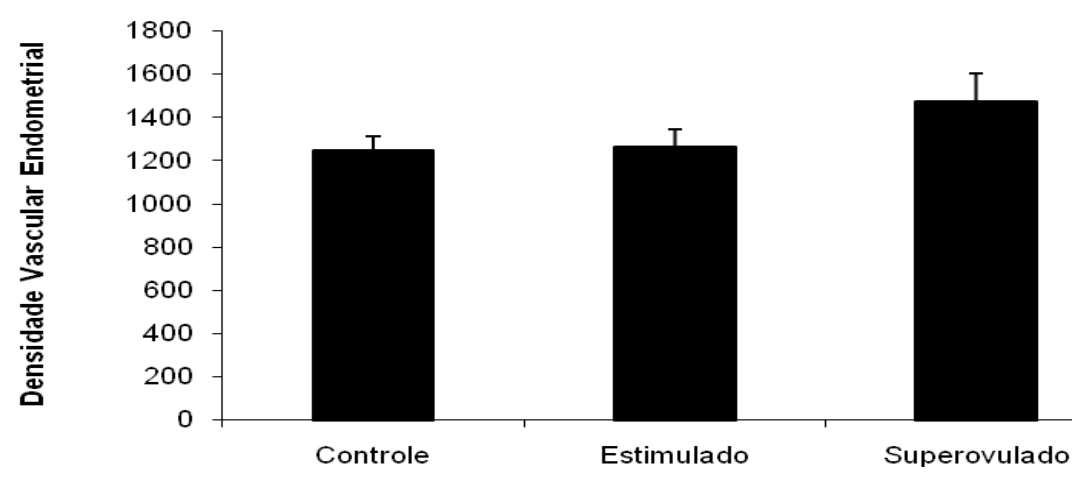

(C)

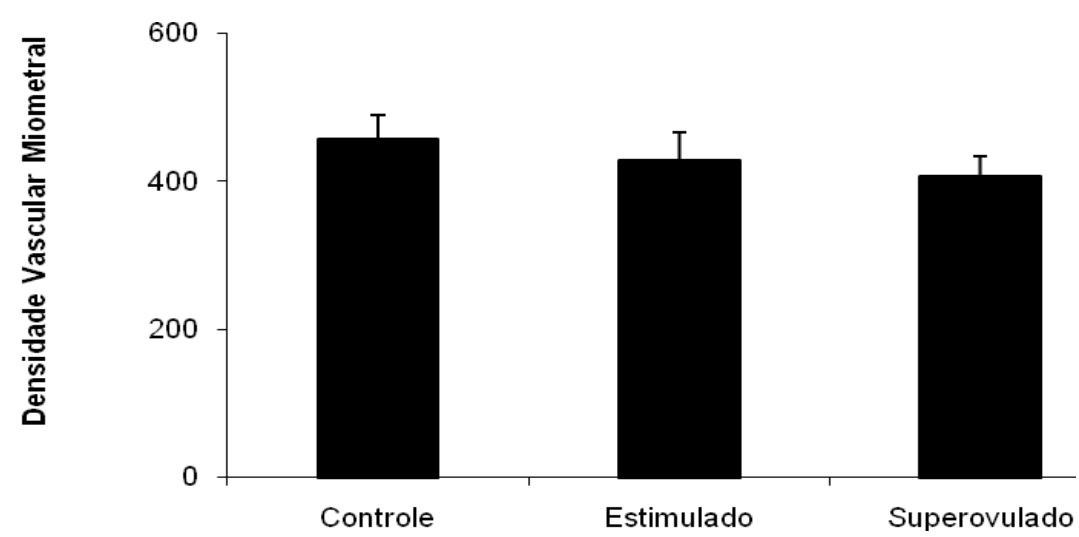

Figura 8 - Análise comparativa da densidade vascular do corno contralateral dos grupos controle, estimulado e da média de ambos os cornos do grupo superovulado: (A) Gráfico representa a densidade vascular do endométrio somado ao miométrio; (B) Gráfico representa a densidade vascular do endométrio; (C) Gráfico representa a densidade vascular do miométrio. Barras representam a média \pm EPM dos grupos, valores expressam a quantidade de vasos/corno uterino; Não foi observada diferença entre os grupos $(\mathrm{p}>0,05)$. 


\subsubsection{DENSIDADE VASCULAR DO CORNO IPSILATERAL X CORNO} CONTRALATERAL

A densidade vascular do corno ipsilateral em relação ao contralateral foi avaliada, no grupo controle e estimulado. Pode-se observar diferença na densidade vascular do endométrio ( $p=0.0045)$, do miométrio ( $p=0.0045$; Figura 9B, C) e unidos ( $p=0.0089$; figura 9A) no grupo controle. Contudo, nos grupos estimulado (Figura 10) e superovulado (Figura 11) não foram encontradas variações na densidade vascular dos cornos uterinos. 

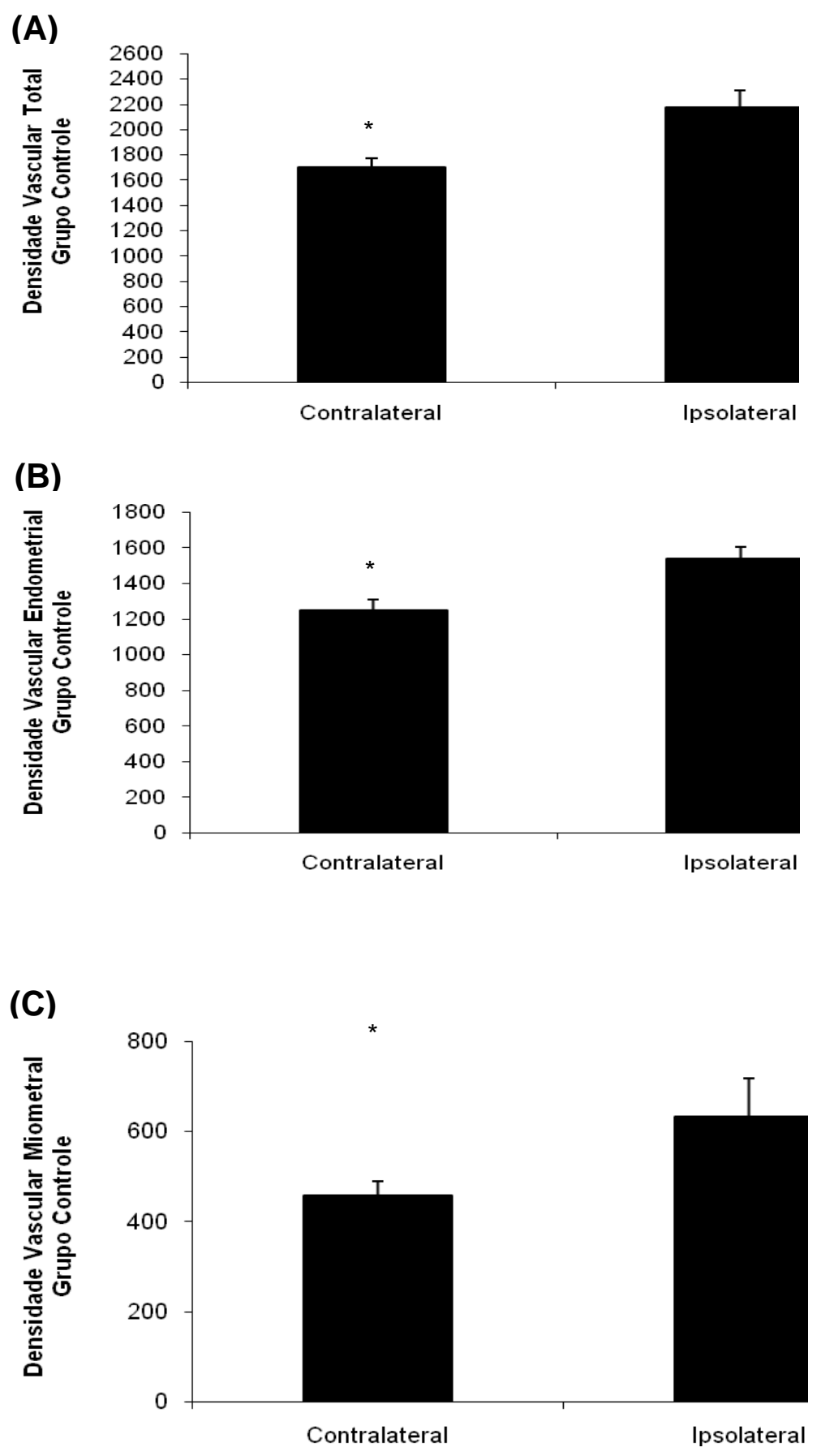

Figura 9 - Análise comparativa da densidade vascular do corno contralateral e ipsilateral do grupo controle. (A) Gráfico representa a densidade vascular do endométrio somada a densidade vascular do miométrio $(\mathrm{p}=0,0089)$; (B) Gráfico representa a densidade vascular do endométrio $(p=0,0045)$; Gráfico representa a densidade vascular do miométrio Barras representam a média \pm EPM dos cornos uterinos, valores expressam a quantidade de vasos/corno uterino; $*$ corresponde a diferença significativa $(p<0,05)$ entre os cornos uterinos. 

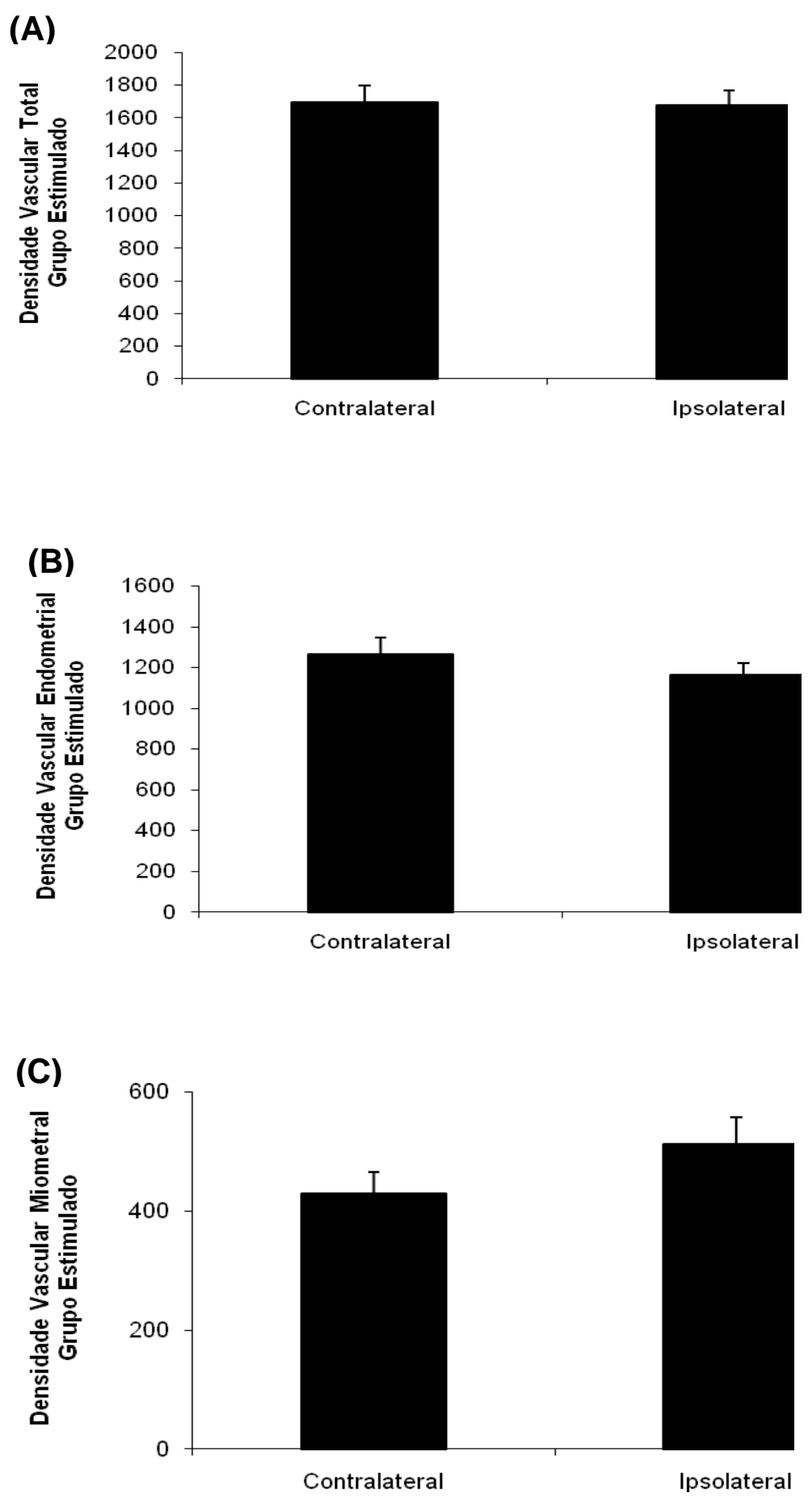

Figura 10 - Análise comparativa da densidade vascular do corno contralateral e ipsilateral do grupo estimulado. Gráfico representa a densidade vascular do endométrio somada ao miométrio. Barras representam a média \pm EPM dos cornos uterinos, valores expressam a quantidade de vasos/segmento uterino coletado; não houve diferença $(\mathrm{p}>0,05)$ entre os cornos uterinos. (A) Gráfico representa a densidade vascular do endométrio; (B) Gráfico representa a densidade vascular do miométrio. 
(A)

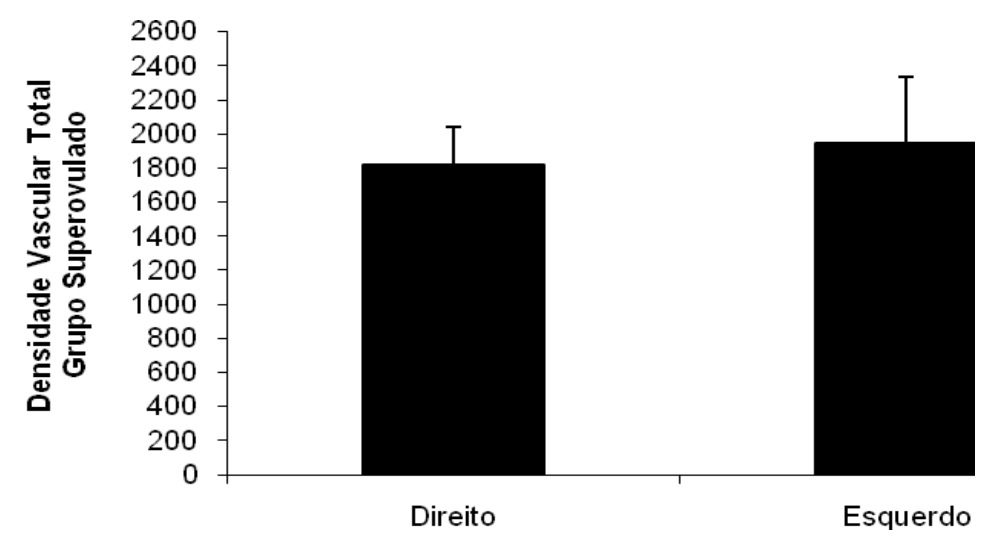

(B)

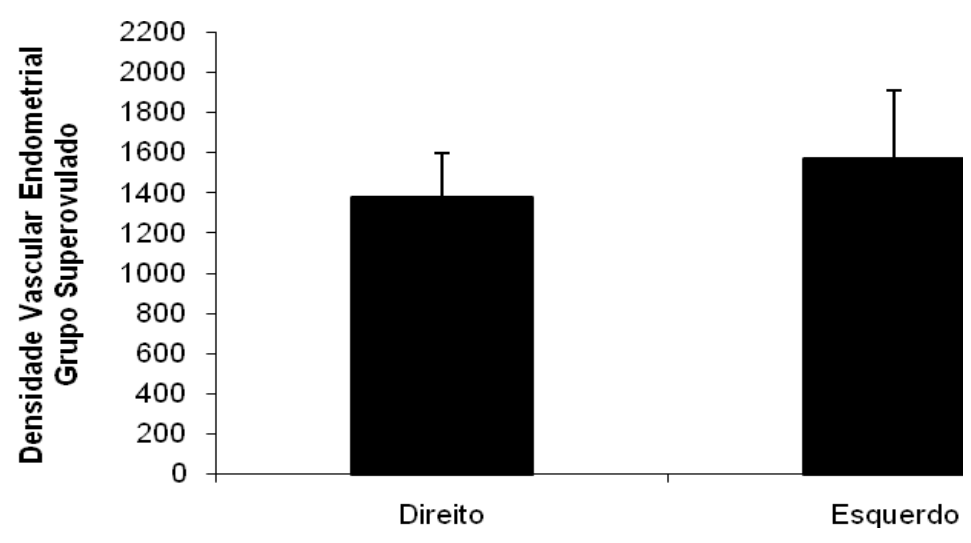

(C)

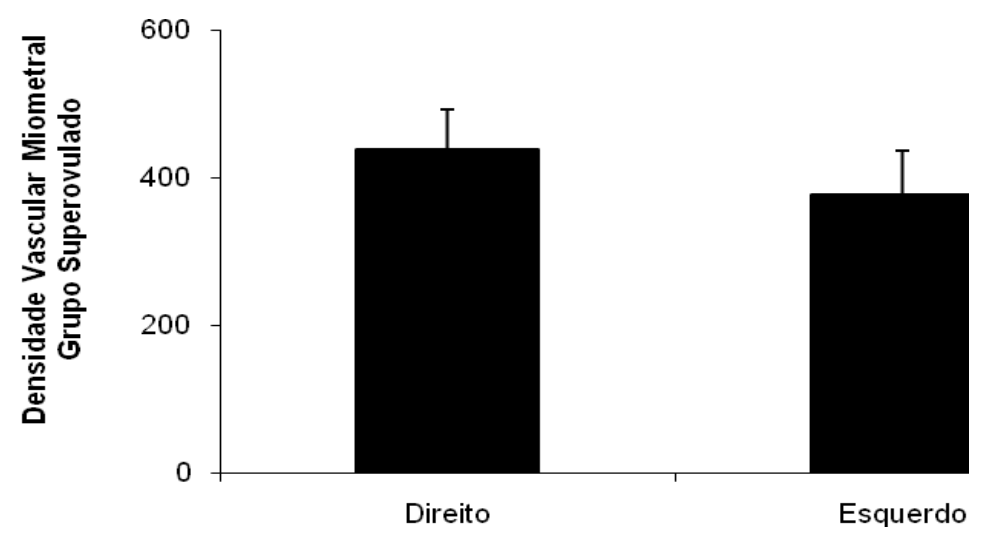

Figura 11: Análise comparativa da densidade vascular do corno direito e esquerdo do grupo superovulado. (A) Gráfico representa a densidade vascular do endométrio somada a densidade vascular do miométrio $(\mathrm{p}=0,0089)$; (B) Gráfico representa a densidade vascular do endométrio $(\mathrm{p}=0,0045)$.(C) Gráfico representa a densidade vascular miométrio Barras representam a média \pm EPM dos cornos uterinos, valores expressam a quantidade de vasos/corno uterino; $*$ corresponde a diferença significativa $(p<0,05)$ entre os cornos uterinos. 
6 DISCUSSÃO 


\section{DISCUSSÃO}

A vascularização endometrial e miometral é apontada como um fator importante na receptividade uterina. Neste estudo avaliamos a densidade vascular no endométrio e miométrio de vacas submetidas ao tratamento com eCG, com objetivo de identificar os efeitos dos tratamentos exercidos na microvascularização uterina em animais estimulados ou superovulados.

A espessura do endométrio e miométrio dos animais não apresentou diferença significativa entre os três grupos. No entanto pôde ser constatado um aumento na espessura do corno uterino ipsilateral em relação ao contralateral nos animais controle e estimulados, enquanto os cornos dos animais superovulados apresentaram uma área que se aproxima da média da área dos cornos ipsilateral e contralateral dos animais controle e estimulado. O aumento da área do corno ipsilateral pode estar relacionado com a presença do $\mathrm{CL}$, possivelmente devido à produção de $\mathrm{P} 4$, hormônio que causa diferenciação e secreção das células do endométrio (CUMMINGS; YOCHIM, 1984; FAZLEABAS; STRAKOVA, 2002; ROBINSON et al., 2008), além de modular a resposta do leito vascular uterino para agentes vasodilatadores (REYNOLDS, 1986) sob sua influência as células endoteliais proliferam e migram (ZHOU et al., 1994; HARRISON-WOOLRYCH et al., 1995). Porém em concentrações elevadas, a P4 inibe a mitose no endométrio (PADYKUL et al., 1989).

Os efeitos vasculares da $\mathrm{P} 4$ se devem à sua ação estimulátoria na produção de VEGF (SONE et al., 1996; HYDER et al., 1998; SHIKAWA, 2003; ROBINSON et al., 2007), proteína esta altamente mitogênica, para células endoteliais (KAMAT et al., 1995), responsável por induzir a sua proliferação, maturação e migração, inibindo também a apoptose. O VEGF induz angiogênese bem como a permeabilização de vasos sanguíneos e sua atividade corresponde à parte central na regulação da vasculogênese (NEUFELD, 2000), além de regular o desenvolvimento vascular sob condições normais (CAO et al., 1998; FRASER et al., 2000) e patológicas (DVORAK et al., 1991).

Conforme descrito por vários grupos (GARRETT et al., 1988; SATTERFIELD et al., 2006; CARTER et al., 2008; CLEMENTE et al., 2009) a P4 influencia o 
elongamento do concepto, o que acontece mais por ação no ambiente uterino do que diretamente no próprio embrião (CLEMENTE et al., 2009). Os dados obtidos neste presente trabalho, que apontam para um aumento da área de endométrio e miométrio nos cornos ipsilaterais dos grupos controle e estimulado no dia 6 pós-ovulação, corroboram com a afirmação de que uma importante função da P4 é preparar o ambiente uterino. Ademais, úteros submetidos a concentrações elevadas de P4 previamente à implantação favorecem o desenvolvimento embrionário (CLEMENTE et al., 2009).

Ao comparar as medidas de área e diâmetro da artéria uterina houve diferença significativa entre o grupo superovulado e controle, além de ter sido observado em animais superovulados que o diâmetro tende a ser maior do que nos animais estimulados. Esta pode ser considerada uma diferença importante, também associada ao nível elevado de progesterona descrito para estes animais por Baruselli et al. (2001), nos quais as concentrações plasmáticas de P4 relatadas são de 4,2 $\pm 3,7 \mathrm{ng} / \mathrm{ml}$ para o grupo

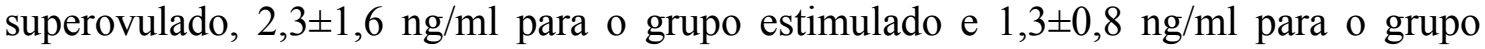
controle. A exposição seqüencial a P4 e E2 provoca ampliação nas paredes dos vasos sanguíneos e da camada muscular das artérias (FAZLEABAS; STRAKOVA, 2002). O aumento do diâmetro da artéria uterina nos animais do grupo superovulado corrobora com os resultados encontrados em outros estudos com animais e seres humanos submetidos ao tratamento superovulatório. Foi relatado que as gonadotrofinas utilizadas em tratamentos superovulatórios como o FSH e hCG ou eCG aumentam o estradiol folicular (PRICE et al., 1999). Segundo um estudo realizado por Takagi et al. (2001) a produção de estradiol em novilhas tratadas com eCG foi em média 4,5 vezes superior às 72 horas após o início da estimulação e duas vezes maior no momento do pico de LH do que a produção do grupo tratado com FSH recombinante humano. Ford et al. (1976) encontraram dados indicativos de uma associação entre a presença do CL e respostas fisiológicas da musculatura lisa das artérias uterinas, pelo menos no corno ipsilateral, em animais não gestantes. O mecanismo pelo qual a presença do corpo lúteo é capaz de afetar a capacidade de resposta na musculatura lisa vascular não foi determinado pelos autores, mas fatores hormonais devem estar envolvidos. O estradiol age como vasodilatador importante na artéria uterina (FORD, 1982; GREISS; ANDERSON, 1970) assim alguns trabalhos correlacionam o aumento no fluxo sangüíneo uterino com os níveis de estrógeno durante o estro (BOLLWEIN et al., 2000; FORD; CHENAULT, 1981) e após a administração de estrógeno em vacas (ROMAN-PONCE et al., 1978). 
Honnens et al. (2008) mostraram em um estudo com vacas submetidas ao tratamento superovulatório com gonadotrofinas um aumento no volume de fluxo sanguíneo e uma marcada diminuição no índice de pulsabilidade da artéria uterina. Um aumento do fluxo de sangue uterino após a estimulação hormonal folicular tem sido demonstrado também em pacientes de FIV na medicina humana (BASSIL et al., 1995; CACCIATORE; TIITINEN, 1996; STRIGINI, 1995; WEINER, 1993).

Van den Driesche et al. (2008) demonstraram que o hCG induz a expressão do fator de indução de hipóxia (HIF-1 $\alpha$ ) em células da granulosa luteinizada. HIF é um fator envolvido na restauração da homeostase do oxigenio em nivel ceular, local e sistemico. Suas funções são reguladas por diversos genes involvidos na angiogenese, eritopoese, glicólise, metabolismo do ferro e sobrevivencia celular.

A expressão do HIF-1 $\alpha$ está altamente correlacionada com a expressão de VEGF sob ambas as condições, de hipóxia e normóxia. Isto sugere que a hCG estimula a expressão de VEGF, e pode ser associada com a regulação do HIF-1 $\alpha$ (VAN DEN DRIESCHE et al., 2008). A expressão do mRNA do VEGF em células da granulosa luteinizadas de humanos demonstrou ser dose e tempo dependente sob influência do hCG in vitro (NEULEN et al., 1995). Na verdade, exposição crônica ou aguda ao hCG estimula diretamente a produção e secreção de VEGF em células da granulosa luteinizadas em macacas (CHRISTENSON; STOUFFER, 1997) e em mulheres (LAITINEN et al., 1997; LEE et al., 1997; NEULEN et al., 1998; WULFF et al., 2001a). Esse aumento de níveis de VEGF, devido a estimulação por gonadotrofina, em conjunto com seu efeito vasodilatador via NOS e NO (OLSSON et al., 2006), podem justificar o aumento de calibre da artéria uterina observado no presente estudo.

Com relação à densidade vascular, encontramos uma diminuição no grupo estimulado em relação ao controle, quando avaliados o endométrio e miométrio do corno ipsilateral. Ao comparar as camadas separadamente encontramos menor densidade vascular no endométrio dos animais estimulados e no miométrio dos animais superovulados, ambos em relação ao grupo controle, o que pode estar relacionado com o desvio de sangue do útero para o ovário, possivelmente para proporcionar o aumento do fornecimento de sangue para os múltiplos folículos ou corpos lúteos, no caso dos 
animais superovulados, ou para o CL único dos animais estimulados, que produzem quantidades maiores de P4 (BARUSELLI et al., 2001)

Hutchinson (1962) observou em vacas uma comunicação entre a artéria uterina e a artéria ovárica adjacentes ao corno uterino gravídico. Em estudos com preparados de corrosão das artérias uterina e ovariana o autor demonstrou que o ovário bovino é suprido pela artéria ovárica que se divide antes de entrar no ovário em um ramo ováriano, que irriga o ovário, ligamento largo e infundíbulo, e um ramo uterino que irriga a porção mais caudal do corno, a tuba uterina e também se anastomosa com um ramo principal da artéria uterina no mesometrial do corno uterino ipsilateral (LAMOND; DROST, 1974). Além de verificar a presença de uma anastomose entre um ramo importante da artéria uterina e a artéria adjacente do ovário, Lamond e Drost (1974) relataram que a anastomose foi maior no lado ipsilateral ao ovário contendo um CL funcional e que a secção do ramo uterino da artéria ovárica resultaram em função ovariana cíclica anormal. Desta forma os autores hipotetizaram que o fluxo sanguíneo poderia sofrer mudanças dependentes do ciclo estral. Ford e Chenault (1981) comprovaram a existencia destas mudanças de fluxo através desta anastomose ao longo do ciclo estral, e concluíram que o fluxo de sangue total do ovário manteve-se elevado até 4 dias antes do estro, em seguida, diminuiu abruptamente. Esta queda abrupta do fluxo sangüíneo ovariano foi alcançada principalmente devido à inversão do fluxo sangüíneo através do ramo uterino da artéria ovárica na direção do útero. No dia do estro (dia 0) o fluxo sanguíneo novamente flui em direção ao ovário, mas torna ao útero até o dia 2 p.o.. Devido a formação do CL e associada a ausência de embrião, o fluxo sanguíneo após o dia 2 é novamente direcionado ao ovário, e por volta do dia 6 p.o. durante a fase luteínica, o fluxo total de sangue do ovário está composto por $20-40 \%$ de sangue de origem da artéria uterina. Este dia coincide com o dia de coleta do presente estudo e pode embasar os achados estereológicos de contagem da densidade vascular, uma vez que o fluxo é um importante indutor mecânico da formação de vasos (CAI; SCHAPER, 2008). Em primatas macacos (WEHRENBERG; DIERSCHKE; WOLF, 1979) e mulheres (FLEISCHER, 1991) também há evidências de que o ovário tem um fornecimento de sangue duplo durante a fase luteínica do ciclo. Segundo os autores acima mencionados o aumento da demanda sanguínea pelo ovário contendo um CL funcional altamente vascularizado é representado não apenas pela artéria ovárica, mas 
também pelo ramo uterino da artéria ovárica que se anastomosa com a artéria uterina no corno ipsilateral.

Ainda, foi sugerido que localmente concentrações aumentadas de P4 nos vasos uterinos ipsilateral ao corpo lúteo exigem maior contratilidade destes vasos (FORD; WEBER; STORMSHAK, 1976), provavelmente induzida pela ação do P4 via seu receptor localizado na camada de células musculares das arteríolas (CHANG; LUBO ZHANG, 2008). Assim, um aumento na resistência do fluxo de sangue no leito vascular uterino ipsilateral ao corpo lúteo (FORD; CHENAULT, 1981) e uma baixa resistência do fluxo de sangue nos vasos dilatados do corpo lúteo funcional (Wiltbank et al., 1989) pode causar uma inversão da direção do fluxo através do ramo uterino da artéria ovárica e permitir que, para aumentar o suprimento de sangue do ovário, o sangue da artéria uterina rume para o corpo lúteo (FORD; CHENAULT, 1981).

Outros autores relatam ainda que as concentrações suprafisiológicas de estradiol$17 \beta$ parecem restringir sua capacidade de vasodilatação (TEKAY; MARTIKAINEN; JOUPPILA; 1995; DE ZIEGLER; BESSIS; FRYDMAN; 1991). Como o estradiol-17 $\beta$ age através de ligação a seus receptores específicos nas células-alvo (BJORNSTROM; SJOBERG; 2005; BYERS, 2005), sua eficácia no que diz respeito à vasodilatação pode ser reduzida devido à expressão negativamente regulada de seus receptores (BYERS et al., 2005) exercida pelo próprio estradiol-17ß.

A melhora na receptividade uterina com o tratamento estimulatório e superovulatório também é associada ao aumento na taxa de concepção (HASLER et al., 1980; SREENAN; DISKIN 1983; MANN; LAMMING 1999; MANN; LAMMING 2001; BINELLI et al., 2001; BARUSELLI et al., 2004a; MANN et al., 2006; LONERGAN et al., 2007; BARUSELLI et al., 2008; BAZER et al., 2009). Estes efeitos acontecem provavelmente devido à presença do embrião, como relatado por Spencer et al. (2007). A estimulação do fluxo sangüíneo uterino durante a gravidez precoce tem sido demonstrado em vacas (FORD et al., 1979; FORD; CHENAULT, 1981), ovelhas (GREISS; ANDERSON, 1970; REYNOLDS; MAGNESS; FORD, 1984), porcas (FORD; CHRISTENSON, 1979; FORD; CHRISTENSON; FORD, 1982) e éguas (BOLLWEIN; MAYER; STOLLA, 2003; SILVA, 2005), e foi atribuído ao efeito local do embrião. Pesquisas também citam a estimulação física pelo embrião como uma 
possível causa para o reforço do fluxo sangüíneo uterino (BOLLWEIN; MAYER; STOLLA, 2003; SILVA, 2005), e vários trabalhos sugerem a produção de substâncias vasoativas pelo embrião e / ou endométrio como responsável pela estimulação local da perfusão uterina observada em bovinos (FORD; CHENAULT; ECHTERNKAMP, 1979; FORD, 1982), ovinos (GREISS; ANDERSON, 1970; FORD, 1982; MAGNESS; FORD; REYNOLDS, 1984) e suínos (FORD, 1982; FORD; CHRISTENSON, 1979; ANDERSON; CHRISTENSON; FORD, 1994).

O embrião chega ao útero no dia 4 depois da ovulação/inseminação e os primeiros sinais enviados para a mãe acontecem a partir do dia 5 quando é detectada a presença de TNF- $\tau$ (SPENCER et al., 2007). É muito interessante observar que na ausência de embrião, como no presente estudo, o organismo é capaz de poupar esforços para uma possível futura gestação e então, não responder ao estímulo de gonadotrofinas como responderia se houvesse a presença do concepto (HONNENS et al., 2008). De fato, as mudanças morfofuncionais induzidas pelo concepto bovino, em estágio tão precoce, ainda não foram elucidadas, mas os dados do presente estudo, obtidos no dia 6 após a ovulação de animais não gestantes, sugerem que o aumento de vascularização do endométrio descrito após tratamento com gonadotrofinas (KRAMER; STEINTS; VAN DER WALT, 1990; BLOECHLE et al., 1997; CHIANG et al., 2000; CHIEN et al., 2002; NG et al., 2004; JARVELA et al., 2005; HONNENS et al., 2008) seja influenciado pelo concepto e não exclusivamente pelo tratamento. O número de potenciais fatores envolvidos no reconhecimento materno da gestação continua a aumentar (SPENCER et al., 2007), o que enfatiza que o entendimento atual sobre a capacidade do embrião em estabelecer um meio ideal para seu desenvolvimento ainda é restrito.

O fluxo de sangue uterino contribui para a receptividade do útero (GOSWAMY; WILLIAMS; STEPTOE, 1988), mas uma perfusão adequada do tecido uterino não resulta necessariamente no sucesso da concepção (TEKAY; MARTIKAINEN; JOUPPILA, 1995; TEKAY; MARTIKAINEN; JOUPPILA, 1996a). Em vez disso, há um número considerável de mulheres em que um aumento do fluxo sangüíneo uterino não é associado com um resultado positivo do tratamento de fertilização in vitro (TEKAY; MARTIKAINEN; JOUPPILA, 1996b). Os autores supracitados avaliaram o fluxo sanguíneo através da ultrasonografia Doppler colorida da artéria uterina; em nosso 
estudo a densidade vascular foi mensurada através da contagem de vasos do endométrio e miométrio uterinos em cortes de tecido, dado que não pode ser mensurado através de um exame ultrasonográfico, devido ao pequeno calibre dos vasos avaliados. Alguns autores não encontraram correlações entre a perfusão uterina e embriões transferíveis, assim consideraram que os valores do fluxo sanguíneo uterino e o índice de pulsatilidade não refletem adequadamente as características do ambiente uterino importantes para desenvolvimento embrionário. Esta falta de correlação pode ser associada aos achados no presente estudo que indicaram uma diminuição da microvascularização dos grupos tratados associada a aumento do diâmetro e área da artéria uterina. Assim, se existe um aumento de fluxo sanguíneo na artéria uterina, este não se reflete no aumento da vascularização das camadas uterinas. O fluxo não foi mensurado no presente estudo, mas pode-se dizer que está aumentado em função dos dados de aumento de área e de diâmetro da artéria uterina, pois está amplamente descrito que um vaso de maior calibre apresenta menor resistência e portanto maior fluxo (KUTLESIC et al., 2008).

O tratamento de fêmeas não cíclicas com GnRH e progesterona aumenta a porcentagem de fêmeas cíclicas e melhora a resposta aos protocolos de IATF. No entanto, induzir a ciclicidade com administração de hCG não aumentou o sucesso dos protocolos de IATF em vacas (LAMB et al., 2009) e em mulheres (GUZICK et al., 1999). Para que ocorra sucesso na utilização do eCG ou hCG, outros fatores como exposição prévia a progesterona e/ou estradiol-17ß (NG, 2009) são necessários. No entanto, o efeito da ação esteroidogênica sobre a vascularização do endométrio é controverso na literatura. Um estudo recente (CHENNAZHI; NAYAK, 2009) apontou que a expressão do VEGF é estimulada por P4 na camada mais superficial de glândulas endometriais e suprimida no estroma uterino. Além disso, mulheres que utilizam anticoncepcionais a base de progestágenos apresentam redução da imunomarcação para VEGF no endométrio (CHARNOCK-JONES et al., 2000) e redução da taxa de gestação (NG, 2009). Se a regulação da vascularização do endométrio é dependente da concentração plasmática de $\mathrm{P} 4$, entre outros fatores esteroidogênicos e não esteroidogênicos (DOUGLAS et al., 2009), e nos animais tratados com eCG do presente estudo a mesma deva estar elevada (conforme descrito em modelo semelhante por BARUSELLI et al., 2001), é possível que o endométrio dos animais estimulados tenha respondido com esta diminuição da densidade vascular observada. O tratamento com 
doses mais elevadas pode ter desencadeado mecanismos compensatórios que não levaram a diminuição da densidade vascular (PRAPAS et al., 2009) no endométrio. É relatado na literatura que, apesar de essencial para a estimulação ovariana, o hCG administrado durante a fase folicular e em doses baixas (até 750 UI) não é capaz de induzir aumento de espessura e receptividade do endométrio (TSARIK et al., 2003; PRAPAS et al., 2009).

A vascularização do endométrio é responsável principalmente por nutrir o feto, e a do miométrio, além de responsável por nutrir as próprias células miometriais, que serão muito requisitadas para contração uterina ao final da gestação, emite ramos que penetram no endométrio (FARRER-BROWN et al, 1970). No presente trabalho foi observado que a densidade vascular do endométrio diminui nos animais tratados com 400 UI de eCG e no miométrio nos animais tratados com 2000 UI de eCG. Como os animais não foram inseminados ou cobertos, a influência da presença do embrião sobre a vascularização não pode ser avaliada, mas pode-se dizer que doses menores de gonadotrofinas (grupo estimulado) não seriam recomendáveis para induzir aumento de vascularização de endométrio, crucial para o sucesso da gestação (TSARIK et al., 2003; PRAPAS et al., 2009).

A utilização da imunomarcação para detecção do KDR (VEGFR2) e posterior contagem dos vasos baseou-se na importância do KDR para as ações do VEGF, principal receptor relacionado às ações vasculares deste fator de crescimento (OLSSON et al., 2006) e na segurança da reação positiva nos capilares uterinos (MINT et al., 2002). Inúmeros trabalhos descrevem a mediação das ações do VEGF-A por este receptor e modelos knockouts para VEGFR2 mostraram-se incapazes de se desenvolver após dia 10 de gestação (revisado em OLSSON et al., 2006). O bloqueio deste receptor com anticorpos anti-VEGFR2 desencadeia diminuição da densidade vascular e da diferenciação das células do estroma endometrial (DOUGLAS et al, 2009). Não foi realizada a contagem da expressão desta proteína nos diferentes grupos estudados pois não era o objetivo deste estudo, no entanto, acreditamos que diferenças poderão ser encontradas uma vez que a densidade vascular não foi equivalente para os três grupos.

As interações que ocorrem entre o útero e o corpo lúteo são muito importantes para o estabelecimento de um ambiente uterino adequado para receber o embrião. Este, 
por sua vez, interage com ambos para garantir sua permanência e posterior nutrição. $O$ processo de formação vascular, dependente primariamente da expressão do VEGF, constitui a base para que a mãe transmita ao embrião/feto todo o necessário para seu desenvolvimento. Este processo e muitos dos fatores nele envolvidos podem ser modulados pela administração de gonadotrofinas exógenas, como no presente estudo, visando otimizar o processo reprodutivo. Apesar de alguns autores (CLEMENTE et al., 2009) não conferirem ao embrião papel fundamental na regulação do ambiente uterino, nossos dados sugerem que o tratamento com eCG em doses estimulantes (400 UI) ou superestimulantes (2000 UI) por si só não acarreta aumento da vascularização do endométrio e miométrio, conforme relatado em outros trabalhos (CHARNOCK-JONES et al., 2000; CHENNAZHI et al., 2009; DOUGLAS et al., 2009), nos quais havia na totalidade dos casos a presença do embrião. 
7 CONCLUSÕES 


\section{CONCLUSÕES}

A partir dos resultados obtidos no presente trabalho pode-se concluir que:

- O tratamento com eCG não influencia a proliferação do endométrio e miométrio dos bovinos.

- A aplicação de doses altas de eCG (2000 UI) é capaz de aumentar o fluxo sanguíneo da artéria uterina, por meio do aumento do diâmetro da artéria uterina.

- Nas condições do estudo realizado o tratamento com eCG não apresenta ação angiogenica no endométrio e miométrio.

- A microvascularização endometrial e miometral não refletem o fluxo sanguíneo da artéria uterina.

- As relatadas ações angiogenicas do eCG, possivelmente são dependentes do dia do ciclo estral e presença de embrião no útero. 
REFERÊNCIAS 


\section{REFERÊNCIAS}

ABULAFIA, O.; SHERER, D. M. Angiogenesis of the ovary. American Journal of Obstetrics and Gynecology, v. 182, p. 240-246, 2000.

ADAKAN, S.; YOLDEMIR, T.; TAVMERGEN, E.; GOKER, E.; KILLI, R. Predictivity of uterine artery, arcuate artery, and intraovarian artery Doppler indices measured on the day of human chorionic gonadotropin injection on pregnancy outcomes. Fertility and Sterility, v. 84, p. 529-532, 2005.

ADAMS, G. P.; NASSER, L. F.; BO, G. A.; MAPLETOFT, R.; GARCIA, A.; DEL CAMPO, M. R. Superstimulatory response of ovarian follicles of wave 1 versus wave 2 in heifers. Theriogenology, v.42, p. 1103-1113, 1994.

ADAMS, G.P,; MATTERI, R.L,; KASTELIC, J.P,; KO, J.C.H,; GINTHER, O.J. Association between surges of follicle stimulating hormone and the emergence of follicular waves in heifers. J Reprod Fertil, v. 94, p. 177-188, 1992.

ADAMS, G.P. Control of ovarian follicular wave dynamics in cattle: implications for synchronization and superstimulation. Theriogenology, v. 41, p. 19-24, 1994.

ALVAREZ, R. H.; CARVAlHO, J. B. P.; ROSA E SILVA, A. A.; PERONE, C. N.; RIBELA, M. T. C. P.; OLIVEIRA, E. B. Endocrine profiles and ovulation rate of cows superovulated with FSH following passive immunization against steroid free-bovine follicular fluid. Brazilian Journal of Veterinary Research Animal Science, v. 35, p. 266-270, 1998.

ALVAREZ, R. H.; DA SILVA, M. V.; DE CARVALHO, J. B.; BINELLI, M. Effects of inbreeding on ovarian responses and embryo production from superovulated Mantiqueira breed cows. Theriogenology, v. 64, p. 1669-1676, 2005.

ANDERSON, L. H.; CHRISTENSON, L. K.; FORD, S. P. Estrogen associated changes in uterine blood-flow and maternal recognition of pregnancy in Chinese (Meishan) pigs. Animal Reproduction Science, v. 36, p. 135-143, 1994.

APPELABUM, M. The uterine biophysical profile. Ultrasound Obstet Gynecol, v. 5, p. 67-68, 1995.

ARMSTRONG, D. T. Recent advances in superovulation of cattle. Theriogenology, $v$. 39, p. 7-24, 1993.

ATHANASSIADES, A.; HAMILTON, G.S.; LALA, P.K. Vascular endothelial growth factor stimulates proliferation but notmigration or invasiveness in human extravillous trophoblast. Biol Reprod, v. 59, p. 643-654, 1998.

BANERJEE, P.; SAPRU, K. ; STRAKOVA, Z. ; FAZLEABASS, A.T. Chorionic gonadotropin regulates prostaglandin E synthase via a phosphatidylinositol 3-kinaseextracellular regulatory kinase pathway in a human endometrial epithelial cell line: 
implications for endometrial responses for embryo implantation. Endocrinology. v.150, p.4326-37, 2002.

BARROS, C.M.; NOGUEIRA, M.F.G. Superovulação em zebuínos de corte. In: 10. Simpósio Internacional de Reprodução Animal Aplicada. Londrina, p. 212-222, 2004.

BARUSELLI, O.S.; RODRIGUES, C.A.; TEIXEIRA, A.A.; FERREIRA, R.M.; AYRES, H.; MANCILHA, R.F.; SOUZA, A.H. Effect of fixed-time embryo transfer on reproductive efficiency in high-producing repeat-breeder Holstein cows. Animal Reproduction Science. no prelo, 2009.

BARUSELLI, P. S., MARQUES, M. O.; MADUREIRA, E. H.; COSTA NETO, W.P.; GRANDINETTI, R. R..; BO, G. A. Increased pregnancy rates in embryo recipients treated with CIDR-B devices. Theriogenology, v. 55, p. 355, 2001

BARUSELLI, P. S.; MADUREIRA, E. H.; MARQUES, M.O.; RODRIGUES, C.A.; NASSER, L. F.T. ; SILVA, R.C P ; REIS, E.L.; SÁ FILHO, M.F. Efeito do tratamento com eCG na taxa de concepção de vacas Nelore com diferentes escores de condição corporal inseminadas em tempo fixo (Análise retrospectiva). In: XVIII Reunião Anual da Sociedade Brasileira de Transferência de Embriões, 2004, Barra Bonita. Acta Scientiae Veterinariae, v. 32, p. 228, 2004.

BARUSELLI, P. S.; MADUREIRA, E. H.; VISINTIN, J. A.; PORTO-FILHO, R.; CARVALHO, N. A. T.; CAMPANILE, G.; ZICARELLI, Z. Failure of oocyte entry into oviduct in superovulated buffalo. Theriogenology, v. 53, p. 491, 2000.

BARUSELLI, P. S.; MARQUES, M. O.; REIS, E. L.; MELLO, J. E.; CAMPOS FILHO, E.P. Taxa de concepção de diferentes protocolos de inseminação artificial em tempo fixo em vacas Bos taurus taurus x Bos taurus indicus durante o período pósparto. In: Simpósio Internacional de Reprodução Animal, 5., Proceedings, v.1, p.380, 2003.

BARUSELLI, P. S.; MARTINS, C.M.; SALES, J.N.S.; FERREIRA, R.M. Novos avanços na superovulação de bovinos. Acta Scientiae Veterinariae. v. 36-SUP, p. 433448, 2008.

BARUSELLI, P. S.; REIS, E. L.; MARQUES, M. O.; NASSER, L. F.; BO, G. A. The use of hormonal treatments to improve reproductive performance of anestrous beef cattle in tropical climates. Animal Reproduction Science, v.82-83, p. 479-486, 2004.

BARUSELLI, P. S.; SÁ FILHO, M. F.; MARTINS, C. M.; NASSER, L. F. T.; NOGUEIRA, M. F. G.; BARROS, C. M.; BO, G.A. Superovulation and embryo transfer in Bos indicus cattle. Theriogenology, v.65, p. 77-88, 2006.

BARUSELLI, P.S.; MARQUES, M.O.; MADUREIRA, E.H.; BÓ, G.A.; COSTA NETO, W.P.;GRANDINETTI, R.R. Superestimulação ovariana de receptoras de embriões bovinos visando o aumento de corpos lúteos, concentração de $\mathrm{P} 4$ e taxa de prenhez. Arquivos da Faculdade de Veterinária UFRGS, v. 28, p. 218, 2000c.

BASSIL S, WYNS C, TOUSSAINT-DEMYLLE D, NISOLLE M, GORDTS S, 
DONNEZ J. The relationship between ovarian vascularity and the duration of stimulation in in-vitro fertilization. Human Reproduction. v. 12, p. 1240-1245, 1997. BAZER, F.W.; WU, G.; SPENCER, T.E.; JOHNSON, G.A.; BURGHARDT, R.C.; BAYLESS, K. Novel Pathways for Implantation and Establishment and Maintenance of Pregnancy in Mammals. Mol Hum Reprod, 2009.

BERNATCHEZ, P. N.; SOKER, S.; SIROIS, M. G. Vascular endothelial growth factor effect on endothelial cell proliferation, migration, and platelet-activating factor synthesis is Flk-1-dependent. The Journal of Biological Chemistry, Baltimore, v. 274, n. 43, p. 31047-31054, 1999.

BINELLI, M. Estratégias anti-luteolíticas para a melhora da sobrevivênvia embrionária em bovinos. In: MADUREIRA E. H.; BARUSELLI, P. S. Controle farmacológico do ciclo estral em ruminantes, p. 99-114, São Paulo: FUNVET, 2001.

BINELLI, M.; THATCHER, W.W.; MATTOS, R.; BARUSELLI, P. S. Antiluteolytic strategies to improve fertility in cattle. Theriogenology, v. 56, p. 1451-1463, 2001.

BJORNSTROM, L.; SJOBERG, M. Mechanisms of estrogen receptor signaling: convergence of genomic and nongenomic actions on target genes. Molecular Endocrinology, v. 19; p. 833-842, 2005.

BLOECHLE, M.; SCHREINER, T.; KUCHLER, I.; SCHURENKAMPER, P.; LISSE, $\mathrm{K}$. Colour Doppler assessment of ascendent uterine artery perfusion in an in-vitro fertilization-embryo transfer programme after pituitary desensitization and ovarian stimulation with human recombinant follicle stimulating hormone. Human Reproduction, v. 12, p. 1772-1777, 1997.

BO, G. A., MARTÍNEZ, M.; NASSER, L. F.; CACCIA, M.; TRIBULO, H.; MAPLETOFT, R. J. Follicular dynamics in bos indicus and bos taurus beef cattle under pasture conditions in Argentina. In: Congresso Brasileiro de Reprodução Animal, v. 2, p. 221, 1993.

BO, G. A.; ADAMS, G. P.; PIERSON, R. A.; MAPLETOFT, R. J. Effect of progestogen plus E-17b treatment on superovulatory response in beef cattle. Theriogenology, v. 45, p. 897-910, 1996.

BO, G. A.; BARUSELLI, P. S.; MARTINEZ, M. F. Pattern and manipulation of follicular development in Bos indicus cattle. Animal Reproduction Science, v. 78, p. 307-326, 2003.

BO, G. A.; BARUSELLI, P. S.; MORENO, D.; CUTAIA, L.; CACCIA, M.; TRIBULO, R. The control of follicular wave development for self-appointed embryo transfer programs in cattle. Theriogenology, v. 57, p. 53-72, 2002.

BO, G. A.; GUERRERO, D. C.; ADAMS, G. P. Alternative approaches to setting up donor cows for superstimulation. Theriogenology, v. 69, p. 81-87, 2008.

BO, G. A; ADAMS, G. P.; PIERSON, R. A.; MAPLETOFT, R. J. Exogenous control of follicular wave emergence in cattle. Theriogenology, v. 43. p. 31-40, 1995. 
BOLLWEIN, H.; MAYER, R.; STOLLA, R. Transrectal Doppler sonography of uterine blood flow during early pregnancy in mares. Theriogenology, v. 60, p. 597-605, 2003.

BOLLWEIN, H.; MEYER, H. H. D.; MAIERL, J.; WEBER, F.; BAUMGARTNER, U.; STOLLA, R. Transrectal Doppler sonography of uterine blood flow in cows during the estrous cycle. Theriogenology, v. 53, p. 1541-1552, 2000.

BOROWICZ, P.P.; ARNOLD, D.R.; JOHNSON, M.L.; GRAZUL-BILSKA, A.T.; REDMER, D.A.; REYNOLDS, L.P. Placental growth throughout the last two thirds of pregnancy in sheep: vascular development and angiogenic factor expression. Biol Reprod, v. 76, p. 259-267, 2007.

BOURGAIN, C.; DEVROEY, P. The endometrium in stimulated cycles for IVF. Hum Reprod Update, v. 9, p. 51-522, 2003.

BUNGARTZ, L.; NIEMANN, H. Assessment of the presence of a dominant follicle and selection of dairy cows suitable for superovulation by a single ultrasound examination. Journal of Reproduction and Fertility, v. 101, p. 583-591, 1994.

BYERS, M. J.; ZANGL, A.; PHERNETTON, T. M.; LOPEZ, G.; CHEN, D. B.; MAGNESS, R. R. Endothelial vasodilator production by ovine uterine and systemic arteries: ovarian steroid and pregnancy control of ER alpha and ER beta levels. Journal of Physiology London, v. 565, p. 85-99, 2005.

CACCIATORE, B.; SIMBERG, N.; FUSARO, P.; TIITINEN, A. Transvaginal Doppler study of uterine artery blood flow in in vitro fertilization- embryo transfer cycles.

Fertility and Sterility, v. 66, p. 130-134, 1996.

CAI, W.; SCHAPER, W. Mechanisms of arteriogenesis. Acta Biochimestry Biophys Sin, v. 40, n. 8, p. 681-692, 2008.

CAO, Y.; LINDEN, P.; FARNEBO, J.; CAO, R.; ERIKSSON, A.; KUMAR, V.; QI, J. H.; CLAESSON-WELSH, L.; ALITALOS, K. Vascular endothelial growth factor C induces angiogenesis in vivo. Proceedings of the National Academy of Sciences of the United States of America, v. 95, p. 14389-14394, 1998.

CARSON, D.D.; BAGCHI, I.; DEY, S.K.; ENDERS, A.C.; FAZLEABAS, A.T.; LESSEY, B.A.; YOSHINAGA, K. Embryo implantation. Develop Biol, v. 223, p. 217 $237,2000$.

CARTER, F.; FORDE, N.; DUFFY, P.; WADE, M.; FAIR, T.; CROWE, M.A.; EVANS, A.C.; KENNY, D.A.; ROCHE, J.F.; LONERGAN, P. Effect of increasing progesterone concentration from Day 3 of pregnancy on subsequent embryo survival and development in beef heifers. Reproduction, Fertility and Development. n.20, p.368-75, 2008.

CHARNOCK-JONES, D. S.; MACPHERSON, A. M.; ARCHER, D. F. The effect of progestins on vascular endothelial growth factor, oestrogen receptor and progesterone 
receptor immunoreactivity and endothelial cell density in human endometrium. Human Reproduction, v.15, p. 85-95, 2000.

CHARNOCK-JONES, D.S.; KAUFMANN, P.; MAYHEW, T.M. Aspects of human fetoplacental vasculogenesis and angiogenesis. I. Molecular regulation. Placenta, v. 25, p. 103-113, 2004.

CHENNAZHI, K. P.; NAYAK, N. R. Regulation of angiogenesis in the primate endometrium: vascular endothelial growth factor. Semin Reprod Med, v. 27, n. 1, p. 80-89, 2009.

CHIANG, C. H.; HSIEH, T. T.; CHANG M. Y.; SHIAU, C. S.; HOU, H. C.; HSU, J. J.; SOONG, Y. K. Prediction of pregnancy rate of in vitro fertilization and embryo transfer in women aged 40 and over with basal uterine artery pulsatility index. Journal of Assisted Reproduction and Genetics, v. 17, n. 8, p. 409-414, 2000.

CHIEN, L. W.; AU, H. K.; CHEN, P. L.; XIAO, J.; TZENG, C. R. Assessment of uterine receptivity by the endometrial-subendometrial blood flow distribution pattern in women undergoing in vitro fertilization-embryo transfer. Fertility and Sterility, v. 78, p. 245-251, 2002.

CHIEN, L. W.; LEE, W. S.; AU, H. K.; TZENG, C. R. Assessment of changes in uteroovarian arterial impedance during the peri-implantation period by Doppler sonography in women undergoing assisted reproduction. Ultrasound Obstet Gynecol, v. 23, p. 496-500, 2004.

CHRISTENSON, L. K.; STOUFFER, R. L. Proliferation of microvascular endothelial cells in the primate corpus luteum during the menstrual cycle and simulated early pregnancy. Endocrinology, v. 37, p. 367-374, 1997.

CLEMENTE, M.; LA FUENTE, J; FAIRL, T; AL NAIBL, A.; GUTIERREZ-ADAN, A.; ROCHEL, J.F; RIZOS, D.; LONERGANL, P. Progesterone and conceptus elongation in cattle: a direct effect on the embryo or an indirect effect via the endometrium?. Reproduction. n. 138, p. 507-17, 2009.

COULAM, C.B.; BUSTILLO, M.; SOENKSEN, D.M.; BRITTEN, S. Ultrasonographic predictors of implantation after assisted reproduction. Fertil Steril, v. 64, p. 1004-1010, 1994.

CUMMINGS, A.M.; YOCHIM, J.M. Differentiation of the uterus in preparation for gestation: a model for the action of progesterone. Journal of Theoretical Biology. $\mathrm{v}$. 106, n. 3, p. 353-74, 1984.

DE VRIES, C.; ESCOBEDO, J. A.; UENO, H.; HOUCK, K.; FERRARA, N.; WILLIAMS, L. T. The fms-like tyrosine kinase, a receptor for vascular endothelial growth factor. Science, v. 255, n. 5047, p. 989-991, 1992.

DE ZIEGLER, D.; BESSIS, R.; FRYDMAN, R. Vascular resistance of uterine arteries: physiological effects of estradiol and progesterone. Fertility and Sterility, v. 55, p. 775-779, 1991. 
DEY, S.K.; LIM, H.; DAS, S.K.; REESE, J.; PARIA, B.C.; DAIKOKU, T.; WANG, H. Molecular cues to implantation. Endocr Rev, v. 25, p. 341-73, 2004.

DINIZ, E. G.; JACOMINI, J. O.; NASCIMENTO, M. R. B. M.; MENDES JR., DISKIN, M. G.; SREENAN, J. M. Fertilization and embryonic mortality rates in beef heifers after artificial insemination. Journal of reproduction and fertility, v. 59, p. 463-468, 1980.

DINIZ, E. G.; JACOMINI, J. O.; NASCIMENTO, M. R. B. M.; MENDES JR., J. O. B.; ESPER, C. R. Eficiência de dois diferentes produtos hormonais na superovulação de vacas da raça Nelore. Revista Brasileira de Reprodução Animal, v. 23, n.3, p. 319-20, 1999.

DISKIN, M. G.; SREENAN, J. M. Fertilization and embryonic mortality rates in beef heifers after artificial insemination. Journal of reproduction and fertility, v. 59, p. 463-468, 1980.

DONALDSON, L.E.; PERRY, B. Embryo production by repeated superovulation of commercial donor cows. Theriogenology, v. 20, p. 163-168, 1983.

DOUGLAS, N. C.; TANG, H.; GOMEZ, R.; PYTOWSKI, B.; HICKLIN, D. J.; SAUER, C. M.; KITAJEWSKI, J.; SAUER, M. V.; ZIMMERMANN, R. C. Vascular endothelial growth factor receptor 2 (VEGFR-2) functions to promote uterine decidual angiogenesis during early pregnancy in the mouse. Endocrinology, v. 150, n. 8, p. 3845-3854, 2009.

DVORAK, H. F.; SIOUSSAT, T. M,.; BROWN, L. F.; BERSE, B.; NAGY, J. A.; SOTREL, A.; MANSEAU, E. J.; VAN DE WATER, L.; SENGER, D. R..; Distribution of vascular permeability factor (vascular endothelial growth factor) in tumors: concentration in tumor blood vessels. Journal of experimental medicine, v. 174, n. 5, p. 1275-1278, 1991.

ENGMANN, L.; SLADKEVICIUS, P.; AGRAWAL, R.; BEKIR, J.; CAMPBELL, S.; TAN, S. L. The pattern of changes in ovarian stromal and uterine artery blood flow velocities during in vitro fertilization treatment and its relationship with outcome of the cycle. Ultrasound Obstet Gynecol, v. 13, p. 26-33, 1999.

FAO Food and agriculture organization of the united nations. Statistics. Faostat. Consumption. 2007. Disponível em: http://faostat.fao.org/site/342/default.aspx. acesso em:14 out. 2009.

FARRER-BROWN, G.; BEILBY, J. O. W.; TARBIT, M. H. The blood supply of the uterus. II. Venous pattern. Journal of Obstetrice and Gynaecology Br Commonw, v. 77, p. 682-689, 1970.

FAZLEABAS, A.T.; STRAKOVA, Z. Endometrial function: cell specific changes in the uterine environment. Mol Cell Endocrinol, v. 186, p. 143-147, 2002.

FERNANDES, C. A. C. Inovulações não cirúrgicas e taxa de gestação de receptoras de embrião. Arquivo Brasileiro de Medicina Veterinária e Zootecnia, v. 51, n 3,1999. 
FERRARA, N. Molecular and biological properties of vascular endothelial growth factor. Journal of molecular Medicine, Berlin, v. 77, n. 7, p. 527-543, 1999.

FIELDS, M. J.; FIELDS, P. A. Morphological characteristics of the bovine corpus luteum during the estrous cycle and pregnancy. Theriogenology, v. 45, n. 7, p.1295325, 1996.

FINDLAY, J. K. Angiogenesis in reproductive tissues. Journal of Endocrinology. v. 111, p. 357-366, 1986.

FLEISCHER, A. C. Ultrasound imaging-2000: assessment of uteroovarian blood flow with transvaginal color Doppler sonography; potential clinical applications in infertility. Fertility and Sterility, v. 55, p. 684-691, 1991.

FORD, S. P.; CHENAULT, J. R. Blood flow to the corpus luteum-bearing ovary and ipsilateral uterine horn of cows during the oestrous cycle and early pregnancy. Journal of Reproduction and Fertility, v. 62, p. 555-562, 1981.

FORD, S. P.; CHRISTENSON, R. K. Blood flow to uteri of sows during the estrous cycle and early pregnancy: local effect of the conceptus on the uterine blood supply. Biology of Reproduction, v. 21, p. 617-624, 1979.

FORD, S. P.; CHRISTENSON, R. K.; CHENAULT, J. R. Pattern of blood flow to the uterus and ovaries of ewes during the period of luteal regression. Journal of Animal Science, v. 49, p. 1510-1516, 1979.

FORD, S. P.; CHRISTENSON, R. K.; FORD, J. J. Uterine blood-flow and uterine arterial, venous and luminal concentrations of estrogens on days 11, 13 and 15 after estrus in pregnant and nonpregnant sows. Journal of Reproduction and Fertility, v. 64, p. 185-190, 1982.

FORD, S. P.; WEBER, L. J.; STORMSHAK, F. Invitro response of ovine and bovine uterine arteries to prostaglandin-F2alpha and periarterial sympathetic-nerve stimulation. Biology of Reproduction, v. 15, p. 58-65, 1976.

FORD, S.P. Control of uterine and ovarian blood flow throughout the estrous cycle and pregnancy of ewes, sows and cows. J Anim Sci, v. 55(Suppl. 2), p. 32-42, 1982.

FORD, S.P.; CHENAULT, J.R.; ECHTERNKAMP, S.E. Uterine blood flow of cows during the oestrous cycle and early pregnancy: effect of the conceptus on the uterine blood supply. J Reprod Fertil, 56: 53-62, 1979.

FRASER, H. M.; DICKSON, S. E; LUNN,S. F.; WULFF, C.; MORRIS, K. D.; CARROLL, V. A.; BICKENELL, R. Suppression of luteal angiogenesis in the primate after neutralization of vascular endothelial growth factor. Endocrinology, v. 141, p. 995-1000, 2000.

FRIEDLER, S.; SCHENKER, J.G.; HERMAN, A.; LEWIN, A. The role of ultrasonography in the evaluation of endometrial receptivity following assisted reproductive treatments: a critical review. Hum Reprod Update, v. 2, p. 323-335, 1996. 
FUCK, E. J.; MORAES, G. V.; MARTINS, E. N.; FALCÃO, A. J. S.; RODRIGUES, C. M.; CARDOZO, R. M.; BARROS, C. M. Uso da gonadotrofina coriônica eqüina em receptoras de embriões para avaliar o incremento da progesterona endógena no dia da inovulação e sua correlação com a taxa de prenhez. Acta Scientiarum, Maringá, v. 24, n. 4, p. 1119-1126, 2002.

GARRETT, J. E.; GEISERT, R.;D., ZAVY, M. T; MORGAN, G. LEvidence for maternal regulation of early conceptus growth and development in beef cattle. Journal of reproduction and fertility, v. 84, n. 3, p. 437-446, 1988.

GASTAL, E. L.; BEG, M. A.; GINTHER, O. J. Changes in vascular perfusion of the endometrium in association with changes in location of the embryonic vesicle in mares.Silva LA,. Biology of Reproduction, v. 72, n. 3, p. 755-761, 2005.

GEISERT, R. D.; PRATT, T. N.; BAZER, F. W.; MAYES, J. S.; WATSON, G. H. Immunocytochemical localization and changes in endometrial progestin receptor protein during the porcine oestrous cycle and early pregnancy. Reproduction Fertility

Development, v.6, p. 749-760, 1994.

GILLE, H.; KOWALSKI, J.; LI, B.; LeCOUTER, J.; MOFFAT, B.; ZIONCHECK, T. F.; PELLETIER, N.; FERRARA, N. Analysis of biological effects and signaling properties of Flt-1 (VEGFR-1) and KDR (VEGFR-2). The Journal of Biological Chemistry, Baltimore, v. 276, n. 5, p. 3222-3230, 2001.

GÓMEZ, R.; SIMÓN, C.; REMOHÍ, J.; PELLICER, A. Vascular endotelial growth factor receptor-2 activation induces vascular permeability in hyperstimulated rats, and this effect is prevented by receptor blockade. Endocrinology, Springfield, v. 143, n. 11, p. 4339-4348, 2002.

GORDON, J.D.; SHIFREN, J.L.; FOULK, R.A. Angiogenesis in the human female reproductive tract. Obstet Gynecol Surv, v. 50, p. 688-697, 1995.

GOSWAMY, R. K.; WILLIAMS, G.; STEPTOE, P. C. Decreased uterine perfusion-a cause of infertility. Human Reproduction, v. 3, p. 955-959, 1988.

GREISS, F. C.; ANDERSON, S. G. Effect of ovarian hormones on uterine vascular bed. American Journal of Obstetric and Gynecology, v. 107, p. 829-\&, 1970.

GREISS, F. C.; ANDERSON, S. G. Uterine blood flow during early ovine pregnancy. American Journal of Obstetric and Gynecology, v. 106, p. 30-6, 1970.

GROUTZ, A.; WOLMAN, I.; JAFFA, A. J.; LESSING, J. B.; YOVEL, I.; AMIT, A. Influence of ovulation induction with human menopausal gonadotropin on uterine blood flow: comparison of unexplained and mechanical infertility. Journal of Ultrasound in Medicine, v. 16, p. 455-458, 1997.

GUILBAULT, L. A. Ovarian superstimulation after follicular wave synchronization with GnRH at two different stages of the estrous cycle in cattle. Theriogenology, v. 49, n. 6, p. 1175-1186, 1998. 
HAFEZ, E. S. E. Fisiologia da reprodução. In: HAFEZ, E. S. E. (Ed). Reprodução animal. $7^{\text {th }}$ ed. São Paulo: Ed. Manole, 2004.

HAOUZI, D.; MAHMOUD, K.; FOURAR, M.; BENDHAOU, K.; DECHAUD, H.; DE VOS, J.; RE'ME, T.; DEWAILLY, D.; HAMAMAH, S. Identification of new biomarkers of human endometrial receptivity in the natural cycle. Human Reprod, v. 2, p. 198-205, 2009.

HARRISON-WOOLRYCH, M.L.; SHARKEY, A.M.; CHARNOCK-JONES, D.S.; SMITH, S.K. Localization and quantification of vascular endothelial growth factor messenger ribonucleic acid in human myometrium and leiomyomata. The Journal of Clinical Endocrinology and Metabolism. v. 80, n. 6, p. 1853-8, 1995.

HASLER, F., BOWEN, R. A.; NELSON, L. D.; SEIDEL, G. E., Jr.Serum progesterone concentrations in cows receiving embryo transfers. J. Reprod. Fértil, v. 58, p. 71-77, 1980.

HASLER, J.F.; MCCAULEY, A.D., SCHERMERHORN, E.C.; FOOTE, H. Superovulatory responses in Holstein cows. Theriogenology, v. 19, p. 83-99, 1983.

HENDRICKS, D.M.; RONE, J.D. A note on the effect of nutrition on ovulation and ovarian follicular populations in the individually fed post-partum beef heifer. Anim Prod,v. 43, p. X7-560, 1986.

HERR, D.; KECK, C.; TEMPFER, C.; PIETROWSKI, D. Chorionic gonadotropin regulates the transcript level of VHL, p53, and HIF-2alpha in human granulosa lutein cells. Molecular Reproduction and Development, v. 69, n. 4, p. 397-401, 2004.

HERVÉ, M. A.; MEDURI, G.; PETIT, F. G.; DOMET, T. S.; LAZENNEC, G.; MOURAH, S.; PERROT-APPLANAT, M. Regulation of the vascular endothelial growth factor (VEGF) receptor Flk-1/KDR by estradiol through VEGF in uterus. Journal of Endocrinology, v. 188, n. 1, 91-99, 2006.

HERZOG, K.; BOLLWEIN, H. Application of Doppler ultrasonography in cattle reproduction. Reproduction of Domestic Animals, v. 42, p. 51-58, 2007.

HICKEY, M.; PILLAI, G.; HIGHAM, J. M.; SULLIVAN, M.; HORNCASTLE, D.; DOHERTY, D.; STAMP, G. Changes in endometrial blood vessels in the endometrium of women with hormone replacement therapy-related irregular bleeding. Human Reproduction, v.18, n. 5, p.1100-1106, 2003.

HONNENS, A.; NIEMANN, H.;PAUL, V. MEYER, H. H. D.; BOLLWEIN, H. Doppler sonography of the uterine arteries during a superovulatory regime in cattle uterine blood flow in superovulated cattle. Theriogenology, v. 70, p. 859-867, 2008.

HUMBLOT, P. Use of pregnancy specific proteins and progesterone assays to monitor pregnancy and determine the timing, frequencies and sources of embryonic mortality in ruminantes. Theriogenology, v. 56, n. 9, p. 1413-1433, 2001. 
HUTCHINSON, H. T. ; VASICKA', A. Uterine contractility in a paraplegic patient. Report of a case. Obstetrics \& Gynecology, v. 20, p. 675-678, 1962.

HYDER, S. M, MURTHY. L.; STANCEL, G. M. Progestin regulation of vascular endothelial growth factor in human breast cancer cells.

ISAKSSON, R.; TIITINEN, A.; CACCIATORE, B. Uterine artery impedance to blood flow on the day of embryo transfer does not predict obstetric outcome. Ultrasound Obstet Gynecol, v. 15, p. 527-530, 2000.

ISHIGAME, H.; MEDAN, M. S.; WATANABE, G.; SHI, Z.; KISHI, H.; ARAI, K. Y. ET AL. A new alternative method for superovulation using passive immunization against inhibin in adult rats. Biology of Reproduction, v. 71, p. 236-243, 2004.

ISHIKAWA, K.; OHBA, T.; TANAKA, N.; IQBAL, M.; OKAMURA, Y.; OKAMURA H. Organ-specific production control of vascular endothelial growth factor in ovarian hyperstimulation syndrome-model rats. Endocrine Journal, v. 50, n. 5, p. 515-525, 2003.

JARVELA, I. Y.; SLADKEVICIUS, P.; KELLY, S.; OJHA, K.; CAMPBELL, S.; NARGUND, G. Evaluation of endometrial receptivity during in-vitro fertilization using three-dimensional power Doppler ultrasound. Ultrasound Obstetric and Gynecology, v. 26, p. 765-769, 2005.

JUNQUEIRA, L. C.; CARNEIRO, J. Aparelho reprodutor feminino. In: JUNQUEIRA, L. C.; CARNEIRO, J. (Ed). Histologia básica. 10ª ed. São Paulo: Ed. Guanabara Koogan, 2004.

KAFI, M.; MCGOWAN, M. R. Factors associated with variation in the superovulatory response of cattle. Animal Reproduction Science, v.48, p. 137-157, 1997.

KAMAT, B. R.; BROWN, L. F.; MANSEAU, E. J.; SENGER, D. R.; DVORAK, H. F. Expression of vascular permeability factor/vascular endothelial growth factor by human granulosa and theca lutein cells. Role in corpus luteum development. American Journal of Pathology, v. 146, n. 1, p. 157-165, 1995.

KATOH, O.; TAUCHI, H.; KAWAISHI, K.; KIMURA, A.; SATOW, Y. Expression of the vascular endothelial growth factor (VEGF) receptor gene, KDR, in hematopoietic cells and inhibitory effect of VEGF on apoptotic cell death caused by ionizing radiation. Cancer Research, Chicago, v. 55, n. 23, p. 5687-5692, 1995.

KAUFMANN, P.; MAYHEW, T.M.; CHARNOCK-JONES, D.S. Aspects of human fetoplacental vasculogenesis and angiogenesis. II. Changes during normal pregnancy. Placenta, v. 25, p. 114-126, 2004.

KAWAMATA, M. Relationships between the number of small follicles prior to superovulatory treatment and superovulatory response in Holstein cows. Journal of Veterinary Medicine Science, v. 56, p. 965-967, 1994. 
KHARFAN-DABAJA, M.A.; PATEL, S.A.; OSUNKOYA, A.O.; KOIOURI, K.; KAMBLE, R.; YANG, J.; HASHMI, M.; OZER, H.; SELBY, G.B. Expression of the vascular endothelial growth factor receptors 1 and 2 in acute myeloid leukemia: incidence and feasibility of immunohistochemical staining. Clinical and Laboratorial Haematology. v. 28, n. 4, p. 254-8, 2006.

KIM, I. H.; SON, D. S.; YEON, S. H.; CHOI, S. W.; PARK, S. B.; RYU, I. S.; ET AL. Effect of dominant follicle removal before superstimulation on follicular growth, ovulation and embryo production in Holstein cows. Theriogenology, v. 55, p. 937-945, 2001.

KIMMINS, S.; MACLAREN, L. A. Oestrous cycle and pregnancy effects on the distribution of estrogen and progesterone receptors in bovine endometrium. Placenta, v. 22, p. 742-748, 2001.

KOHRAM, H.; TWAGIRAMUNGU, H.; BOUSQUET, D.; DUROCHER, J.; GUILBAULT, L. A. Ovarian superstimulation after follicular wave synchronization with GnRH at two different stages of the estrous cycle in cattle. Theriogenology, v. 49, n. 6, p. 1175-1186, 1998.

KRAMER, B.; STEIN, B. A.; VAN DER WALT, A. Exogenous gonadotropins - serum oestrogen and progesterone and the effect on endometrial morphology in the rat.

Journal of Anatomy, v. 173, p. 177-186, 1990.

KUNG, H.N.; CHIEN, C.L.; CHAU, G.Y.; DON, M.J.; LU, K.S.; CHAU, Y.P. Involvement of NO/cGMP signaling in the apoptotic and anti-angiogenic effects of beta-lapachone on endothelial cells in vitro. Journal of Cell Physiology. v. 211, n. 2, p. 522-32, 2007.

KUNG, S. P.; LEE, C. H.; YANG, A. H.; CHI, C. W.; TSENG, L. M.; WU C. W. Expression of c-kit, Flk-1, and Flk-2 receptors in benign and malignant tumors of follicular epithelial origin. , v. 69, n. 2, p. 74-79, 2006.

KUPESIC, S.; BEKAVAC, I.; BJELOS, D.; KURJAK, A. Assessment of endometrial receptivity by transvaginal color doppler and three-dimensional power doppler ultrasonography in patients undergoing in vitro fertilization procedures. Journal of Ultrasound Medicine, v. 20, p. 125-134, 2001.

KUTLESIĆ, R.; MILOSAVLJEVIĆ, M.; VUKOMANOVIĆ, P.; STEFANOVIĆ, M. Color Doppler imaging and measurements of intraovarian and intrauterine vascularization on basal ultrasound examination in spontaneous ovulatory and anovulatory cycles. Vojnosanit Pregl, v. 65, n. 10, p. 743-750, 2008.

LAITINEN, M.; RISTIMÄKI, A.; HONKASALO, M.; NARKO, K.; PAAVONEN, K.; RITVOS, O. Differential hormonal regulation of vascular endothelial growth factors VEGF, VEGF-B, and VEGF-C messenger ribonucleic acid levels in cultured human granulosa-luteal cells. Endocrinology, v. 138, n. 11, p. 4748-4756, 1997. 
LAMB G.C.; DAHLEN, C.R.; LARSON, J.E.; MARQUEZINI, G.; STEVENSON, J.S. Control of the estrous cycle to improve fertility for fixed-time artificial insemination (TAI) in beef cattle: A review. Journal of Animal Science. no prelo, 2009.

LAMOND, D. R.; DROST, M. Blood supply to the bovine ovary. Journal of Animal Science, v. 38, n. 1, p. 106-112, 1974.

LEE , J.; GRAY, A.; YUAN, J.; LUOH, S. M.; AVRAHAM, H.; WOOD, W. I. Vascular endothelial growth factor-related protein: a ligand and specific activator of the tyrosine kinase receptor Flt4. Proceedings of the National Academy of Sciences, v. 5, n. 93 (5), p. 1988-1992,1996.

LEE, A.; CHRISTENSON, L. K.; PATTON, P. E.; BURRY, K. A.; STOUFFER, R. L. Vascular endothelial growth factor production by human luteinized granulosa cells in vitro. Human Reproduction, v. 12, n. 12, p. 2756-61, 1997.

LEE, J.; GRAY , A.; YUAN, J.; LUOH, S. M.; AVRAHAM, H.; WOOD, W. I. Vascular endothelial growth factor-related protein: a ligand and specific activator of the tyrosine kinase receptor Flt4.Proceedings of the National Academy of Sciences , v. 5, n. 93(5). p. 1988-1992, 1996.

LERNER, S.P.; THAYNE, W.V.; BAKER, R.D.; HENSCHE, T.; MEREDITH, S.; INSKEEP, E.K.; DAILEY, R.A.; LEWIS, P.E.; BUTCHER, R.L. Age, dose of FSH and other factors affecting superovulation in Holstein cows. J Anim Sci, v. 63, p. 176-183, 1986.

LEUNG, D. W.; CACHIANES, G.; KUANG, W.J; GOEDDEL, D. V.; FERRARA, N. Vascular endothelial growth factor is a secreted angiogenic mitogen. Science. v. v. 246, n. 4935, p. 306-309,1989.

LILIC, V.; TUBIC-PAVLOVIC, A.; RADOVIC-JANOSEVIC, D.; PETRIC, A.; STEFANOVIC, M.; ZIVADINOVIC, R. Moguc'nost procene endometrijalne receptivnosti na osnovu doplerskih I ultrazyuc `nih parametara. Medicinski Pregled, v. 60, p. 237-240, 2007.

LINDSELL, C.E.; MURPHY, B.D.; MAPLETOFT, R.J. Superovulatory and endocrine responses in heifers treated with FSH-P at different stages of the estrous cycle.

Theriogenology, v. 26, p. 209-219, 1986.

LINDSEY, B. R.; LOONEY, C. R.; FUNK, D. J.; FABER, D. C. The effect of apparent dominant follicle removal (DFR) prior to FSH treatment on superstimulated response in problem donors. Theriogenology, v. 41, p. 238, 1994.

LONERGAN, P.; WOODS, A.; FAIR, T.; CARTER, F.; RIZOS, D.; WARD, F.; QUINN, K.; EVANS, A. Effect of embryo source and recipient progesterone environment on embryo development in cattle. Reproduction, Fertility and Development, v. 19, p. 861-868, 2007.

LOZANO, J. M.; LONERGAN, P.; BOLAND, M. P.; O'CALLAGHAN, D. Influence of nutrition on the effectiveness of superovulation programmes in ewes: effect on 
oocyte quality and post-fertilization development. Reproduction, v. 125, p. 543-553, 2003.

MADUREIRA, E. H.Sincronização com progestágenos. In: SIMPÓSIO INTERNACIONAL DE REPRODUÇÃO ANIMAL APLICADA, Anais São Paulo. p.117-128. 2004

MANN, G. E., LAMMING, G. E. Relationship between maternal endocrine environment, early embryo development and inhibition of the luteolytic mechanism in cows. Reproduction, 121, 175-180, 2001.

MANN, G. E., LAMMING, G. E. The influence of progesterone during early pregnancy in cattle. Reprod. Domest. Anim. 34, 269-274, 1999.

MANN, G. E.; LAMMING, G. E. Progesterone inhibition of the development of the luteolytic signal in cows. Journal of Reproduction and Fertility, v. 104, n. 1, p. 1-5, 1995.

MANN, G. E.; FRAY, M. D., LAMMING, G. E. (2006). Effects of time of progesterone supplementation on embryo development and interferon-tau production in the cow. Vet. J, 171, 500-503, 2006.

MAPLETOFT, R. J.; STEWARD, K. B.; ADAMS, G.P. Recent advances in the superovulation in cattle. Reproduction, Nutrition, Development, v. 42, p. 601-611, 2002 .

MARINOV, U.; LOVELL, J. E. Cytology of the bovine uterine epithelium during the estrous cycle. American Journal Veterinary Research, v. 19, p. 13-29, 1968.

MARTINS, C. M. Adequação do protocolo de superovulação com inseminação artificial em tempo fixo em Bos taurus. Tese de mestrado, 2005.

MERC, L. T.; BARCO, M. J.; BAU, S.; TROYANO, J. Are endometrial parameters by three-dimensional ultrasound and power Doppler angiography related to in vitro fertilization/embryo transfer outcome? Fertility and Sterility, v. 89, n. 1, p. 111-117, 2008.

MEYER, M.; CLAUSS, M.; LEPPLE-WIENHUES, A.; WALTENBERGER, J.; AUGUSTIN, H. G.; ZICHE, M.; LANZ, C.; BUTTNER, M.; RZIHA, H.; DEHIO, C. A novel vascular endothelial growth factor encoded by Orf virus, VEGF-E, mediates angiogenesis via signalling through VEGFR-2 (KDR) but not VEGFR-1 (Flt-1) receptor tyrosine kinases. The Embo Journal, Oxford, v. 18, n. 2, p. 363-374, 1999.

MINTS, M.; BLOMGREN, B.; FALCONER, C.; PALMBLAD, J. Expression of the vascular endothelial growth factor (VEGF) family in human endometrial blood vessels. Scand J Clin Lab Invest, v. 62, n. 3, p. 167-75, 2002.

MONTIEL, F.; AHUJA, C. Body condition and suckling as factors influencing the duration of postpartum anestrus in cattle: a review. Animal Reproduction Science, v.85, p.1-26, 2005. 
MOOR, R. M.; KRUIP, T. A. M.; GREEN, D. Intraovarian control of foliculogenesis: limits to superovulation; Theriogenology, v. 21, n. 1, p. 103-116, 1984.

MURPHY, B.D.; MARTINUK, S.D. Equine chorionic gonadotrophin. Endocrine Rewiews, v. 12, p. 27- 44, 1991.

NEUFELD, G.; COHEN, T.; GENGRINOVITCH, S.; POLTORAK, Z. vascular endothelial growth factor and its receptors. The Faseb Journal, Israel, v. 13, p. 9-22, 2000 .

NEULEN, J.; YAN, Z.; RACZEK, S.; WEINDEL, K.; KECK, C.; WEICH, H. A.; MARMÉ, D.; BRECKWOLDT, M. Human chorionic gonadotropin-dependent expression of vascular endothelial growth factor/vascular permeability factor in human granulosa cells: importance in ovarian hyperstimulation syndrome. The Journal of clinical endocrinology and metabolism, Freiburg, v. 80, n. 6, p. 1967-1971,1995.

NG, N. H. Y.; CHAN, C.C. W.; TANG, O. S.; YEUNG, W. S. B. Endometrial and subendometrial blood flow measured during early luteal phase by three-dimensional power Doppler ultrasound in excessive ovarian responders. Human Reproduction, v. 19, n.4, p. 924-931, 2004.

NISWENDER, G. D.; REIMERS, T. J.; DIEKMAN, M. A.; NELT, T. M. Blood flow: a mediator of ovarian function. Biology of Reproduction. v. 14, p. 64-81, 1976.

NORWITZ, E.R.; SCHUST, D.J.; FISHER, S.J. Implantation and the survival of early pregnancy. N Engl J Med, v. 345, p. 1400-1408, 2001.

OGAWA, S.; OKU, A.; SAWANO, A.; YAMAGUCHI, S.; YAZAKI, Y.; SHIBUYA, M. Anovel type of vascular endothelial growth factor, VEGF-E (NZ-7 VEGF), preferentially utilizes KDR/FLK-1 receptor and carries a potent mitotic activity without heparin-binding domain. The Journal of Biological Chemistry, Baltimore, v. 273, n. 47, p. 31273-31282, 1998.

OLSSON, A. K.; DIMBERG, A.; KREUGER, J.; CLAESSON-WELSH, L. VEGF receptor signalling - in control of vascular function, National Rev Molecular Cell Biology, v. 7, n. 5, p. 359-371, 2006.

PADYKULA, H. A.; COLES, L. G.; OKULICZ, W. C.; RAPAPORT, S. I.; MCCRACKEN, J. A.; KING, N. W.; J. R.; LONGCOPE, C. KAISERMANABRAMOF, I. R. The basalis of the primate endometrium: a bifunctional germinal compartment. Biology of reproduction, v. 40, n. 3, p. 681-690, 1989.

PAPA, P.C.; MOURAL, C. E. B. ; ARTONI, L. P.; FÁTIMA, L. A.; CAMPOS, D. B.; MARQUES JR., J. E. B.; BARUSELLI, P. S.; BINELLI, B. M.; PFARRER, C.;

LEISER, R. VEGF system expression in different stages of estrous cycle in the corpus luteum of non-treated and superovulated water buffalo. Domestic Animal Endocrinology, 2007.

PARIA, B.C.; REESE, J.; DAS, S.K.; DEY, S.K. Deciphering the cross-talk of implantation: advances and challenges. Science, v.296, p. 2185-2188, 2002. 
PARK, J. E.; CHEN, H. H.; WINER, J.; HOUCK, K. A.; FERRARA, N. Placenta growth factor Potentiation of vascular endothelial growth factor bioactivity, in vitro and in vivo, and high affinity binding to Flt-1 but not to Flk-1/KDR. The Journal of Biological Chemistry, Baltimore, v. 269, n. 41, p. 25646-25654, 1994.

PEICHEV, M.; NAIVER A.J.; PEREIRA, D.; ZHU, Z.; LANE, W.J.; WILLIAMS, M.; OZ, M.C.; HIOLDIN, D.J.; WITTE, L.; MOORE, M.A.; RAFII, S. Expression of VEGFR-2 and AC133 by circulating human CD34(+) cells identifies a population of functional endothelial precursors. Blood. v. 95, n. 3, p. 952-8, 2000.

PETERSON, A. J.; LEE, R. S. Improving successful pregnancies after embryo transfer. Theriogenology, v. 59, p. 687-697, 2003.

PRICE, C. A.; CARRIERE, P. D.; GOSSELIN, N.; KOHRAM, H.; GUILBAULT, L. A. Effects of superovulation on endogenous LH secretion in cattle, and consequences for embryo production. Theriogenology, v. 51, n. 1, p. 37-46, 1999.

PRIEDKALNS, B. Female reproductive system. In: DELLMANN H. D.; BROWN, E. M. (Ed.). Textbook of Veterinary Histology. Philadelphia: Lea and Febiger, p. 319349, 1976.

PURWANTARA, B.; SCHMIDT, M.; GREVE, T.; CALLESEN, H. Follicular dynamics prior to and during superovulation in heifers. Theriogenology, v. 40, p. 913921, 1993.

RAINE-FENNING, N. J.; CAMPBELL, B. K.; KENDALL N. R.; CLEWES J. S.; JOHNSON I. R. Endometrial and subendometrial perfusion are impaired in women with unexplained subfertility. Human Reproduction, v. 19 n. 11, p. 2605-2614, 2004.

RED-HORSE, K.; DRAKE, P.M.; FISHER, S.J. Human pregnancy: the role of chemokine networks at the fetal-maternal interface. Expert Rev Mol Med, v. 6, p. 1-14, 2004.

REDMER, D.A.; REYNOLDS, L. P. Angiogenesis in the ovary. Reviews of Reproduction. v. 1, p. 182-192, 1996.

REICHENBACH, H. D.; OLIVEIRA, M. A. L.; LIMA, P. F.; SANTOS FILHO, A. S.; ANDRADE, J. C. O. Transferência e criopreservação de embriões bovinos. In: GONSALVES, P. B. D.; FIGUEIREDO, J. R.; FREITAS, V. J. F. Biotécnicas Aplicadas à Reprodução Animal, p.153-160, São Paulo: Varela, 2002.

REIS, E.L.; MARQUES, M.O.; CARVALHO, N.A.T., NASSER, CL.F.; COSTA NETO, W.P.; BARUSELLI, P.S. Aumento da taxa de concepção em receptoras de embrião bovino com maiores concentrações plasmáticas de progesterona no dia da inovulação. Acta Scientiae Veterinariae, v. 32, p. 88, 2004.

REMOHI, J.; ARDILES, G.; GARCIA-VELASCO, J.A.; GAITAN, P.; SIMON, C.; PELLICER, A. Endometrial thickness and serum oestradiol concentrations as predictors of outcome in oocyte donation. Hum Reprod, v. 12, p. 2271-2276, 1997.

Review article: steroid hormones and uterine vascular adaptation to pregnancy. 
REYNOLDS, L. P. Utero-ovarian interactions during early pregnancy: role of conceptus-induced vasodilation. Animal Science, v. 62, p. 47-61, 1986.

REYNOLDS, L. P.; MAGNESS, R. R.; FORD, S. P. Uterine blood flow during early pregnancy in ewes: interaction between the conceptus and the ovary bearing the corpus luteum. Journal of Animal Science, v. 58, p. 423-429, 1984.

REYNOLDS, L. P; KILLILEA, S. D. REDMER, D.A. Angiogenesis in the female reproductive system. FASEB Journal., v.1 n. 6 (3), p. 886-892, 1992

REYNOLDS, L.P.; BOROWICZ, P.P.; VONNAHME, K.A.; JOHNSON, M.L.; GRAZUL-BILSKA, A.T.; WALLACE, J.M.; CATON, J.S.; REDMER, D.A. Animal models of placental angiogenesis. Placenta, v. 26, p. 689-708, 2005.

REYNOLDS, L.P.; KILLILEA, S.D.; REDMER, D.A. Angiogenesis in the female reproductive system. FASEB J, v. 6, p. 886-892, 1992.

ROBERTS, G. P.; PARKER, J. M. Fractionation and comparison of proteins from bovine uterine fluid and bovine allantoic fluid. Biochemistry Biophysics Acta, v. 446, p. 69-76, 1976.

ROBINSON, R. S.; HAMMOND, A. J.; MANN, G. E.; HUNTER, M. G. A novel physiological culture system that mimics luteal angiogenesis. Reproduction, v. 135, n. 3, p. 405-413, 2008.

ROBINSON, R. S.; NICKLIN, L. T.; HAMMOND, A. J.; SCHAMS, D.; HUNTER, M. G.; MANN, G. E. Fibroblast growth factor 2 is more dynamic than vascular endothelial growth factor A during the follicle-luteal transition in the cow. Biology of Reproduction, v. 77, n. 1, p. 28-36, 2007.

ROMAN-PONCE, H.; THATCHER, W. W.; CATON, D.; BARRON, D. H.; WILCOX, C. J. Thermal-stress effects on uterine blood-flow in dairy-cows. Journal of Animal Science; v. 46, p. 175-180, 1978.

SALLE, B.; BIED-DAMON, V.; BENCHAIB, M.; DESPERES, S.; GAUCHERAND, P.; RUDIGOZ, R. C. Preliminary report of an ultrasonography and colour Doppler uterine score to predict uterine receptivity in an in-vitro fertilization programme.

Human Reproduction, v. 13, p. 1669-1673, 1998.

SANTOS, J. E. P.; CERRI, R. L. A.; BALlOU, M. A.; HIGGINBOTHAM, G. E.; KIRK, J. H. Effect of timing of first clinical mastitis occutence on lactational and reproductive performance of Holstein dairy cows. Animal Reproduction Science, v. 80, p. 31-45, 2004.

SATTERFIELD, M. C.; BAZER, F. W. SPENCER, T. E. Progesterone regulation of preimplantation conceptus growth and galectin 15 (LGALS15) in the ovine uterus. Biology of reproduction, v. 75, n. 2, p. 289-296, 2006.

SCHILD, R. L.; KNOBLOCH, C.; DORN, C.; FIMMERS, R.; VAN DER VEN, H.; HANSMANN, M. Endometrial receptivity in an in vitro fertilization program as 
assessed by spiral artery blood flow, endometrial thickness, endometrial volume, and uterine artery blood flow. Fertility and Sterility, v. 75, p. 361-366, 2001.

SILVA, L.A.; GASTAL, E.L.; BEG, M.A.; GINTHER, O.J. Changes in vascular perfusion of the endometrium in association with changes in location of the embryonic vesicle in mares. Biol Reprod, v. 72, p. 755-61, 2005.

SILVA, L.A; GINTHER, O.J.; Local effect of the conceptus on uterine vascular perfusion during early pregnancy in heifers. Reproduction. no prelo, 2009.

SINGH, J.; DOMINGUEZ, M.; JAISWAL, R.; ADAMS, G. P. A simple ultrasound test to predict the superstimulatory response in cattle. Theriogenology, v. 62, p. 227-243, 2004.

SLEE, R. B.; HILLIER, S. G.; LARGUE, P.; HARLOW, C. R.; MIELE, G.; CLINTON, M. Differentiation-dependent expression of connective tissue growth factor and lysyl oxidase messenger ribonucleic acids in rat granulosa cells. Endocrinology, Edinburgh, v. 142, n. 3, p. 1082-1089, 2001.

SMITH, S. K. Regulation of angiogenesis in the endometrium. Trends Endocrinol Metab, v. 12, p. 147-151, 2001.

SONE, H.; OKUDA, Y.; KAWAKAMI, Y.; HANATANI, M.; SUZUKI, H.; KOZAWA, T.; HONMURA, S.; YAMASHITA, K. Vascular endothelial growth factor level in aqueous humor of diabetic patients with rubeotic glaucoma is markedly elevated. Diabetes Care, v. 19, n. 11, p. 1306-1307, 1996.

SPENCER, T. E.; BAZER, F. W. Conceptos signals for establishment and maintenance of pregnancy. Reproduction Biology Endocrinology, v. 2, p. 49, 2004.

SPENCER, T. E.; JOHNSON, G. A.; BAZER, F. W.; BURGHARDT, R. C. Fetalmaternal interactions during the establishment of pregnancy in ruminants. In:

INTERNATIONAL SYMPOSIUM ON REPRODUCTION IN DOMESTIC RUMINANTS, 7. 2006, Wellington, New Zealand. Proceedings of the Seventh International Symposium on Reproduction in Domestic Ruminants, 2006, p. 379396.

SPERCER, T. E.; BECKER, W. C.; GEORGE, P.; MIRANDO, M. A.; OGLE, T. F.; BAZER, F. W. Ovine interferon- ${ }_{\mathrm{T}}$ inhibits estrogen receptor up-regulation and estrogeninduced luteolysis in cyclic ewes. Endocrinology, v. 136, p. 4932-4944, 1995.

SREENAN, F. ; LYNCH, C.O. ; KENNY, D.A. ; CHILDS ,S. ; DISKIN, M.G. The relationship between periovulatory endocrine and follicular activity on corpus luteum size, function, and subsequent embryo survival. Theriogenology. no prelo, 2009.

SREENAN, J. M. Non-surgical embryo transfer in cattle. Theriogenology, v. 9, p. 6983, 1978.

SREENAN, J. M., DISKIN, M. G. Early embryonic mortality in the cow: its relationship with progesterone concentration. Vet. Rec, 112, 517-521, 1983. 
STEER, C. V.; CAMPBELL S, TAN SL, CRAYFORD T, MILLS C, MASON BA, COLLINS WP. The use of transvaginal color flow imaging after in vitro fertilization to identify optimum uterine conditions before embryo transfer. Fertility and Sterility. v. 57, p. 372-376, 1992.

STEER, C. V.; TAN, S. L.; DILLON, D.; MASON, B. A.; CAMPBELL, S. Vaginal color Doppler assessment of uterine artery impedance correlates with immunohistochemical markers of endometrial receptivity required for the implantation of an embryo. Fertility and Sterility, v. 63, p. 101-108, 1995.

STEWART, F.; ALLEN, W.R. Biological functions and receptor binding activities of equine chorionic gonadotrophins. Journal of Reproduction and Fertility, v. 62, p. 527-36, 1981.

STRIGINI, F. A. L.; SCIDA, P. A. M.; PARRI, C.; VISCONTI, A.; SUSINI, S.; GENAZZANI, A. Modifications in uterine and intraovarian artery impedance in cycles of treatment with exogenous gonadotropins- effects of luteal-phase support. Fertility and Sterility, v. 64, p.76-80, 1995.

SUNDSTROM, P. Establishment of a successful pregnancy following in-vitro fertilization with an endometrial thickness of no more than 4-mm. Human Reprod, v. 13, p. 1550-1552, 1998.

SUTO, K.; YAMAZAKI, Y.; MORITA, T.; MIZUNO, H. Crystal structures of novel vascular endothelial growth factors (VEGF) from snake venoms. The Journal of Biological Chemistry, Japan, v. 280, p. 2126-2131, 2005.

TAKAGI, M.; KIM, I. H.; IZADYAR, F.; HYTTEL, P.; BEVERS, M. M.; DIELEMAN, S. J.; HENDRIKSEN, P. J. M.; VOS, P. L. A. M. Impaired final follicular maturation in heifers after superovulation with recombinant human FSH.

Reproduction, v. 121, p. 941-951, 2001.

TEKAY, A.; MARTIKAINEN, H.; JOUPPILA, P. Blood flow changes in uterine and ovarian vasculature, and predictive value of transvaginal pulsed colour Doppler ultrasonography in an in-vitro fertilization programme. Human Reproduction, v. 10, p. 688-693, 1995.

TEKAY, A.; MARTIKAINEN, H.; JOUPPILA, P. Comparison of uterine blood flow characteristics between spontaneous and stimulated cycles before embryo transfer.

Human Reproduction, v. 11, p. 364-368, 1996a.

TEKAY, A.; MARTIKAINEN, H.; JOUPPILA, P. The clinical value of transvaginal colour Doppler ultrasound in assisted reproductive technology procedures. Human Reproduction, v. 11, p. 1589-1591, 1996b.

TERMAN, B. I.; DOUGHER-VERMAZEN, M.; CARRION, M. E.; DIMITROV, D.; ARMELLINO, D. C.; GOSPODAROWICZ, D.; BOHLEN, P. Identification of the KDR tyrosine kinase as a receptor for vascular endothelial cell growth factor.

Biochemical and Biophysical Research Communications, New York, v.187, n. 3, p. 1579-1586, 1992. 
TESARIK, J.; HAZOUT, A.; MENDOZA, C. Luteinizing hormone affects uterine receptivity independently of ovarian function. Reprod Biomed Online, v. 7, p. 59-64, 2003.

THIBIER, M. More than half a million bovine embryos transferred in 2002. Embryo Transf Newslett IETS, p. 12-9, 2003.

TOHMA, H.; HASEGAWA, I.; SEKIZUKA, N.; TANAKA, K. Uterine blood flowassessment in an intrauterine insemination program for unexplained infertility. The Journal of Reproductive Medicine, v. 42, p. 463-466, 1997.

VAN DEN DRIESCHE, S.; MYERS, M.; GAY, E.; THONG, K. J. DUNCAN, W. C. HCG up-regulates hypoxia inducible factor-1 alpha in luteinized granulosa cells: implications for the hormonal regulation of vascular endothelial growth factor $\mathrm{A}$ in the human corpus luteum. Molecular human reproduction, v. 14, n. 8, p. 455-464, 2008.

WAGATSUMA, A.; TAMAKI, H.; OGITA, F. Sequential expression of vascular endothelial growth factor, Flt-1, and KDR/Flk-1 in regenerating mouse skeletal muscle. Physiology Reserch, v. 55, n. 6, p. 633-640, 2006.

WALTENBERGER, J.; CLAESSON-WELSH, L.; SIEGBAHN, A.; SHIBUYA, M.; HELDIN, C.H. Different signal transduction properties of KDR and Flt1, two receptors for vascular endothelial growth factor. The Journal of Biology Chemistry. v. 269, n. 43, p. 26988-95, 1994.

WANG, H. S.; SOONG, Y. K. Detection of the subendometrial vascularization flow index by threedimensional ultrasound may be useful for predicting the pregnancy rate for patients undergoing in vitro fertilization-embryo transfer. Fertility and Sterility, v. 79 , n. 3 , p. $507-511,2003$.

WEHRENBERG, W. B.; DIERSCHKE, D. J.; WOLF, R. C. Utero-ovarian pathways and maintenance of early-pregnancy in Rhesus-Monkeys. Biology of Reproduction, v. 20, p. 601-605, 1979.

WEINER, Z.; THALER, I.; LEVRON, J.; LEWIT, N.; ITSKOVITZ-ELDOR, J. Assessment of ovarian and uterine blood flow by transvaginal color Doppler in ovarianstimulated women: correlation with the number of follicles and steroid hormone levels. Fertil and Sterility, v. 59, p. 743-749, 1993.

WEN, L.; CHEN, L. H.; LI, H. Y.; CHANG, S. P.; LIAO, C. Y.; TSUI, K. H.; SUNG, Y. J.; CHAO, K. C. Roles of estrogen and progesterone in endometrial hemodynamics and vascular endothelial growth factor production. Journal of Chinese Medicine Association, v. 72, n. 4, p. 188-193, 2009.

WILDMAN, E. E. Dairy cow body condition scoring system and its relationship to selected production characteristics. Journal Dairy Science, v.65, n.3, p.495-501, 1982.

WILTBANK, M. C.; GALLAGHER, K. P.; DYSKO, R. C.; KEYES, P. L. Regulation of blood-flow to the rabbit corpus-luteum-effects of estradiol and human chorionicgonadotropin. Endocrinology, v. 124, p. 605-611, 1989. 
WU, G.; BAZER, F.W.; CUDD, T.A.; MEININGER, C.J.; SPENCER, T.E. Maternal nutrition and fetal development. J Nutr, v.134, p. 2169-2172, 2004.

WU, H. M.; CHIANG, C. H.; HUANG, H. Y.; CHAO, A. S.; WANG, H. S.; SOONG, Y. K. Detection of the subendometrial vascularization flow index by threedimensional ultrasound may be useful for predicting the pregnancy rate for patients undergoing in vitro fertilization-embryo transfer. Fertility and Sterility, v. 79, n. 3 , p. 507-511, 2003.

WULFF, C.; WILSON, H.; RUDGE, J. S.; WIEGAND, S. J.; LUNN, S. F.; FRASER, H. M. Luteal angiogenesis: preventionand intervention by treatment with vascular endothelial growth factor trap(A40). The Journal of Clinical Endocrinology and Metabolism, n. 86, p. 3377-3386, 2001.

YAMAZAKI, Y.; TOKUNAGA, Y.; TAKANI, K.; MORITA, T. Identification of the heparin-binding region of snake venom vascular endothelial growth factor (VEGF-F) and its blocking of VEGF-A165. Biochemistry, Japan, v. 44, p. 8858-8864, 2005.

YAVAS, Y.; WALTON, J. S. Induction of ovulation in postpartum suckled beef cows: a review. Theriogenology, v. 54, p. 1-23, 2000.

YU, E. H.; CHAN, C. C.; TANG, O. S.; YEUNG, W. S.; HO, P. C. Factors affecting endometrial and subendometrial blood flow measured by three-dimensional power Doppler ultrasound during IVF treatment. Human Reproduction, v. 21, n. 4, p. 10621069, 2006.

ZAIDI J, BARBER J, KYEI-MENSAH A, BEKIR J, CAMPBELL S, TAN SL. Relationship of ovarian stromal blood flow at baseline ultrasound to subsequent follicular response in an in vitro fertilisation program. Obstetrics and Gynecology. v. 88, p. 779-784, 1996a.

ZAIDI J, CAMPBELL S, PITTROFF R, TAN SL. Endometrial thickness, morphology, vascular penetration and velocimetry in predicting implantation in an in vitro fertilization program. Ultrasound in Obstetrics \& Gynecology. v. 6, p. 191-198, 1995.

ZAIDI J, PITTROFF R, SHAKER A, KYEI-MENSAH A, CAMPBELL S, TAN SL. Assessment of uterine artery blood flow on the day of human chorionic gonadotropin administration by transvaginal color Doppler ultrasound in an in vitro fertilization program. Fertility and Sterility. v. 65, p. 377-381, 1996 b.

ZAVY, M. T. Embryonic mortality in cattle. In: ZAVY, M. T.; GEISERT, R. D. (Ed.). Embryonic mortality in domestic species. Boca Raton: CRC Press, 1994. P. 99-140.

ZELEZNIK, A. J.; SCILER, H. M.; REICHERT, L. E. Gonadotropin-binding sites in the Rhesus monkey ovary: role of the vasculature in the selective distribution of human chorionic gonadotropin to the preovulatory follicle. Endocrinology. v. 109, p. 356-361, 1981. 